\title{
Peptoid Residues Make Diverse, Hyperstable Collagen Triple-Helices
}

\author{
Julian L. Kessler ${ }^{\dagger}$, Grace Kang ${ }^{\dagger}$ Zhao Qin ${ }^{\ddagger}$, Helen Kang ${ }^{\dagger}$, Frank G. Whitby ${ }^{\S}$, Thomas E. Cheatham III^,
} Christopher P. Hills, Yang $\mathrm{Li}^{+, *}$, and S. Michael $\mathrm{Yu}^{+}, \|$

${ }^{\dagger}$ Department of Biomedical Engineering, University of Utah, Salt Lake City, Utah 84112, USA

${ }^{\ddagger}$ Department of Civil \& Environmental Engineering, Collagen of Engineering \& Computer Science, Syracuse University, Syracuse, New York 13244, USA

${ }^{\circledR}$ Department of Biochemistry, University of Utah School of Medicine, Salt Lake City, UT 84112, USA

${ }^{\wedge}$ Department of Medicinal Chemistry, College of Pharmacy, L. S. Skaggs Pharmacy Research Institute, University of Utah, Salt Lake City, Utah 84112, USA

"Department of Pharmaceutics and Pharmaceutical Chemistry, University of Utah, Salt Lake City, Utah 84112, USA

${ }^{*}$ Correspondence to: Yang Li (yang.d.li@utah.edu)

\section{Table of Contents}

\begin{tabular}{|c|c|}
\hline Section 1: Supplementary Discussion & $\mathrm{S} 2$ \\
\hline Section 2: Materials and Methods & S3 \\
\hline Materials & S3 \\
\hline Solid phase synthesis & S4 \\
\hline On-resin functionalization via "click" chemistry & S6 \\
\hline Cleavage protocols & S6 \\
\hline Purification and mass spectrometry & S6 \\
\hline Circular dichroism spectroscopy & S7 \\
\hline X-ray crystallography & S8 \\
\hline Metadynamics calculation of energy landscape & S9 \\
\hline Molecular dynamics simulations of X-CMPs & S9 \\
\hline Gelatin binding assays & $\mathrm{S} 10$ \\
\hline UV-triggered hydrogel dissolution and spatial control of cell attachment & S11 \\
\hline Section 3: Figures and Tables & $\mathrm{S} 12$ \\
\hline Table S1. Chemical structures of all host-guest X-CMPs and their $T_{\mathrm{m}}$ values. & $\mathrm{S} 12$ \\
\hline Table S2. X-ray crystallography data. & S13 \\
\hline Table S3. Reported PDB entries of collagen model peptides. & S14 \\
\hline Table S4. Primary structures and $T_{\mathrm{m}}$ of CMPs with X-Y double substitutions. & $\mathrm{S} 15$ \\
\hline Table S5. CSD entries of peptoid-containing small molecules. & $\mathrm{S} 16$ \\
\hline Table S6. Examples of crystal structures of peptoids in CSD. & S17 \\
\hline Table S7. Structures and $T_{\mathrm{m}}$ of Nnbz-, Nnbz2-, and Nnbz3-CMPs. & S18 \\
\hline Table S8. Cis-trans ratios of the amide bond of selected N-gly residues. & S19 \\
\hline Figure S1. Crystal structure of Nlys-CMP. & S20 \\
\hline Figure S2. Crystal structure of Nphe-CMP. & $\mathrm{S} 21$ \\
\hline Figure S3. Ramachandran plots for Nlys- and Nphe-CMPs. & $\mathrm{S} 22$ \\
\hline Figure S4. Newman-like projection of NMe-Ala. & $\mathrm{S} 23$ \\
\hline Figure S5. MA-PEG-CMP conjugation and UV-induced unfolding. & S24 \\
\hline Figure S6. Spatial control of cell adhesion using MA-PEG-CMP. & $\mathrm{S} 25$ \\
\hline Section 4: HPLC, MALDI and CD of all peptides & S26 \\
\hline Analyses of X-CMP peptides (in alphabetical order) & S26 \\
\hline Analyses of X-PP5 peptides (in alphabetical order) & S55 \\
\hline
\end{tabular}




\section{Section 1: Supplementary Discussion}

X-CMP functionalization through click chemistry. One simple way to introduce functionality into a CMP is to install an alkyne or azido group, which allows facile derivatization through 'click' chemistry. To prepare an XCMP capable of undergoing such reactions, we prepared Nakn-CMP which features a central N-gly residue bearing an alkyne moiety. Nakn's unbranched aliphatic sidechain is similar to that of NEt (Figure 6a) and the two residues produced almost identical CD melting temperatures. Click reactions between the sidechain alkyne and azides bearing unprotected hydroxyl or mannose moieties proceeded efficiently on resin in the presence of $\mathrm{Cu}(\mathrm{I}) / \mathrm{TBTA}$ (Figure 6a, see Materials and Methods for synthesis protocols). Following click conjugation with 2-azidoethanol, the $T_{\mathrm{m}}$ of the Nakn triple-helix increased by $3{ }^{\circ} \mathrm{C}$, presumably due to the increased size of the $N$-C $\alpha$-triazole ring (Figure 6a). Conjugation with 2-azidoethylmannose had almost no effect on $T_{\mathrm{m}}$ (Figure 6a). Previously, click reactions were used to functionalize CMP via $(4 R)$ azidoproline; however the formation of the triazole-proline units resulted in $T_{\mathrm{m}}$ drop of at least $7{ }^{\circ} \mathrm{C}^{1}$. Our results demonstrate that the $N$-appended sidechains at the X position can better tolerate spatially demanding triazole units within the triple-helix than $\mathrm{C} \gamma$-substituted proline derivatives ${ }^{1}$, and it showcase a perhaps more stable approach for click-functionalization of triple-helical CMPs. 


\section{Section 2: Materials and Methods}

\section{Materials}

All commercial chemicals and solvents were used as received. The solvents, resin, Fmoc amino acids, and reagents used in the synthesis and purification of the peptides and peptoids were purchased from the suppliers listed in the table below.

\begin{tabular}{|c|c|c|}
\hline General reagents & Supplier & Catalog number \\
\hline$N$-Methylpyrrolidinone (NMP) & Fisher Scientific & BP1172 \\
\hline$N, N$-Dimethylformamide (DMF) & Fisher Scientific & BP1160 \\
\hline Dimethyl sulfoxide (DMSO) & Sigma-Aldrich & 276855 \\
\hline Methylene Chloride (DCM) & Fisher Scientific & D37 \\
\hline Acetonitrile & Fisher Scientific & A998 \\
\hline TentaGel R RAM resin & Peptides International & RTS-9995-PI \\
\hline Fmoc-Gly-OH & EMD Millipore & 852001 \\
\hline Fmoc-Pro-OH & EMD Millipore & 852017 \\
\hline Fmoc-Hyp(tBu)-OH & EMD Millipore & 852036 \\
\hline Fmoc-Lys(Boc)-OH & AAPPTec & AFK105 \\
\hline Fmoc-Phe-OH & AAPPTec & AFF101 \\
\hline Fmoc-Tyr(tBu)-OH & EMD Millipore & 852020 \\
\hline Fmoc-Ile-OH & Advanced ChemTech & FI2326 \\
\hline Piperidine & Sigma-Aldrich & 104094 \\
\hline Bromoacetic acid & Sigma-Aldrich & 17000 \\
\hline$N, N$ '-Diisopropylcarbodiimide (DIC) & Sigma-Aldrich & D125407 \\
\hline $\begin{array}{l}\text { O-(7-Azabenzotriazol-1-yl)- } N, N, N^{\prime}, N^{\prime}- \\
\text { tetramethyluronium hexafluorophosphate (HATU) }\end{array}$ & Chem-Impex & 12881 \\
\hline 1-Hydroxy-7-azabenzotriazole (HOAT) & AAPPTec & CXZ012 \\
\hline $\begin{array}{l}\text { (7-Azabenzotriazol-1- } \\
\text { yloxy)trispyrrolidinophosphonium } \\
\text { hexafluorophosphate (PyAOP) }\end{array}$ & AAPPTec & CXZ070 \\
\hline$N$-Ethyldiisopropylamine (DIEA) & EMD Millipore & 845017 \\
\hline Acetic anhydride & Alfa Aesar & L04295 \\
\hline Trifluoroacetic acid (TFA) & Fisher Scientific & BP618 \\
\hline Triisopropylsilane (TIS) & Sigma-Aldrich & 233781 \\
\hline 1,2-Ethanedithiol (EDT) & Sigma-Aldrich & 02390 \\
\hline DL-Dithiothreitol & Sigma-Aldrich & D0632 \\
\hline Anisole & Sigma-Aldrich & 123226 \\
\hline Ethyl ether & Fisher Scientific & E138 \\
\hline
\end{tabular}




\section{Solid phase synthesis}

All sequences were prepared on TentaGel R RAM resin (substitution level: $0.2 \mathrm{mmol} / \mathrm{g}$ ) via solid phase synthesis. Typically, $50 \mathrm{mg}$ of resin (containing $10 \mu \mathrm{mol}$ of reaction sites) was used to prepare one host-guest peptide/peptoid sequence. Prior to the first coupling, resin was swelled in $0.4 \mathrm{~mL}$ of NMP for $30 \mathrm{~min}$. Each amino acid residue was coupled by agitating the resin with a solution of Fmoc protected residue (50 $\mu \mathrm{mol})$, HATU (50 $\mu \mathrm{mol}, 19 \mathrm{mg})$, HOAT $(50 \mu \mathrm{mol}, 6.8 \mathrm{mg})$ and DIEA $(75 \mu \mathrm{mol}, 13 \mu \mathrm{L})$ in $0.4 \mathrm{~mL}$ of NMP for over $3 \mathrm{hr}$. The Fmoc protective group was removed by treating the resin with piperidine ( $20 \%$ by volume in NMP) for 20 min. Following each reaction, the resin was drained and washed with NMP $(3 \times 10 \mathrm{~mL})$. All coupling and deprotection reactions were monitored by the standard Kaiser (for primary amines) and chloranil (for secondary amines) tests.

Except residues Sar, NMe-Ala, and Nnbz, which were coupled by using the respective Fmoc-protected compounds and the above-mentioned HATU chemistry, all other peptoid residues were incorporated on-resin using the twostep sub-monomer method reported by Zuckermann and others ${ }^{2}$.

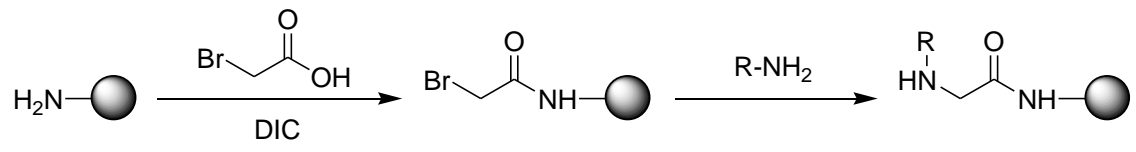

(1)

(2)

(1) Acylation reactions were performed by addition of a solution of bromoacetic acid (100 $\mu \mathrm{mol}, 13.9 \mathrm{mg})$ and DIC $(98 \mu \mathrm{mol}, 15.2 \mu \mathrm{L})$ in DMF $(0.5 \mathrm{~mL})$ to $10 \mu \mathrm{mol}$ of resin-bound amine. Reaction mixtures were agitated at room temperature for $30 \mathrm{~min}$. Each acylation was repeated once before the resin was drained and washed with NMP $(3 \times 10 \mathrm{~mL})$. (2) Each displacement reaction was performed by addition of a primary amine $(200 \mu \mathrm{mol})$ in $0.5 \mathrm{~mL}$ of NMP, followed by agitation overnight at room temperature. Following the displacement, the resin was drained and washed with DMF $(3 \times 10 \mathrm{~mL})$. The reaction was monitored by the chloranil test. Typically, resin beads turned dark green in a chloranil test following a displacement reaction of $2 \mathrm{hr}$, suggesting successful coupling of a peptoid residue; we chose to run the reactions overnight to ensure completion. In the table below, the primary amine used to create each peptoid residue is listed, and special reaction conditions and observations are noted. In general, the next amino acid following a peptoid residue (e.g., Fmoc-Gly-OH or Fmoc-Pro-OH) was coupled with full completion using the above-mentioned 5 eq HATU protocol. 


\begin{tabular}{|c|c|c|c|c|}
\hline Residue & R-NH2 Reagent & Supplier & $\begin{array}{l}\text { Catalog } \\
\text { number }\end{array}$ & Note \\
\hline Sar & Fmoc-Sar-OH & EMD Millipore & 852055 & Coupled by Fmoc \& HATU chemistry \\
\hline NMe-Ala & Fmoc- $N$-methyl-L-alanine & Chem-Impex & 2650 & Coupled by Fmoc \& HATU chemistry \\
\hline Nnbz & $\begin{array}{l}\text { Fmoc( } N \text {-o-nitrobenzyl)Gly- } \\
\text { OH }\end{array}$ & \multicolumn{2}{|c|}{ Synthesized in-house ${ }^{3,4}$} & Coupled by Fmoc \& HATU chemistry \\
\hline Nakn & Propargylamine & Sigma-Aldrich & P50900 & $\begin{array}{l}\mathrm{H}_{2} \mathrm{~N}-\mathrm{Gly}-\mathrm{Nakn}-\text { peptide } \\
\text { test, resin beads and the solution do not } \\
\text { turn dark blue despite the presence of } \\
\text { primary amine, perhaps because the } \\
\text { Nakn sidechain affects the ninhydrin } \\
\text { reactions. }\end{array}$ \\
\hline Nasn & Glycinamide & Combi-Blocks & QA-8748 & $\begin{array}{l}\text { Glycinamide is not soluble in NMP. } \\
\text { The displacement reaction was carried } \\
\text { out in } 0.5 \mathrm{~mL} \text { DMSO. }\end{array}$ \\
\hline Nasp & Glycine tert-butyl ester & Alfa Aesar & L16258 & \\
\hline Nchx & Cyclohexanemethylamine & Sigma-Aldrich & 101842 & \\
\hline Nhcy & $\begin{array}{l}\text { 2-(tert-butylsulfanyl)ethan-1- } \\
\text { amine }\end{array}$ & Enamine & $\begin{array}{l}\text { EN300- } \\
110537\end{array}$ & \\
\hline Ndxn & $\begin{array}{l}\text { C-[1,4]Dioxan-2-yl- } \\
\text { methylamine }\end{array}$ & Matrix Scientific & 008403 & $\begin{array}{l}\text { a racemic mixture of } R \text { and } S \\
(1,4) \text { dioxan-2-yl-methylamine }\end{array}$ \\
\hline NEt & $\begin{array}{l}\text { Ethylamine solution }(2.0 \mathrm{M} \text { in } \\
\text { THF) }\end{array}$ & Sigma-Aldrich & 395072 & \\
\hline Nleu & Isobutylamine & Sigma-Aldrich & $\mathrm{I} 14150$ & \\
\hline Nlys & $\mathrm{N}$-Boc-1,4-butanediamine & Chem-Impex & 31317 & \\
\hline Nmet & 2-(Methylthio)ethylamine & Sigma-Aldrich & 632929 & \\
\hline Nphe & Benzylamine & Sigma-Aldrich & 185701 & \\
\hline Nrpe & (R)-(+)- $\alpha$-Methylbenzylamine & Sigma-Aldrich & 115541 & $\begin{array}{l}\text { The Gly residue following Nrpe/Nspe } \\
\text { was coupled by agitating the resin (10 }\end{array}$ \\
\hline Nspe & (S)-(-)- $\alpha$-Methylbenzylamine & Sigma-Aldrich & 115568 & $\begin{array}{l}(100 \mu \mathrm{mol}) \text { and DIC }(100 \mu \mathrm{mol}) \text { in } 0.5 \\
\mathrm{~mL} \text { of DMF. }\end{array}$ \\
\hline Ntyr & $\begin{array}{l}\text { (4-tert- } \\
\text { butoxyphenyl)methanamine }\end{array}$ & Enamine & $\begin{array}{l}\text { EN300- } \\
55516\end{array}$ & \\
\hline Nval & Isopropylamine & Sigma-Aldrich & 471291 & $\begin{array}{l}\text { The Gly residue following Nval was } \\
\text { coupled by agitating the resin }(10 \\
\mu \text { mol }) \text { in a solution of Fmoc-Gly-OH } \\
(100 \mu \mathrm{mol}) \text { and DIC }(100 \mu \mathrm{mol}) \text { in } 0.5 \\
\mathrm{~mL} \text { of DMF. }\end{array}$ \\
\hline Ndota & $\begin{array}{l}1,4,7,10- \\
\text { Tetraazacyclododecane-1,4,7- } \\
\text { tris(t-butyl acetate)-10-(4- } \\
\text { aminobutyl)acetamide }\end{array}$ & Macrocyclics & B-279 & $\begin{array}{l}\text { The displacement reaction was } \\
\text { completed by agitating the resin ( } 10 \\
\mu \text { mol) in } 0.5 \mathrm{~mL} \text { of NMP containing } \\
\text { the primary amine }(63 \mu \mathrm{mol}) \text { and DIEA } \\
(115 \mu \mathrm{mol}) \text { overnight. }\end{array}$ \\
\hline
\end{tabular}




\section{On-resin functionalization via "click" chemistry}

The azido compound $(60 \mu \mathrm{mol})$, such as 2-Azidoethanol (Carbosynth, FA07084) or 2-Azidoethyl $\alpha$-Dmannopyranoside (Synthose, AM482), was dissolved in $0.5 \mathrm{~mL}$ of DMF along with $\left[\mathrm{Cu}(\mathrm{MeCN})_{4}\right] \mathrm{PF}_{6}(10 \mu \mathrm{mol}$, $3.7 \mathrm{mg}$, Sigma-Aldrich, 346276) and TBTA (20 $\mu \mathrm{mol}, 10.6 \mathrm{mg}$, Sigma-Aldrich, 678937). This solution was added to the resin-bound alkyne-containing peptide Nakn-CMP $(5 \mu \mathrm{mol})$, and the mixture was agitated at room temperature overnight. The resin was drained and washed with DMF $(5 \times 10 \mathrm{~mL})$ before the "click"-functionalized product was cleaved.

\section{Cleavage protocols}

Following the coupling and Fmoc-deprotection of the last Gly residue, the $N$-terminal amine of each sequence was acetylated by mixing the resin $(5 \mu \mathrm{mol})$ with a solution of acetic anhydride $(500 \mathrm{mM})$, HOAT $(14.7 \mathrm{mM})$, and DIEA $(129 \mathrm{mM})$ in $0.5 \mathrm{~mL}$ of NMP at room temperature for $30 \mathrm{~min}$. The resin was drained, washed with NMP $(3 \times 10 \mathrm{~mL})$ and DCM $(5 \times 10 \mathrm{~mL})$. Unless otherwise mentioned below, the resin $(5 \mu \mathrm{mol})$ was treated with $1 \mathrm{~mL}$ mixture of TFA / TIS / water (95:2.5:2.5) for over $3 \mathrm{hr}$ with stirring. Subsequently, the resin was washed with 0.5 $\mathrm{mL}$ of TFA twice. After the resin was filtered, the TFA cleavage solution was collected and evaporated under a stream of nitrogen down to approximately $0.5 \mathrm{~mL}$. The crude peptide/peptoid products were precipitated by adding $5 \mathrm{~mL}$ of cold ethyl ether to the TFA solution on ice.

\begin{tabular}{|c|l|}
\hline Sequence & \multicolumn{1}{c|}{ Special cleavage protocol } \\
\hline Nmet & The resin was treated with a mixture of TFA/EDT/water/TIS $(94: 2.5: 2.5: 1)$ for over $3 \mathrm{~h}$. \\
\hline \multirow{5}{*}{ Nhcy } & $\begin{array}{l}\text { Step } 1: \text { For } 5 \mu \text { mol of crude product, the resin was treated with a mixture }(1 \mathrm{~mL}) \text { of TFA/TIS/water } \\
(95: 2.5: 2.5) \text { for over } 2 \mathrm{hr} \text {, then the crude product was collected. }\end{array}$ \\
\cline { 2 - 2 } & $\begin{array}{l}\text { Step 2: The tBu protective group was removed from the Nhcy residue by stirring the crude product } \\
\text { in a mixture }(3 \mathrm{~mL}) \text { of TFA/DMSO/anisole }(97.9: 2: 0.1) \text { at room temperature for } 1 \mathrm{hr} \text {, then the } \\
\text { product was precipitated and collected again. }\end{array}$ \\
\cline { 2 - 2 } & $\begin{array}{l}\text { Step 3: The crude product was dried then dissolved in } 2 \mathrm{~mL} \text { of water containing } 15 \mathrm{mg} \text { of } \\
\text { dithiothreitol to reduce any oxidized thiol groups before purification. }\end{array}$ \\
\hline
\end{tabular}

\section{Purification and mass spectrometry}

All peptides were purified by reverse-phase high performance liquid chromatography (HPLC) on an Agilent Zorbax SB C-18 column, using a mixture of water (A) and acetonitrile (B) (linear gradient: 5\% to 35\% acetonitrile over 30 min). Both eluents A and B contained 0.1\% TFA. The column oven was heated to $70{ }^{\circ} \mathrm{C}$ to prevent triple-helix formation. After semi-preparative purifications, the collected fractions containing the target peptides were analyzed by analytical HPLC again using the following gradient parameters.

\begin{tabular}{|c|c|c|c|c|c|c|}
\hline Time (min) & 0 & 2 & 4 & 25 & 25.5 & 30 \\
\hline B\% & $5 \%$ & $5 \%$ & $10 \%$ & $40 \%$ & $5 \%$ & $5 \%$ \\
\hline
\end{tabular}


The flow rates used for semi-preparative and analytical HPLC were 4 and $1.5 \mathrm{~mL} / \mathrm{min}$, respectively. The pure fractions were lyophilized. The lyophilized products were reconstituted in pure water as stock solutions to be used for structural characterizations. Peptide concentrations in the stock solutions were determined by measuring the ultraviolet (UV) absorbance of the solutions at $214 \mathrm{~nm}$ for the collagen mimetic host-guest sequences (extinction coefficient: $2200 \mathrm{M}^{-1} \mathrm{~cm}^{-1}$ per peptide bond) or $280 \mathrm{~nm}$ for the Tyr-containing polyproline host-guest sequences (extinction coefficient: $1280 \mathrm{M}^{-1} \mathrm{~cm}^{-1}$ per tyrosine residue) on a SpectraMax M2e microplate reader (Molecular Devices) using a quartz cell with $1 \mathrm{~cm}$ cell path length.

All purified peptides/peptoids were verified by mass spectrometry. Mass spectra were obtained at the University of Utah Mass Spectrometry and Proteomics core facility on a Bruker UltrafleXtreme matrix-assisted laser desorption/ionization time-of-flight (MALDI/TOF) mass spectrometer.

\section{Circular dichroism (CD) spectroscopy}

$\mathrm{CD}$ measurements of the peptide solutions were recorded in quartz cells with a path length of $0.1 \mathrm{~cm}$, on a JASCO J-1500 CD spectrophotometer. Prior to CD spectra or melting experiments, peptide stock solutions were diluted to $150 \mu \mathrm{M}$ in $1 \times \mathrm{PBS}$ (pH: 7.4 for triple-helical peptides) or in $5 \mathrm{mM}$ phosphate buffer (pH: 7.0 for polyproline hostguest peptides) and heated at $80{ }^{\circ} \mathrm{C}$ for $5 \mathrm{~min}$ followed by incubation at $4{ }^{\circ} \mathrm{C}$ for at least $48 \mathrm{hr}$. Sequences containing guest residues with acidic or basic sidechains were also diluted to $150 \mu \mathrm{M}$ in $\mathrm{NaOH}(10$ or $35 \mathrm{mM})$ or $\mathrm{HCl}(15 \mathrm{mM})$ solutions.

$\mathrm{CD}$ spectra were scanned at $4{ }^{\circ} \mathrm{C}$ (for triple-helical peptides) or $25^{\circ} \mathrm{C}$ (for polyproline host-guest peptides) using the following parameters: bandwidth, $5 \mathrm{~nm}$; digital integration time, $16 \mathrm{~s}$; scanning speed, $20 \mathrm{~nm} / \mathrm{min}$; data pitch, $0.1 \mathrm{~nm}$. For the polyproline host-guest series, all reported spectra were the average of three independent scans, and were corrected from the blank buffer background.

Thermal melting curves were obtained by monitoring the ellipticity at $225 \mathrm{~nm}$ from $4{ }^{\circ} \mathrm{C}$ to $90{ }^{\circ} \mathrm{C}$ at a heating rate of $0.5^{\circ} \mathrm{C} / \mathrm{min}$. The mean residue ellipticity (MRE, $\left.[\theta]\right)$ was calculated using the equation $[\theta]=(\theta \times m) /(c \times l \times n)$, where $\theta$ is measured ellipticity (mdeg), $m$ is molecular weight $(\mathrm{g} / \mathrm{mol}), c$ is concentration $(\mathrm{mg} / \mathrm{mL}), l$ is path length of the cuvette $(\mathrm{mm})$, and $n$ is the number of amino acid residues in the peptide. The derivative of a melting curve was generated using the JASCO Spectra Manager software (Version 2.10.05), and the temperature at the minimum of the derivative curve was defined as the melting temperature $\left(T_{\mathrm{m}}\right)$. Each $T_{\mathrm{m}}$ value reported in this study was averaged from two CD thermal unfolding experiments, in which the difference between the two measured $T_{\mathrm{m}}$ values was less than $1{ }^{\circ} \mathrm{C}$ for all triple-helical host-guest peptides.

\section{X-ray crystallography}

Purified, lyophilized Nlys-CMP [Ac-(GlyProHyp) ${ }_{3}$-GlyNlysHyp-(GlyProHyp) $)_{3}$ ] was dissolved in water to a final concentration of $5.0 \mathrm{mg} / \mathrm{mL}$. Crystals were grown by vapor diffusion in sitting drops of $0.3 \mu \mathrm{L}$ of the peptide 
solution and $0.3 \mu \mathrm{L}$ of 2.1 M DL-malic acid ( $\mathrm{pH} 7.0)$ corresponding to well F8 in the commercially-available crystal screen JCSG-plus (Molecular Dimensions) at $21^{\circ} \mathrm{C}$. Crystals appeared within 10 days. Purified, lyophilized NpheCMP [Ac-(GlyProHyp) ${ }_{3}-$ GlyNpheHyp-(GlyProHyp) $)_{3}$ ] was dissolved in water to a final concentration of 10.0 $\mathrm{mg} / \mathrm{mL}$. Crystals were grown by vapor diffusion in sitting drops of $0.3 \mu \mathrm{L}$ of the peptide solution and $0.3 \mu \mathrm{L}$ of 2.4 M sodium malonate dibasic monohydrate ( $\mathrm{pH}$ 7.0) corresponding to well F9 in the commercially available crystal screen JCSG-plus (Molecular Dimensions) at $4{ }^{\circ} \mathrm{C}$. Crystals appeared within 1 week.

In preparation for data collection, crystals were suspended in a small rayon loop attached to a mounting pin, immersed in $20 \mu \mathrm{L}$ crystallization buffer with $25 \%$ added glycerol, then cryocooled by plunging into liquid nitrogen. Data were collected from crystals maintained at $100 \mathrm{~K}$. Diffraction data were collected on beam lines 12-2 (NlysCMP) and 9-2 (Nphe-CMP) at the Stanford Synchrotron Radiation Lightsource (SSRL). The resulting data were integrated and scaled using HKL2000 . Phases were determined by molecular replacement with Phaser-MR ${ }^{6}$ using $^{-}$ PDB structure $1 \mathrm{G} 9 \mathrm{~W}$ as a search model. Models were built with $\mathrm{COOT}^{7}$ and refined with Refmac5 ${ }^{8}$. UCSF Chimera version 1.14 was used to render molecular structure figures. Data and refinement statistics are indicated in Table S3.

\section{Metadynamics calculation of energy landscape}

We applied well-tempered metadynamics to study the thermal stability of the peptoid conformation within the XCMP system. This technique enhances the sampling in molecular simulations and enabled us to measure the free energy landscape as a function of the two backbone dihedral angles $\varphi$ (defines how the peptoid unit folds against the previous amino acid) and $\psi$ (defines how the peptoid unit folds against the following amino acid). The metadynamics simulations are performed by NAMD and the PLUMED package ${ }^{9-11}$, with molecular modeling details given in the method below. This method has been applied before to study the energy landscape for adhesion ${ }^{12}$ and the thermal stability of protein ${ }^{13}$. The energy deposition event occured every $200 \mathrm{fs}$ in the form of a Gaussian with height $0.01 \mathrm{kcal} \mathrm{mol}^{-1}$ and width of $0.35 \mathrm{rad}$ for each dihedral angle. The resulting free energy landscape as a function of time is obtained by summing all Gaussians deposited up to a specified time. We summarized the calculation results in Figure 4c, which include the results after depositing and summing 200,000 Gaussians for different molecular models. This number of Gaussians was used because it yields the convergence of the free energy landscape. It is shown in Figure $4 \mathrm{c}$ that different center acid yields a different energy landscape. The native state is highly similar to the expected polyproline conformation and the $(\varphi, \psi)$ values corresponding to the lowest free energy in each X-CMP are $\left(-63.1^{\circ}, 180^{\circ}\right)$ for Gly, $\left(-86.0^{\circ},-166.2^{\circ}\right)$ for Sar, $\left(-74.5^{\circ}, 180^{\circ}\right)$ for Nleu, and $\left(-45.9^{\circ}\right.$, $143.3^{\circ}$ ) for Pro. Besides the native state, Gly and Sar have a second energy well with slightly higher energy level and an energy barrier (-16.9 kcal/mol for Gly and $-19.4 \mathrm{kcal} / \mathrm{mol}$ for Sar) to cross. However, the energy landscapes of Nleu (well depth of $-21.7 \mathrm{kcal} / \mathrm{mol}$ ) and Pro (well depth of $-19.9 \mathrm{kcal} / \mathrm{mol}$ ) do not give a clear second energy 
well. The energy minimum of Nleu is apparently more localized than Pro, indicating that an X-CMP containing Nleu may be more thermally stable than Pro.

\section{Molecular dynamics simulations of X-CMPs}

We built the molecular structure and atomic interaction of X-CMPs by combining DFT calculation with CHARMM General Force field (CHARMM GenFF) ${ }^{14}$. The standard CHARMM27 force field ${ }^{15}$ was updated to enable the modeling and simulation of peptide-peptoid hybrid system. To be more specific, the DFT calculation for each peptoid was performed by using HyperChem (Hypercube, Inc. Gainesville, FL, USA), which uses the 3-21G basis set $^{16}$ to represent the electronic wave function. Geometric optimization with the conjugate gradient method was used to find the minimized coordinates of all the atoms. These optimized structures were used to make automatic analogy with the CHARMM GenFF to define the charge distribution within the molecule, and parameters of bond, angle and dihedral angle and vdw parameters. All the parameters had penalty score generally lower than 10, indicating the analogy was fair ${ }^{14}$. The intrinsic coordinate of each peptoid molecule was also defined according to the optimized structure, ensuring the initial geometry had optimum energy.

Classical full atomistic molecular dynamics (MD) simulations were used to fully equilibrate the X-CMP system in the explicit solvent composed of $100 \mathrm{mM} \mathrm{NaCl}$ and TIP3P water prior to metadynamics using the updated CHARMM27 all atom energy force field ${ }^{15}$. The simulation system was $11 \times 5 \times 5 \mathrm{~nm}^{3}$ in size. The net charge of the system was set to zero by adjusting the ratio between cation and anion; each ion was initially distributed randomly in water and at least $5 \AA$ from the peptide-peptoid structure. For the initial run, each of the backbone atoms were constrained in space by elastic springs with stiffness of $5 \mathrm{kcal} / \mathrm{mol} / \AA^{2}$ in all 3 directions, while the sidechain atoms and solvent molecules were free to move. The simulation time step was $2 \mathrm{fs}$ with rigid bonds modeled for all the covalent bonds between hydrogen atoms and other heavy atoms. We used particle mesh Ewald (PME) function with a grid width $<1 \AA$ to calculate the electronic interaction as an efficient method to accurately include all the longdistance electrostatics interactions. We ran 500,000 steps of energy minimization by using a conjugate gradient and line search algorithm followed by a $1 \mathrm{~ns}$ dynamics run for initial equilibrium. The dynamics simulation was performed in the NPT (constant pressure of $1 \mathrm{~atm}$ and constant temperature of $310 \mathrm{~K}$ ) ensemble controlled by the Langevin dynamics to reach a constant pressure and temperature (with $5 \mathrm{ps}^{-1}$ damping coefficient for temperature, $100 \mathrm{fs}$ oscillation period and $50 \mathrm{fs}$ damping time scale for pressure control) with the shrinkable volume during the run. After the initial run, we restarted the simulation, released the constraints on the backbone atoms, and continued using NPT ensemble for $20 \mathrm{~ns}$ for the purpose of getting a fully equilibrated X-CMP structure. The simulations were performed by using a NAMD package ${ }^{2}$ (v2.12) in the local Linux workstation with multiple graphics processing units (GeForce GTX 1080) support through Compute Unified Device Architecture (CUDA v8.0). 


\section{Gelatin binding assays}

Fluorescein-labeled peptides F-Pro-CMP and F-Nnbz2-CMP [sequences: F-GlyGlyGly-(GlyProHyp) ${ }_{7}$, F-Ahx$(\text { GlyProHyp })_{2}\left(\right.$ GlyNnbzHyp) ${ }_{2}($ GlyProHyp) 3 ; GlyGlyGly: spacer, Ahx: aminohexanoic acid, spacer] were prepared by reacting the $\mathrm{N}$-terminal amines of the sequences on-resin with 6 molar equivalents of 5(6)-carboxyfluorescein (designated as F-, Sigma-Aldrich, 21877) activated by 6 molar equivalents of PyAOP with 12 molar equivalents of DIEA in NMP for over $24 \mathrm{hr}$. The labeled peptides were cleaved from the resin, purified by HPLC with protection from ambient light, and analyzed by MALDI (F-Pro-CMP, MALDI-MS, calculated and observed: 2440 [M+Na] $]^{+}$; F-Nnbz2-CMP, MALDI-MS, calculated and observed: $\left.2572[\mathrm{M}+\mathrm{Na}]^{+}\right)$. The pure fluorescent peptides were lyophilized and dissolved in $1 \times$ PBS.

Wells of a 96-well plate were coated with approximately $6 \mu \mathrm{L}$ of $85^{\circ} \mathrm{C}$ gelatin (Sigma-Aldrich, G2500) solution in $1 \times$ PBS $(10 \% \mathrm{w} / \mathrm{v})$ and incubated at $4{ }^{\circ} \mathrm{C}$ for $15 \mathrm{~min}$ to allow gelation. The thin gelatin hydrogel films were crosslinked with a MES buffered solution (pH 4.7, $100 \mu \mathrm{L} /$ well) containing $2 \mathrm{mM}$ of NHS (N-hydroxysuccinimide) and $10 \mathrm{mM}$ EDC [1-Ethyl-3-(3-dimethylaminopropyl)carbodiimide] with shaking overnight at room temperature. The crosslinked gelatin films were washed with $200 \mu \mathrm{L}$ of $25^{\circ} \mathrm{C} 1 \times \mathrm{PBS} 10$ times. PBS solution $(50 \mu \mathrm{L})$ containing $10 \mu \mathrm{M}$ of F-Pro- or F-Nnbz2-CMP was heated at $85{ }^{\circ} \mathrm{C}$ for $15 \mathrm{~min}$ to dissociate the triple-helices before being immediately added to each well and allowed to bind for $1 \mathrm{hr}$ at room temperature. Following binding, the plate was washed three times with $1 \times \mathrm{PBS}$ at room temperature before the fluorescence (ex: $489 \mathrm{~nm}$, em: $533 \mathrm{~nm}$ ) was measured on a SpectraMax M2e microplate reader. Subsequently, half the wells treated with F-Nnbz2-CMP were exposed to UV light for $15 \mathrm{~min}$ (mercury arc lamp, $365 \mathrm{~nm}, 15.5 \mathrm{~mW} / \mathrm{cm}^{2}$ ). Afterwards, the gelatin hydrogels were washed with $1 \times$ PBS at room temperature $(3 \times 30 \mathrm{sec}, 4 \times 15 \mathrm{~min})$ before their fluorescence was measured again. The binding experiment for each peptide was run three times with protection from ambient light.

\section{UV-triggered hydrogel dissolution and spatial control of cell attachment}

To prepare multi-arm (MA) PEG-CMPs, 8-arm PEG-Mal-40000 (Jenkem) was dissolved in 1×PBS to produce an $8 \%$ solution and added directly to a powder of Cys-GlyGlyGly-(GlyProHyp) $)_{2}-(\text { GlyNnbzHyp) })_{2}-(\text { GlyProHyp })_{3}$ (MALDI-MS, calculated $2352.3[\mathrm{M}+\mathrm{H}]^{+}$, observed: $\left.2353.1[\mathrm{M}+\mathrm{H}]^{+}, 8 \mathrm{eq}\right)$. Gelation was observed almost immediately. Conjugation efficiency was measured by HPLC, which showed that 70\% of the Cys-Nnbz2-CMP was conjugated to the multi-arm polymer (Figure S5). Fluorescently labeled gels were prepared by dissolving dry MAPEG-CMP in a PBS (1×) solution containing $650 \mu \mathrm{M}$ of F-Nnbz2-CMP. The Nnbz2-CMP conjugated MA-PEGCMP hydrogel $(50 \mu \mathrm{L})$ was melted by heating to $80{ }^{\circ} \mathrm{C}$, added to the bottom of a microtube, and allowed to gel at $4{ }^{\circ} \mathrm{C}$ for $15 \mathrm{~min}$. After gelation, $250 \mu \mathrm{L}$ of $1 \times \mathrm{PBS}\left(25^{\circ} \mathrm{C}\right)$ was added atop the green colored gel. No diffusion of fluorescence into the PBS was observed. The gel was then exposed to UV light (Mercury arc lamp, $365 \mathrm{~nm}, 33$ $\mathrm{mW} / \mathrm{cm}^{2}$ ) for $30 \mathrm{~min}$ until the gel was no longer visible at the bottom of the tube. After UV irradiation, the green color fully permeated the solution indicating release of the F-Nnbz2-CMP and dissolution of the gel (Figure S5). 
To utilize the MA-PEG-CMP (Nnbz2-CMP) to spatially control cell attachment (Figure S6) and migration (Figure 6f), we prepared a thin gelatin film on the bottom of a 6-well plate (size: $\sim 1 \mathrm{~cm}^{2}$, thickness: $\sim 50 \mu \mathrm{m}$ ) and crosslinked it with EDC/NHS as described above. MA-PEG-CMP was melted by heating to $80{ }^{\circ} \mathrm{C}$ and diluted in hot $1 \times \mathrm{PBS}$ to a final concentration of $31.25 \mu \mathrm{M}$. The MA-PEG-CMP solution $\left(85 \mu \mathrm{L}, 80^{\circ} \mathrm{C}\right)$ was applied to the film surface and allowed to dry completely. Wells patterned before cell addition (Figure S6) were exposed to UV light (mercury arc lamp, $365 \mathrm{~nm}, 15.5 \mathrm{~mW} / \mathrm{cm}^{2}$ ) through a transparency mask placed directly onto the film surface for $10 \mathrm{~min}$. Patterns were produced using CorelDraw and printed onto transparences by CAD/Art Services (Brandon, OR). Films were then washed with $1 \times \mathrm{PBS}$ and sterilized with $70 \%$ ethanol by immersion in water for $1 \mathrm{hr}$ and washed with sterile $1 \times$ PBS. MDA-MB-231 cells $\left(1.4 \times 10^{4}\right.$ cells $\left./ \mathrm{mL}\right)$ in $3 \mathrm{~mL}$ of Dulbecco's modified eagle medium (supplemented with $10 \%$ fetal bovine serum and $1 \%$ mix of penicillin-streptomycin) were added to each well and were incubated at $37{ }^{\circ} \mathrm{C}$ in a $5 \% \mathrm{CO}_{2}$ atmosphere. Growth media was changed every 2 days. Cell attachment was monitored with an EVOS light microscope (Thermofisher Scientific, Figure S6). In another experiment, after cells grew to about $80 \%$ confluency on the gelatin films modified with MA-PEG-CMP, wells were drained of growth media, and areas at the boundary between gelatin and MA-PEG-CMP were exposed to UV light (Mercury arc lamp, $365 \mathrm{~nm}, 33$ $\left.\mathrm{mW} / \mathrm{cm}^{2}\right)$ for $8 \mathrm{~min}$ through a photomask elevated by thin spacers $(0.9 \mathrm{~mm}$ in height, which prevented cells from contacting the film surface). After UV patterning, wells were briefly washed with $1 \times \mathrm{PBS}$, and growth media was replaced. The cells were incubated for an additional $24 \mathrm{hr}$ before their migration were observed with the EVOS light microscope (Figure 6f). 


\section{Section 3: Supplementary Tables and Figures}

Table S1. Residues, structures, and $T_{\mathrm{m}}$ values of the host-guest X-CMPs used in this study.

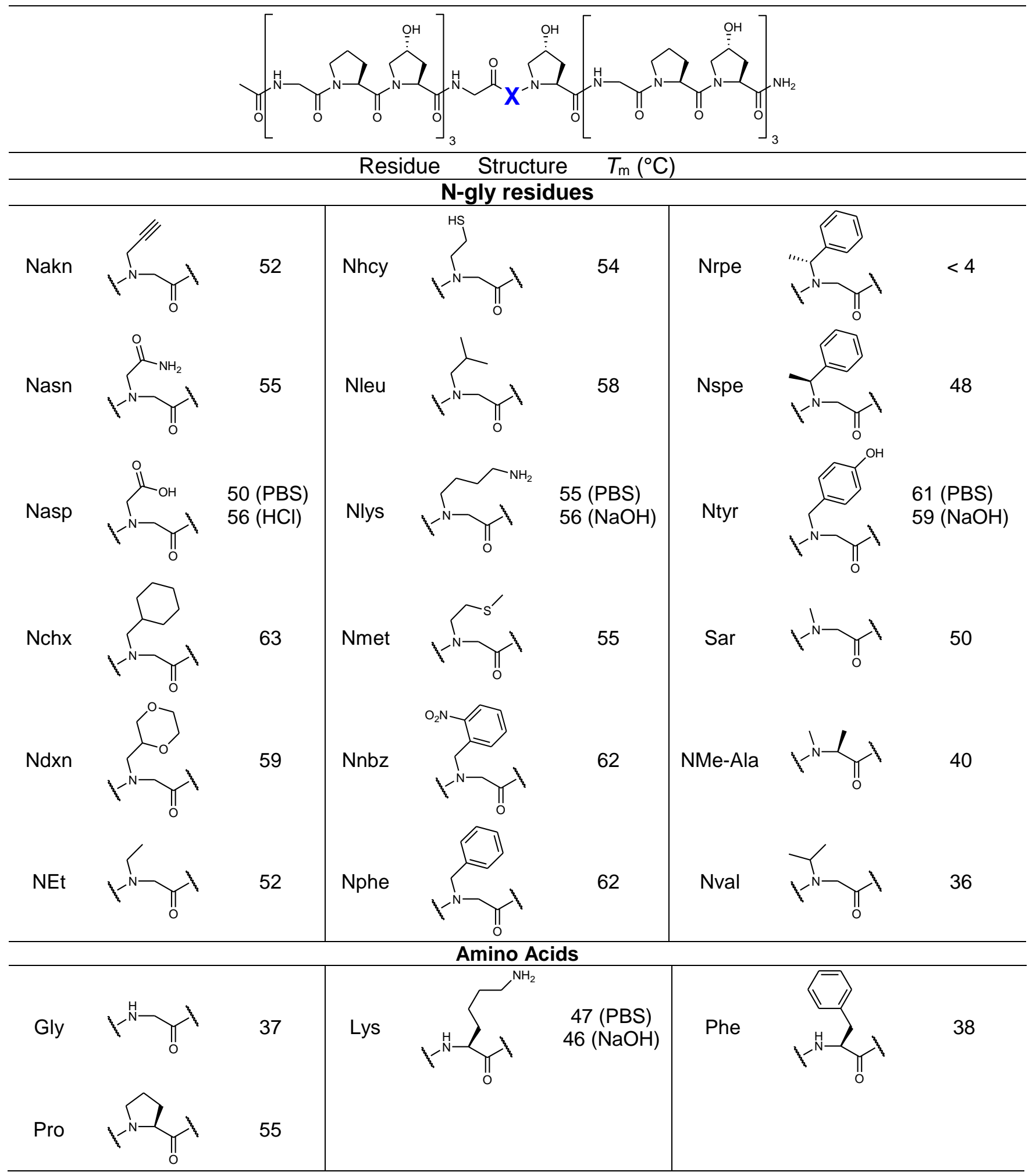


Table S2. X-CMP crystallographic data and refinement statistics.

\begin{tabular}{|c|c|c|}
\hline Data & & \\
\hline Peptoid guest residue & N-Lysine & N-Phenylalanine \\
\hline X-ray Source/Wavelength & SSRL 12-2 / 0.7500 & SSRL 9-2 / 0.9795 \\
\hline Data processing software & HKL2000 & XDS \\
\hline Space Group & $\mathrm{C} 2$ & $\mathrm{P} 1$ \\
\hline $\begin{array}{l}\text { Unit cell dimensions } \\
\mathrm{a}, \mathrm{b}, \mathrm{c}(\AA) \\
\alpha, \beta, \gamma\left({ }^{\circ}\right)\end{array}$ & $\begin{array}{l}72.34,24.76,25.36 \\
90.00,98.72,90.00\end{array}$ & $\begin{array}{l}20.44,31.33,35.41 \\
88.72,74.96,89.79\end{array}$ \\
\hline Resolution $(\AA)$ & $40.0-0.95$ & $34.19-1.10$ \\
\hline Resolution $(\AA)$ - (high-resolution shell) & $(0.98-0.95)$ & $(1.12-1.10)$ \\
\hline \# Reflections measured & 579681 & 446025 \\
\hline \# Unique reflections & 24848 & 31530 \\
\hline Redundancy & 23 & 14 \\
\hline Completeness $(\%)$ & $88.9(72.3)$ & $90.6(66.3)$ \\
\hline$\langle\mathrm{I} / \sigma \mathrm{I}\rangle$ & $8.0(0.9)$ & $17.8(1.4)$ \\
\hline $\mathrm{CC}(1 / 2)$ & $0.999(0.734)$ & $0.999(0.459)$ \\
\hline Mosaicity $\left(^{\circ}\right)$ & 0.44 & 0.30 \\
\hline Rpim & $0.019(0.344)$ & $0.029(1.237)$ \\
\hline \multicolumn{3}{|l|}{ Refinement } \\
\hline Refinement software program & Refmac5 & Refmac5 \\
\hline Resolution $(\AA)$ & $13.62-0.95$ & $34.2-1.10$ \\
\hline Resolution $(\AA)$ - (high-resolution shell) & $(0.977-0.952)$ & $(1.125-1.096)$ \\
\hline \# Reflections used for refinement & 23613 & 29490 \\
\hline \# Reflections in Rfree set & 1221 & 2021 \\
\hline Rcryst & $0.139(0.319)$ & $0.154(0.289)$ \\
\hline Rfree & $0.158(0.329)$ & $0.198(0.371)$ \\
\hline RMSD: bonds $(\AA) /$ angles $\left(^{\circ}\right)$ & $0.013 / 1.848$ & $0.014 / 2.010$ \\
\hline$\langle\mathrm{B}\rangle\left(\AA^{2}\right)$ : all atoms / \# atoms & $10.7 / 532$ & $15.4 / 1129$ \\
\hline$<\mathrm{B}>\left(\AA^{2}\right)$ : water molecules / \#water & $16.5 / 115$ & $23.6 / 254$ \\
\hline
\end{tabular}


Table S3. Protein Data Bank (PDB) IDs for collagen crystal structures used in backbone analysis.

\begin{tabular}{|c|c|c|}
\hline $1 \mathrm{BKV}$ & $1 \mathrm{~V} 6 \mathrm{Q}$ & $3 \mathrm{WN} 8$ \\
\hline $1 \mathrm{CAG}$ & $2 \mathrm{D} 3 \mathrm{H}$ & $4 \mathrm{AXY}$ \\
\hline $1 \mathrm{CGD}$ & $2 \mathrm{~V} 53$ & $4 \mathrm{DMT}$ \\
\hline $1 \mathrm{EI} 8$ & $2 \mathrm{~V} 53$ & $4 \mathrm{LOR}$ \\
\hline $1 \mathrm{G} 9 \mathrm{~W}$ & $3 \mathrm{~A} 1 \mathrm{H}$ & $4 \mathrm{Z} 1 \mathrm{R}$ \\
\hline $1 \mathrm{~V} 4 \mathrm{~F}$ & $3 \mathrm{P} 46$ & \\
\hline
\end{tabular}


Table S4. X-CMP sequences with X and Y substitutions at the central repeat designed to investigate the effect of hydrophobic neighbors on triple-helical stability. For these constructs, we selected Nphe and Ile to replace Pro and Hyp. Following Goodman's hypothesis that hydrophobic effects are the critical factor for inducing triple-helix formation ${ }^{17,18}$, we expected that the destabilization resulting from the Y position Hyp $\rightarrow$ Ile substitution would be attenuated when $\mathrm{X}=\mathrm{Nphe}$, since hydrophobic interactions between the Nphe-Ile pair are stronger than Pro-Ile. Our results showed that Hyp $\rightarrow$ Ile decreased $T_{\mathrm{m}}$ by 10 or $11{ }^{\circ} \mathrm{C}$ regardless of the $\mathrm{X}$ residue, suggesting that adjacent hydrophobic interactions do not contribute significantly to the triple-helix stability. These results further support the notion that hydrophobicity of peptoid residues is not the most important factor in stabilization the collagen triple-helix.

Pro-lle


Table S5. Reference codes for peptoid structures analyzed from the Cambridge Molecular Database (CSD).

\begin{tabular}{|c|c|c|c|c|c|}
\hline ACEVEM & CUCPAR & GIKBEJ & KALWAX & QECXEE & XEDKOH \\
\hline ACEVIQ & CUCPEV & GLSARM & KEPNAU & QETQEO & YIYJUN \\
\hline ACTDGU10 & CUKGIA & HAXMOI & KEXZAQ & QETQIS & YOCWUK \\
\hline ACUMOC & CUQRUB & HAXMOI10 & LEBDEB & QICFEP & YOJNUH \\
\hline ACUMUI & CUQSAI & HEYZAN & LIPDOD & QODTIO & YUHDIQ \\
\hline ALASAR & CYDSAR & HEYZER & LOSLEL & ROLDUR & YUHDOW \\
\hline ASUXOB & CYGSGS & HUCVIK & LOWGOT & TBXSAG & YUHDUC \\
\hline BEHTEN & CYTSAR & HUCVOQ & MIJVEH & UKUTUP & YUHFAK \\
\hline BIPWAY & DEDQAU & HXSARM & NAFJEJ & UMAYEM & YUHGIT \\
\hline BIPWAY10 & DEKSAN & ICYSPA & NAMPIA & UWUFUO & YUHGOZ \\
\hline BIPWEC10 & DETWUU & IGEJUB & NIZHIO & UXOYEN & ZADREB \\
\hline BRAXGU & FIFSOE & IJAQIV & NUWNEY & UXOYOX & ZADRIF \\
\hline CALSAR & FOLMUQ & IJAQIV10 & OGAZOM & VACLOD & ZAJDUJ \\
\hline CAZSEB & GABHEX & IPUQAN & OGAZUS & VACLUJ & ZAJZAO \\
\hline CBBLPB10 & GABXEN & IPUQER & PAGTIA & VEJGEY & ZATJEL \\
\hline CHPSAR & GEDYOG & JOKMAX & PAGTOG & VEJGIC & ZEWREA \\
\hline COSARC10 & GEDYUM & KADFOL & PAGTUM & VEJGUO & ZEWRIE \\
\hline CPSAYL10 & GIDNUC & KALVIE & PIJPAZ & WEBZEI & \\
\hline CTSARC & GIJZUW & KALVOK & POHMUU & WEXPOE & \\
\hline CUCNUJ & GIKBAF & KALVUQ & POXPAT & WEXPUK & \\
\hline & & & & & \\
\hline
\end{tabular}


Table S6. Examples of N-gly-containing small molecule structures from CSD (Figure 4a).

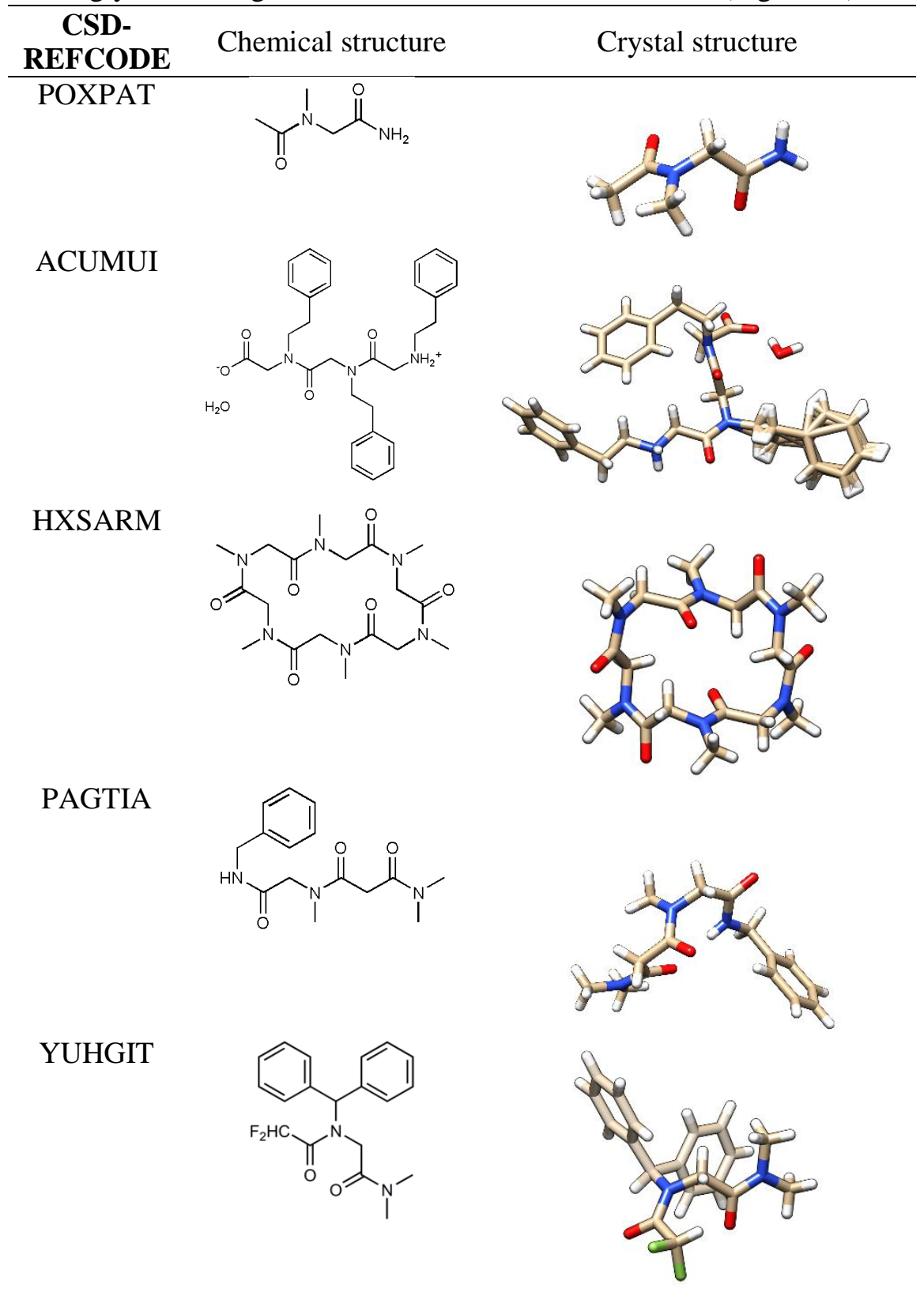


Table S7. UV-responsive X-CMPs. Additional Nnbz groups increase $T_{\mathrm{m}}$ indicating that peptoid stabilization by Ngly is additive. When the nitrobenzyl sidechain is removed by exposure to UV light, the triple-helix becomes dramatically less stable as the Nnbz residue is converted to Gly (Figure 6b).

Name


Table S8. The cis-trans ratios of the amide bond of selected peptoid residues in this study.
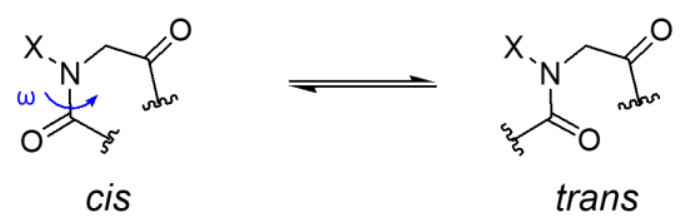

\begin{tabular}{|c|c|c|c|c|}
\hline Residue & Sidechain $X$ & $K_{\text {cis/trans }}$ (solvent) & Reference & $T_{\mathrm{m}}$ of X-CMP $\left({ }^{\circ} \mathrm{C}\right)$ \\
\hline Pro & & $\begin{array}{l}0.22\left(\mathrm{D}_{2} \mathrm{O}\right) \\
0.26\left(\mathrm{D}_{2} \mathrm{O}\right) \\
0.33 \text { (dioxane) }\end{array}$ & $\begin{array}{l}\text { J. Am. Chem. Soc. 2001, 123, 4, } \\
\text { 777-778 } \\
\text { Org. Lett. 2020, 22, 2, 348-351 } \\
\text { J. Am. Chem. Soc. 2002, 124, 11, } \\
\text { 2497-2505 }\end{array}$ & 55 \\
\hline Sar & & $\begin{array}{l}0.42\left(\mathrm{CD}_{3} \mathrm{OD}\right) \\
0.60\left(\mathrm{CD}_{3} \mathrm{CN}\right)\end{array}$ & \multirow{3}{*}{$\begin{array}{l}\text { J. Am. Chem. Soc. 2009, 131, 45, } \\
\text { 16555-16567 }\end{array}$} & 50 \\
\hline $\mathrm{NEt}$ & & $\begin{array}{l}0.47\left(\mathrm{CD}_{3} \mathrm{OD}\right) \\
0.66\left(\mathrm{CD}_{3} \mathrm{CN}\right)\end{array}$ & & 52 \\
\hline Nphe & & $\begin{array}{l}0.62\left(\mathrm{CD}_{3} \mathrm{OD}\right) \\
1.15\left(\mathrm{CD}_{3} \mathrm{CN}\right)\end{array}$ & & 62 \\
\hline
\end{tabular}


a

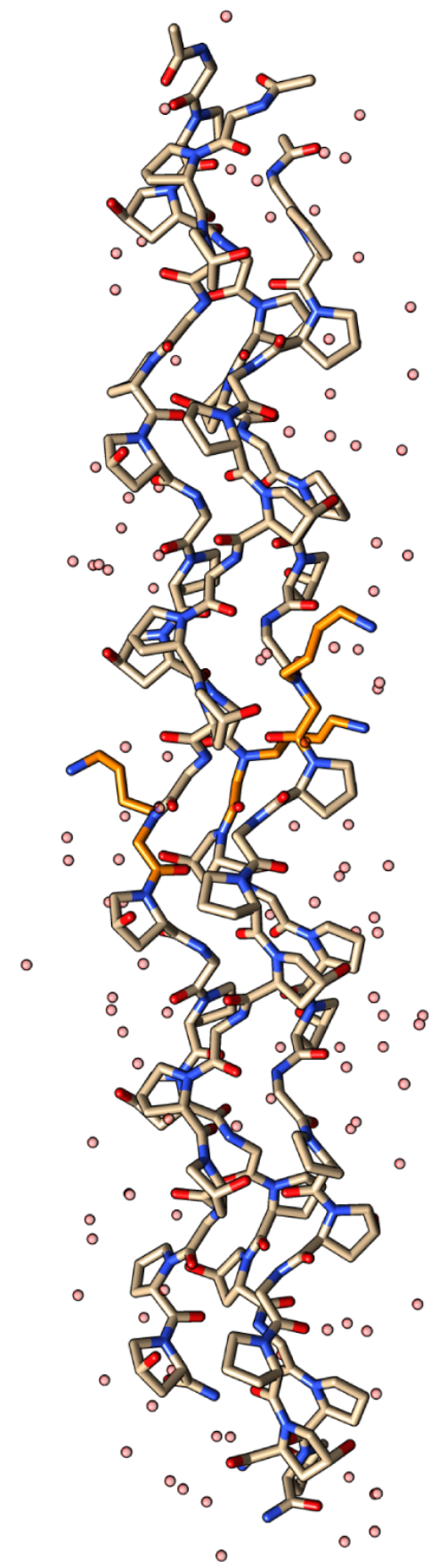

b

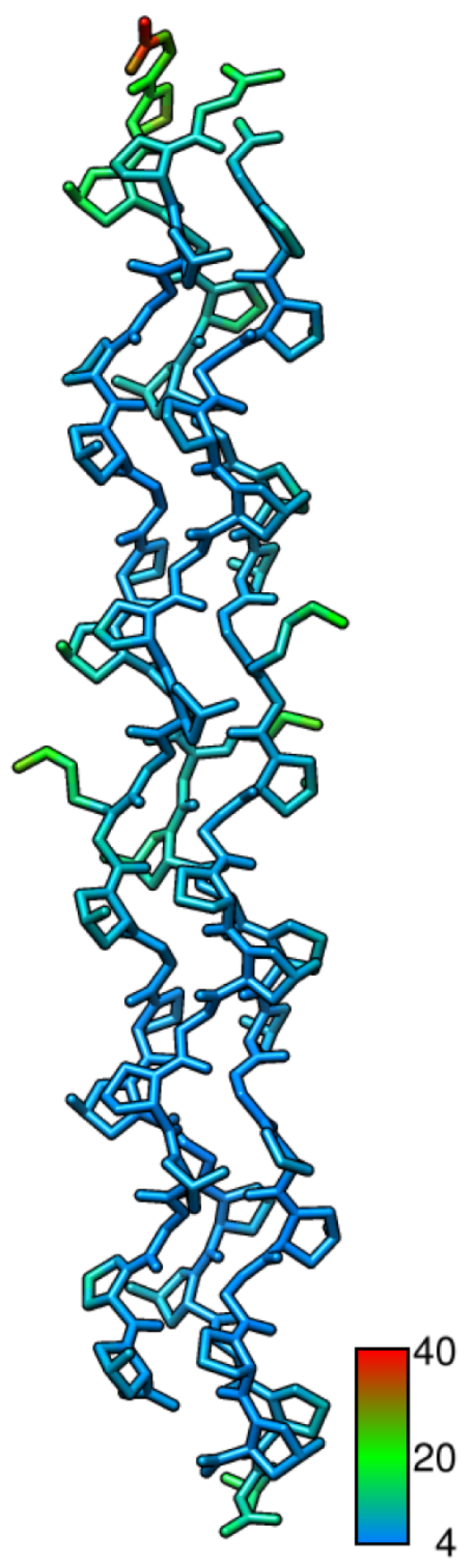

Figure S1. Crystal structure of Nlys-CMP. a, Overall triple-helical structure, showing one trimer in the asymmetric unit, including complete hydration shell, determined at $0.95 \AA$ resolution. Central Nlys residues are colored in orange. b, Illustration of B-factors in the crystal structure: Overall B-factors are low through most of the triplehelical subunits with higher B-factors only appearing near the ends, indicating that the structure is less ordered near the ends of the helix. 

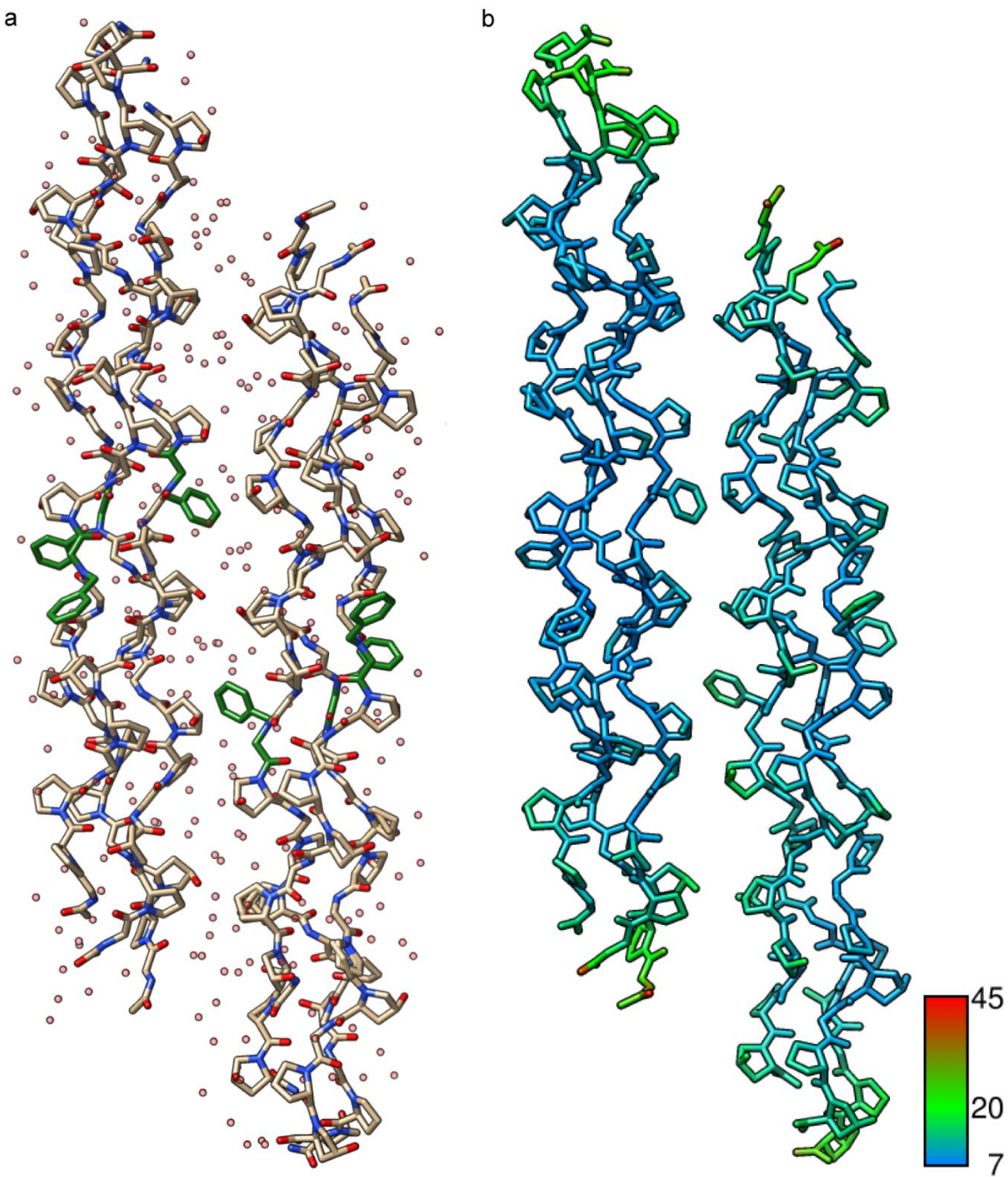

Figure S2. Crystal structure of Nphe-CMP. a, Overall triple-helical structure, showing two trimers in the asymmetric unit, including the complete hydration shell, determined at $1.10 \AA$ resolution. Central Nphe residues are colored in green. $\mathbf{b}$, Illustration of B-factors in the crystal structure: Overall B-factors are low through most of the triple-helical subunits with higher B-factors only appearing near the ends, indicating that the structure is less ordered near the ends of the helix. 

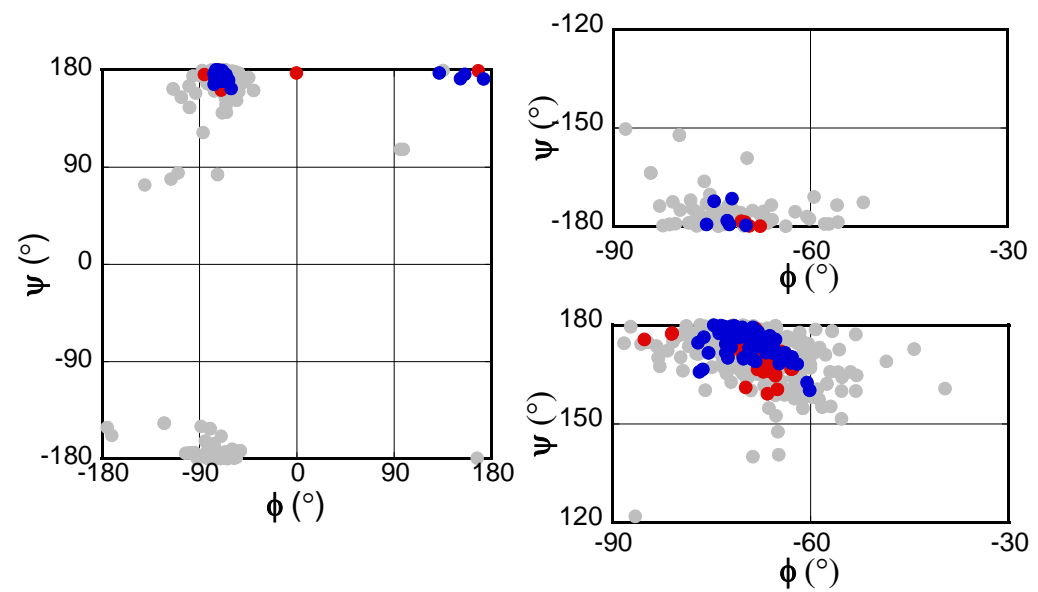

Figure S3a. Distribution of glycine $\varphi$ and $\psi$ angles in the solved crystal structures for Nlys- (red) and Nphe-CMPs (blue) vs glycine residues in collagen structures from literature (grey). Average dihedral angles $(\varphi, \psi)$ for all nonterminal glycine residues are almost identical to previously reported structures: $\left(-69 \pm 3^{\circ}, 174 \pm 5^{\circ}\right)$. Terminal glycines were removed because they have very high B-factors. The collagen structures used for comparison are listed in Table S4.
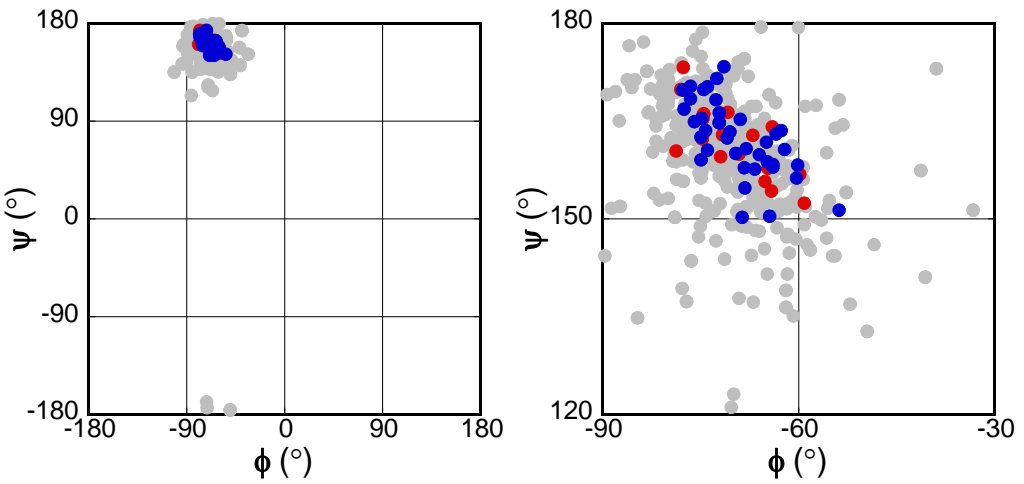

Figure S3b. Distribution of proline $\varphi$ and $\psi$ angles in the solved crystal structures for Nlys- (red) and Nphe-CMPs (blue) vs X position amino acids in collagen structures from literature (grey). Average dihedral angles for all proline residues are $\left(-70 \pm 6^{\circ}, 162 \pm 6^{\circ}\right)$. The collagen structures used for comparison are listed in Table S4.
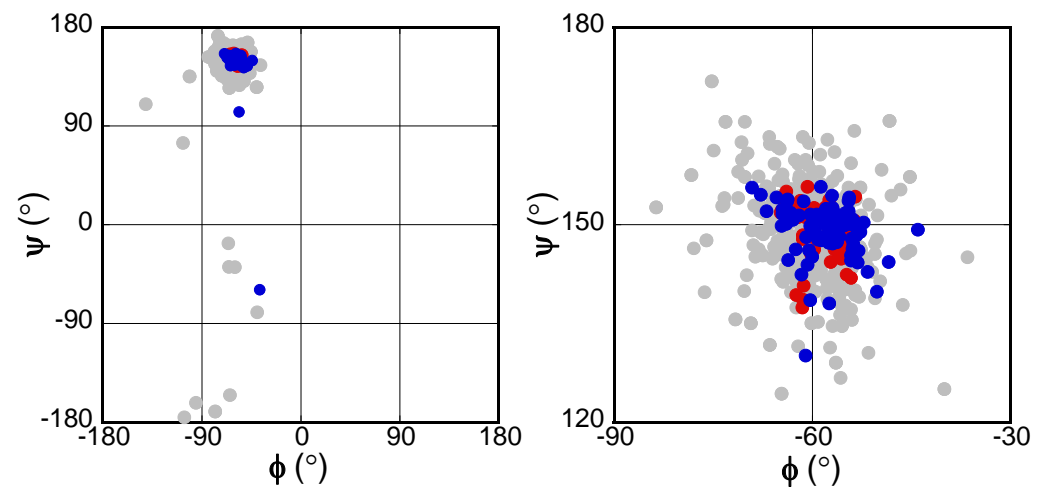

Figure S3c. Distribution of hydroxyproline $\varphi$ and $\psi$ angles in the solved crystal structures for Nlys- (red) and NpheCMPs (blue) vs Y position amino acids in collagen structures from literature (grey). Average dihedral angles for all hydroxyproline residues are $\left(-58 \pm 5^{\circ}, 147 \pm 7^{\circ}\right)$. The collagen structures used for comparison are listed in Table S4. 
a
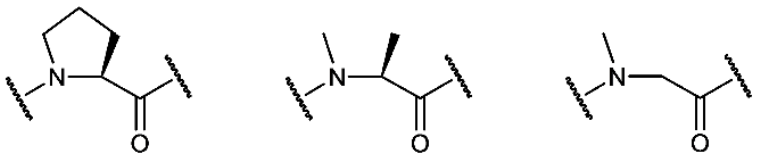

Pro, $55^{\circ} \mathrm{C}$

NMe-Ala, $40^{\circ} \mathrm{C}$

Sar, $50^{\circ} \mathrm{C}$

b
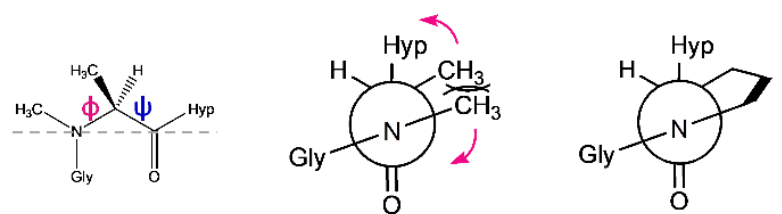

Figure S4. Guest residue $N$-methyl-L-alanine (NMe-Ala). a, Structures of Pro, NMe-Ala, and Sar, as well as the $T_{\mathrm{m}}$ values of their corresponding X-CMP triple-helices. b, Newman-like Projection of NMe-Ala showing the plausible steric clash of adjacent methyl groups in the polyproline backbone conformation. 
a

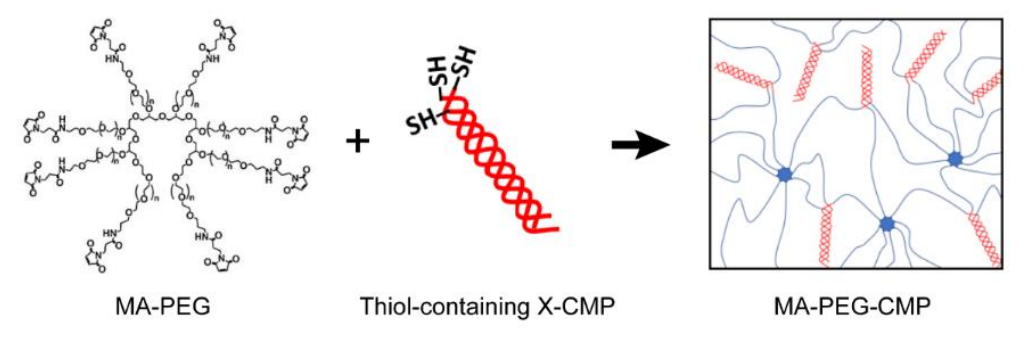

b

C
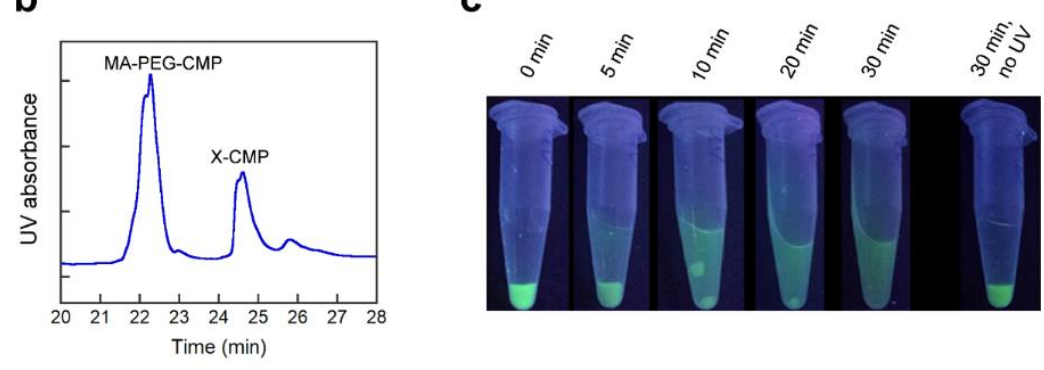

Figure S5. MA-PEG-CMPs produce a stable hydrogel capable of UV-induced dissolution. a, Schematic of maleimide groups at the termini of the 8-arm PEG reacting with the thiol-containing X-CMPs (Cys-Nnbz2-CMP) to form a triple-helix crosslinked hydrogel. b, HPLC of MA-PEG-CMP showing 70\% of Cys-Nnbz2-CMP conjugated to the 8-arm PEG. c, MA-PEG-CMP mixed with fluorescein labeled F-Nnbz2-CMP formed a green hydrogel that traps the green colored F-Nnbz2-CMP via triple-helical crosslinks. Upon UV exposure, the triplehelical crosslinks unfold, releasing the fluorescent peptide into solution. 

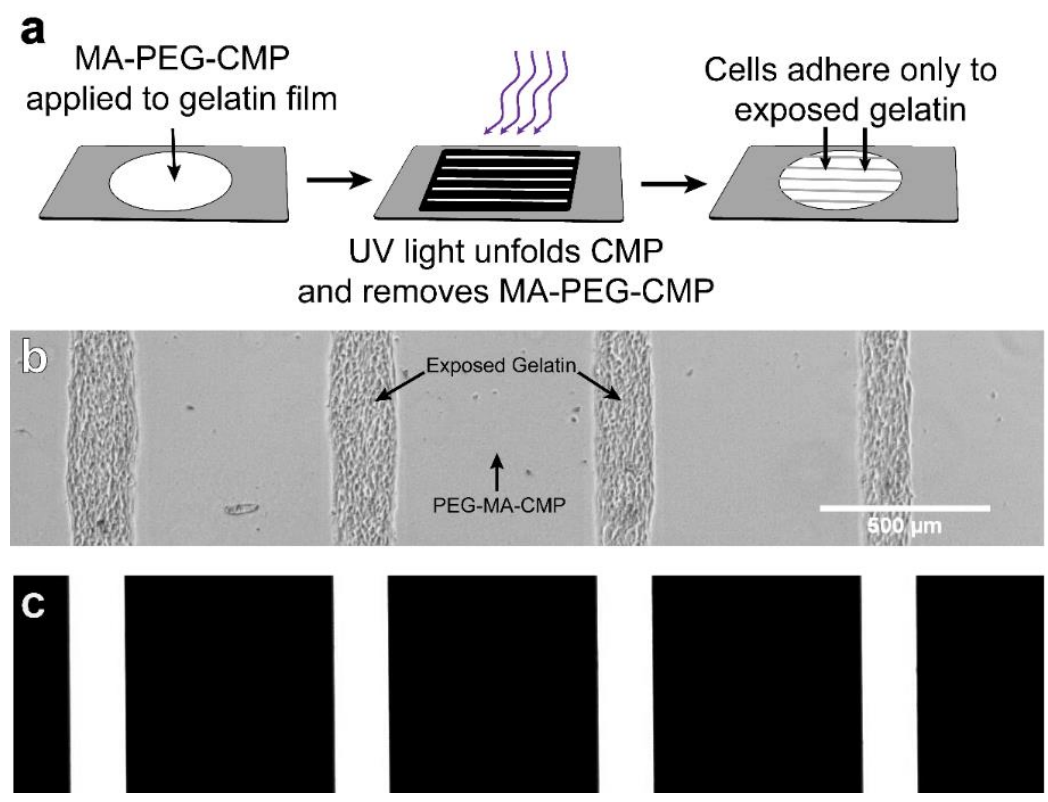

Figure S6. Spatial control of cell attachment using MA-PEG-CMP. a, Schematic of a gelatin substrate spatially modified with MA-PEG-CMP hydrogels through photo-patterning. Gelatin and collagen are excellent natural matrices for cell adhesion and migration; surface modification with a bulky, hydrophilic polymer can inhibit cell attachment. Nnbz2-CMP-conjugated MA-PEG-CMP hydrogel was added to the center of a gelatin film and allowed to bind. Next, we exposed this film to UV light through a photomask printed with a line pattern to remove the MAPEG-CMP conjugate and expose the gelatin substrate in selected areas. Finally, MDA-MB-231 cells were seeded atop the MA-PEG-CMP modified gelatin and were found to adhere only to the exposed gelatin regions. $\mathbf{b}$, Light micrograph showing cell attachment in a spatial pattern similar to the photomask used in this experiment (c). 


\section{Supplementary Section 4: HPLC, MALDI and CD of all peptides}

X-CMP peptides

\section{Pro-CMP}<smiles>CC(C)CNC(=O)CN1CCCC1C(=O)N1CCC(O)C1</smiles>

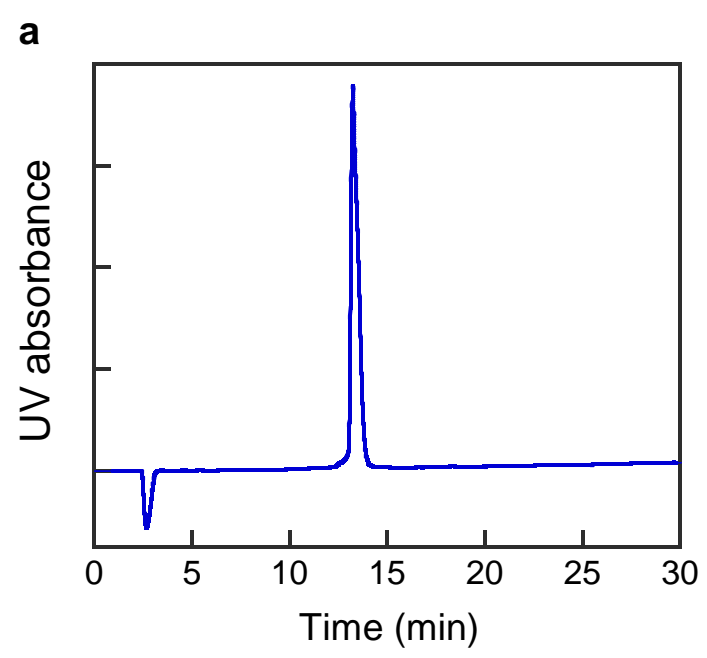

b
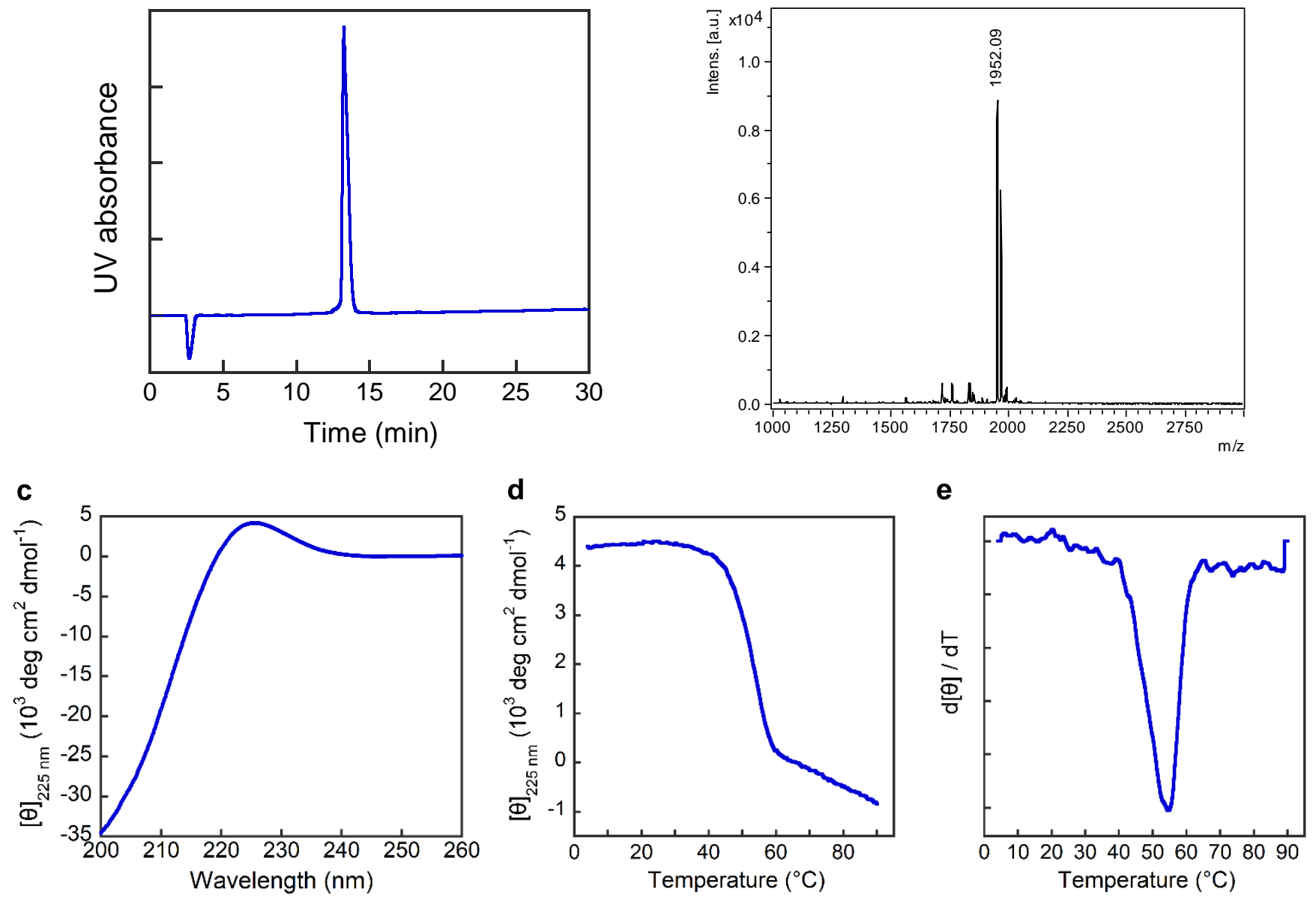
a, The HPLC chromatogram of purified peptide, $t_{R}=13.2 \mathrm{~min}$.
b, MALDI-MS, calculated: $1951.9[\mathrm{M}+\mathrm{Na}]^{+}$, observed: $1952.1[\mathrm{M}+\mathrm{Na}]^{+}$.
c, The CD spectrum in PBS buffer at $4{ }^{\circ} \mathrm{C}$.
d, The CD thermal melting curve in PBS buffer.
e, The first derivative of the melting curve, $T_{\mathrm{m}}=55^{\circ} \mathrm{C}$. 


\section{Pro-Ile-CMP}
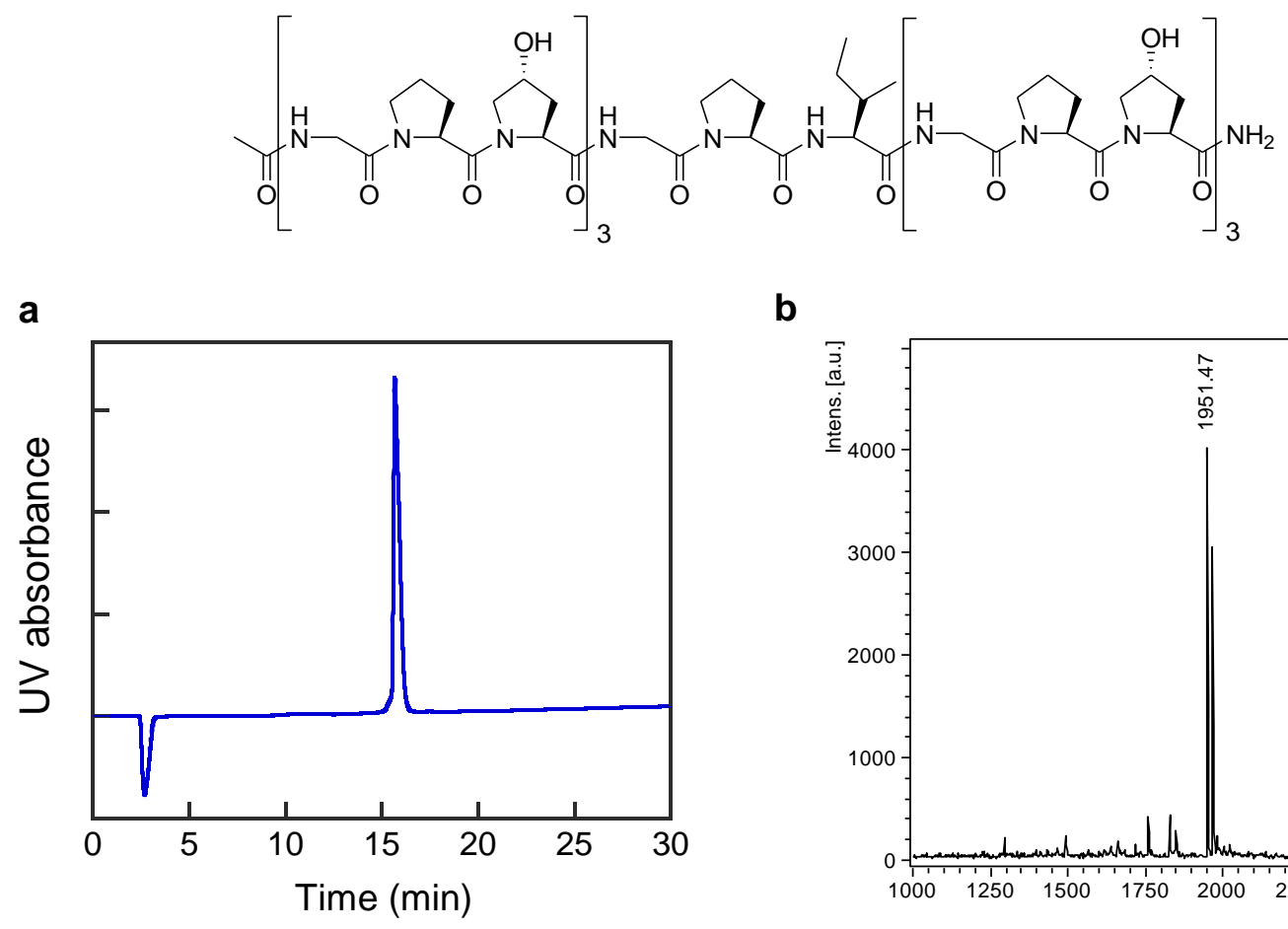

b
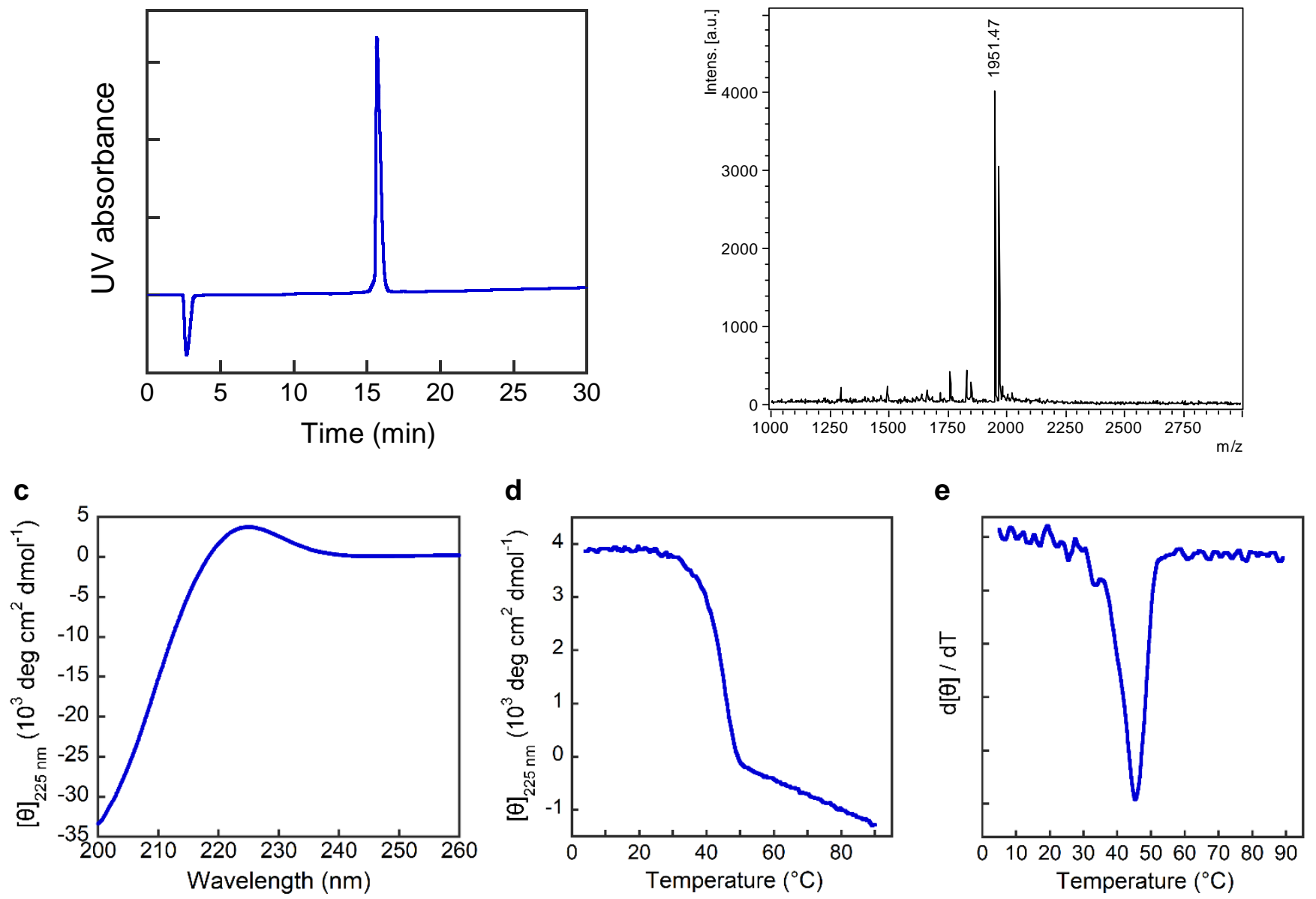
a, The HPLC chromatogram of purified peptide, $t_{R}=15.7$ min.
b, MALDI-MS, calculated: $1951.9[\mathrm{M}+\mathrm{Na}]^{+}$, observed: $1951.5[\mathrm{M}+\mathrm{Na}]^{+}, 1967.5[\mathrm{M}+\mathrm{K}]^{+}$.
c, The CD spectrum in PBS buffer at $4{ }^{\circ} \mathrm{C}$.
d, The CD thermal melting curve in PBS buffer.
e, The first derivative of the melting curve, $T_{\mathrm{m}}=45.5^{\circ} \mathrm{C}$. 


\section{Gly-CMP}

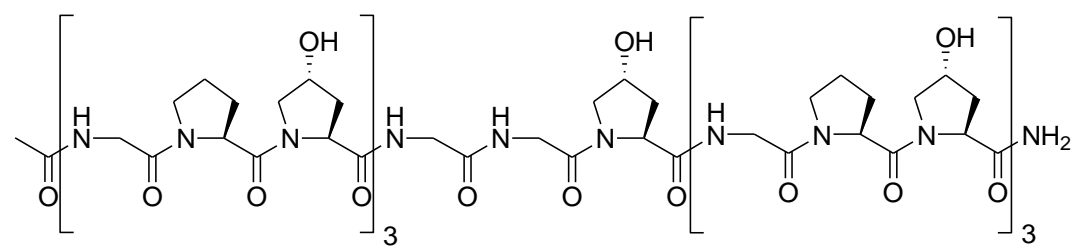

a

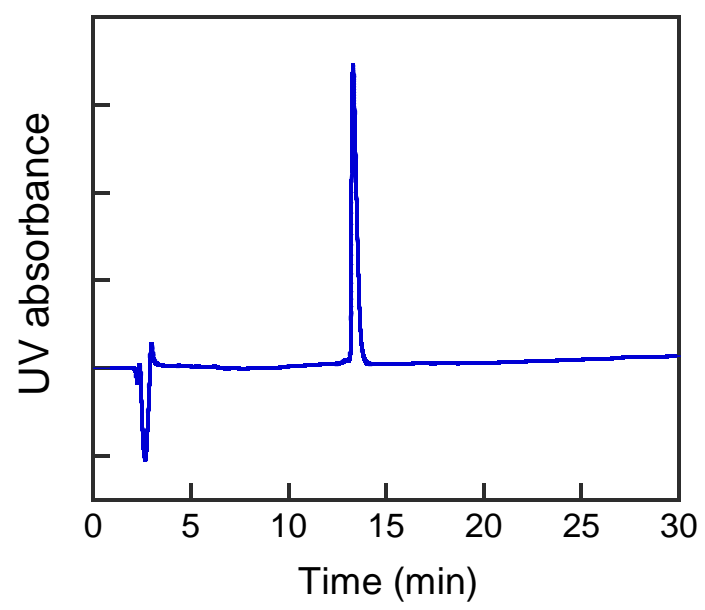

b

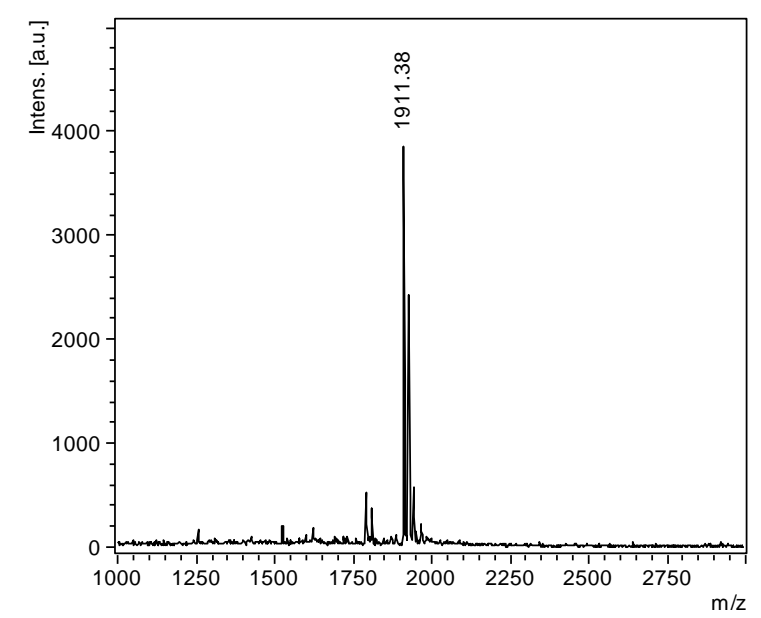

C

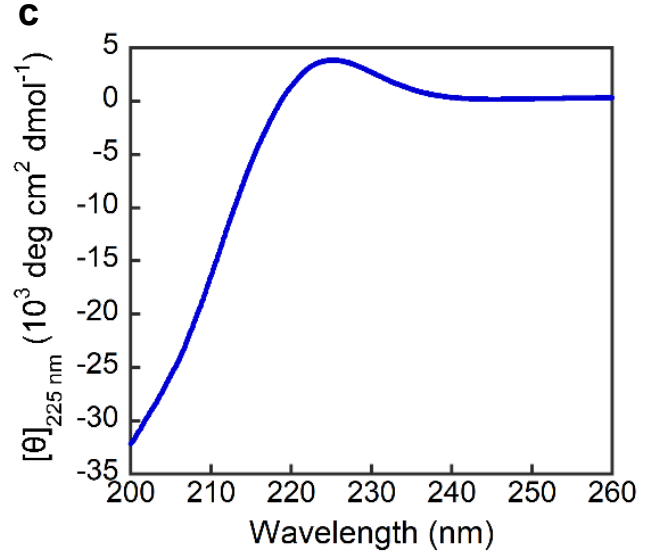

d

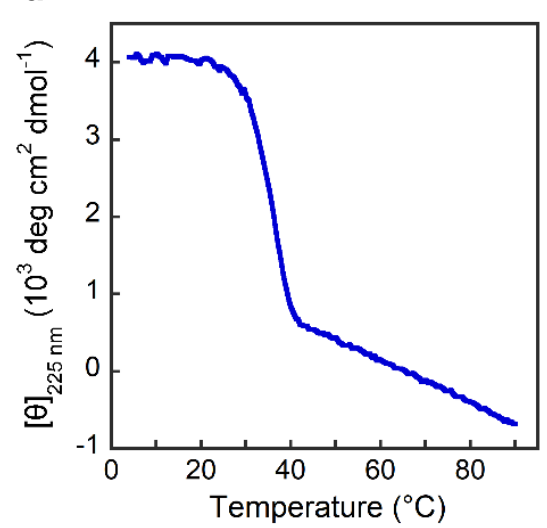

e

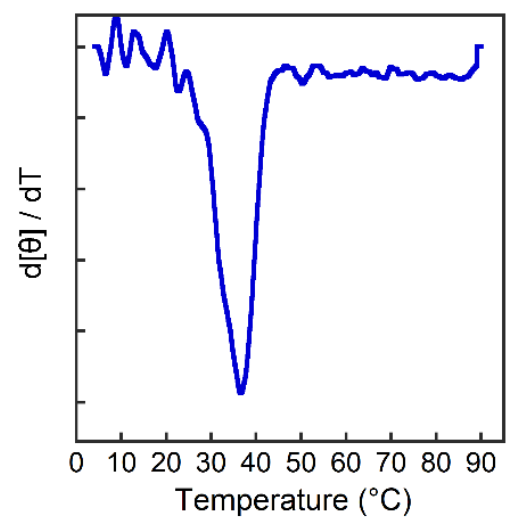

a, The HPLC chromatogram of purified peptide, $t_{R}=13.3 \mathrm{~min}$.

b, MALDI-MS, calculated: $1911.9[\mathrm{M}+\mathrm{Na}]^{+}$, observed: $1911.4[\mathrm{M}+\mathrm{Na}]^{+}$.

c, The CD spectrum in PBS buffer at $4{ }^{\circ} \mathrm{C}$.

d, The CD thermal melting curve in PBS buffer.

e, The first derivative of the melting curve, $T_{\mathrm{m}}=37^{\circ} \mathrm{C}$. 


\section{Lys-CMP}

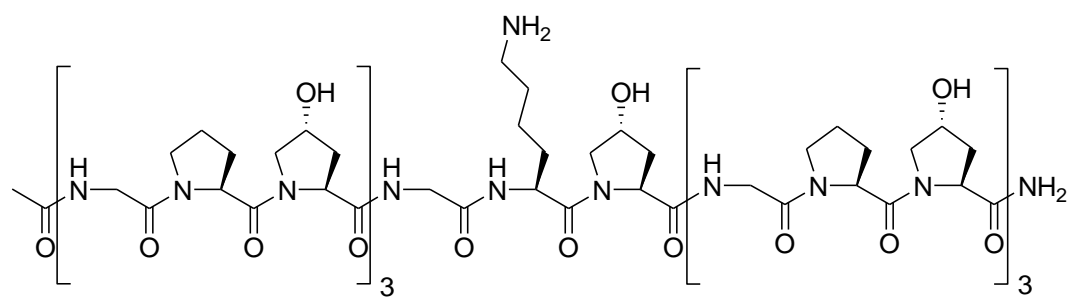

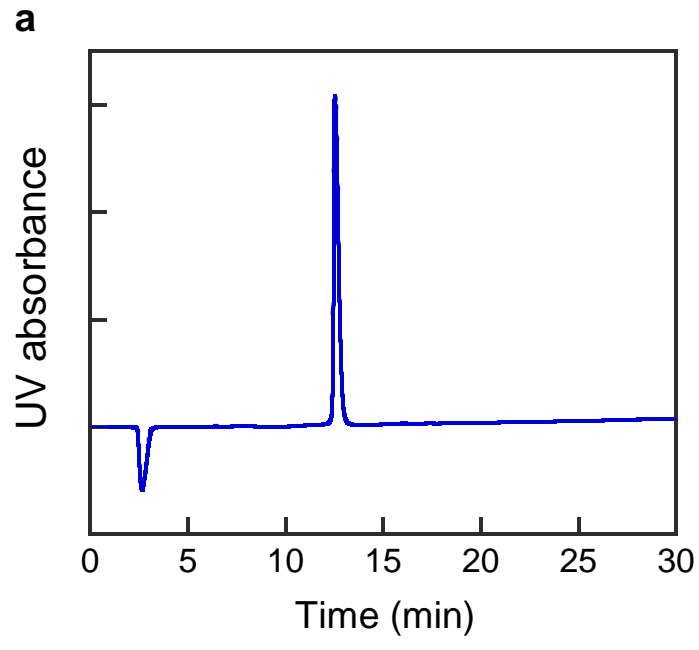

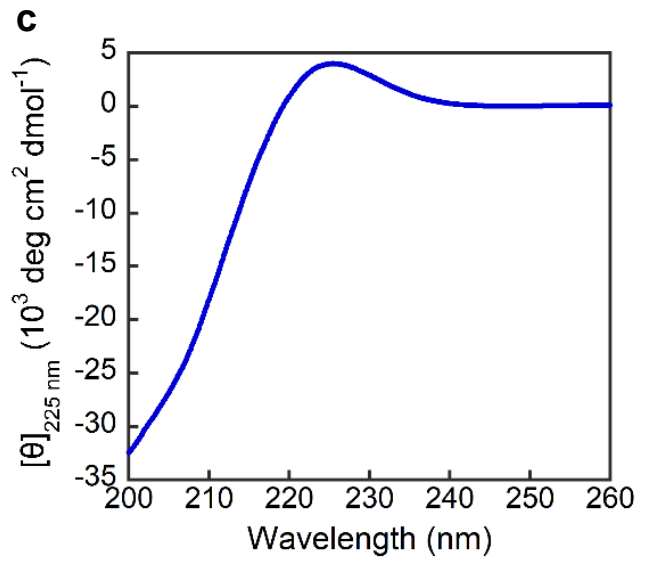

d b
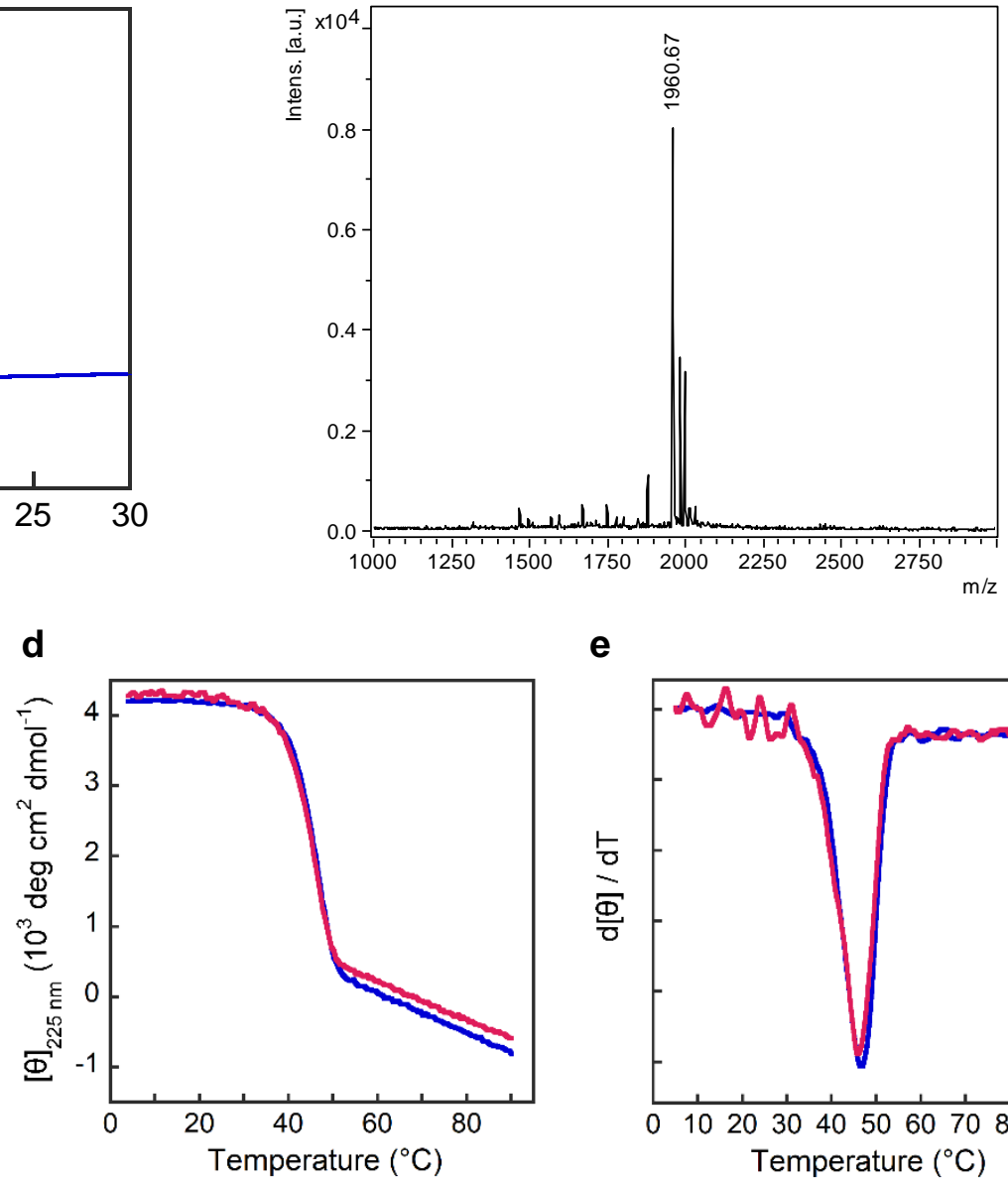

e

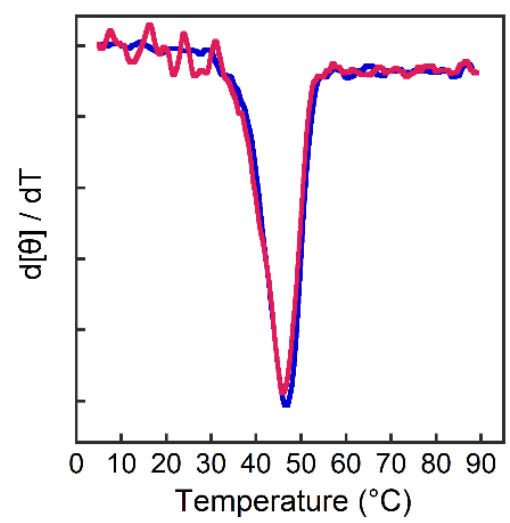

a, The HPLC chromatogram of purified peptide, $t_{R}=12.5 \mathrm{~min}$.

b, MALDI-MS, calculated: $1960.9[\mathrm{M}+\mathrm{H}]^{+}$, observed: $1960.7[\mathrm{M}+\mathrm{H}]^{+}, 1982.7[\mathrm{M}+\mathrm{Na}]^{+}, 1998.7[\mathrm{M}+\mathrm{K}]^{+}$.

c, The CD spectrum in PBS buffer at $4{ }^{\circ} \mathrm{C}$.

d, The CD thermal melting curves in PBS buffer (blue) and $32 \mathrm{mM} \mathrm{NaOH}$ solution (pH 12.51, red).

e, The first derivatives of the melting curves, $T_{\mathrm{m}}=47^{\circ} \mathrm{C}$ (PBS, blue) or $46{ }^{\circ} \mathrm{C}(\mathrm{NaOH}$, red). 


\section{Phe-CMP}

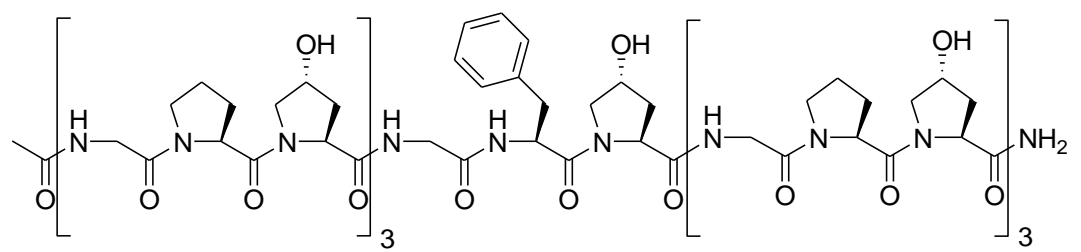

a

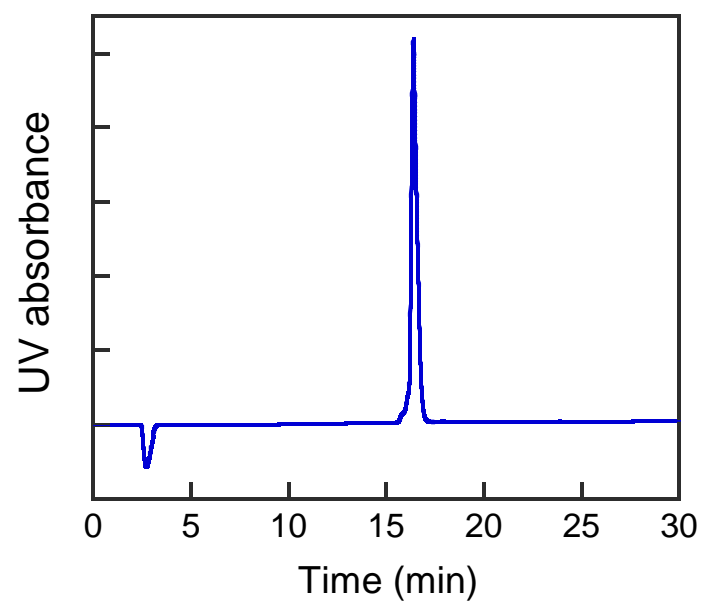

b

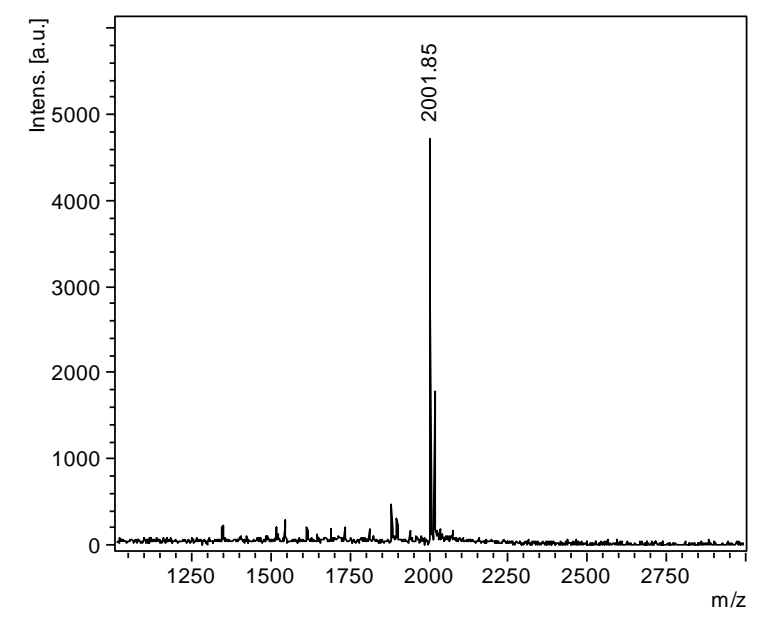

C

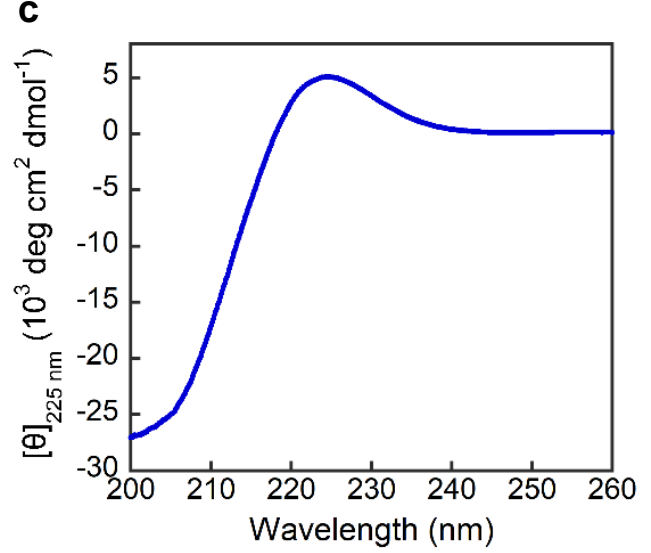

d

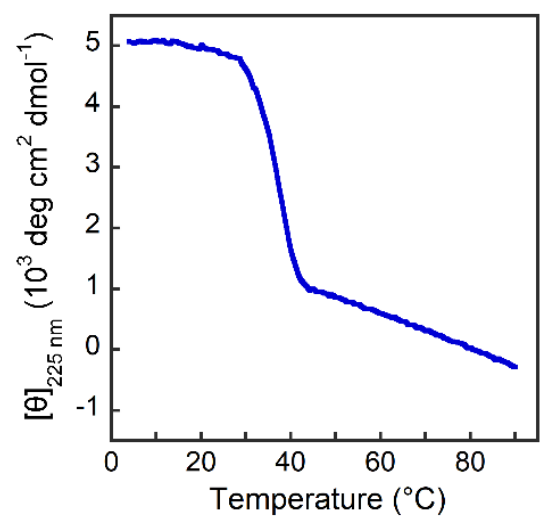

e

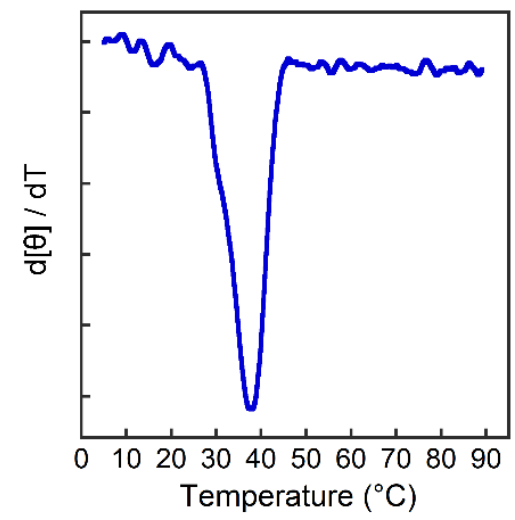

a, The HPLC chromatogram of purified peptide, $t_{R}=16.4$ min.

b, MALDI-MS, calculated: $2001.9[\mathrm{M}+\mathrm{Na}]^{+}$, observed: $2001.9[\mathrm{M}+\mathrm{Na}]^{+}$.

c, The CD spectrum in PBS buffer at $4{ }^{\circ} \mathrm{C}$.

d, The CD thermal melting curve in PBS buffer.

e, The first derivative of the melting curve, $T_{\mathrm{m}}=38{ }^{\circ} \mathrm{C}$. 


\section{Sar-CMP}

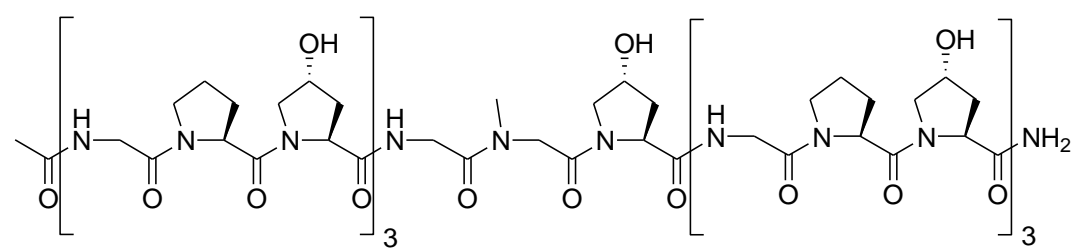

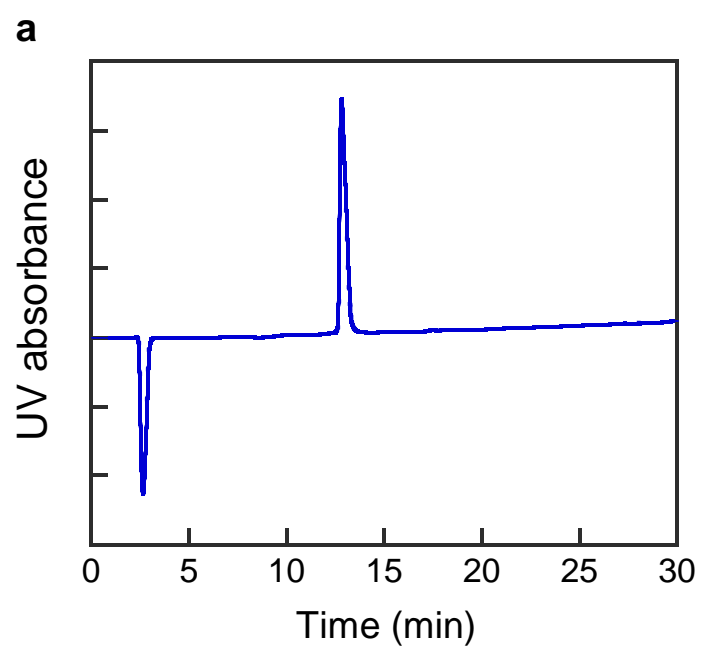

C

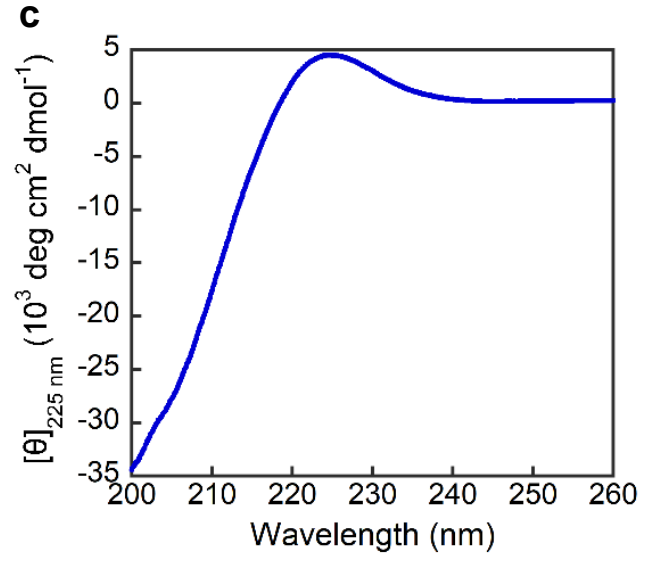

d b
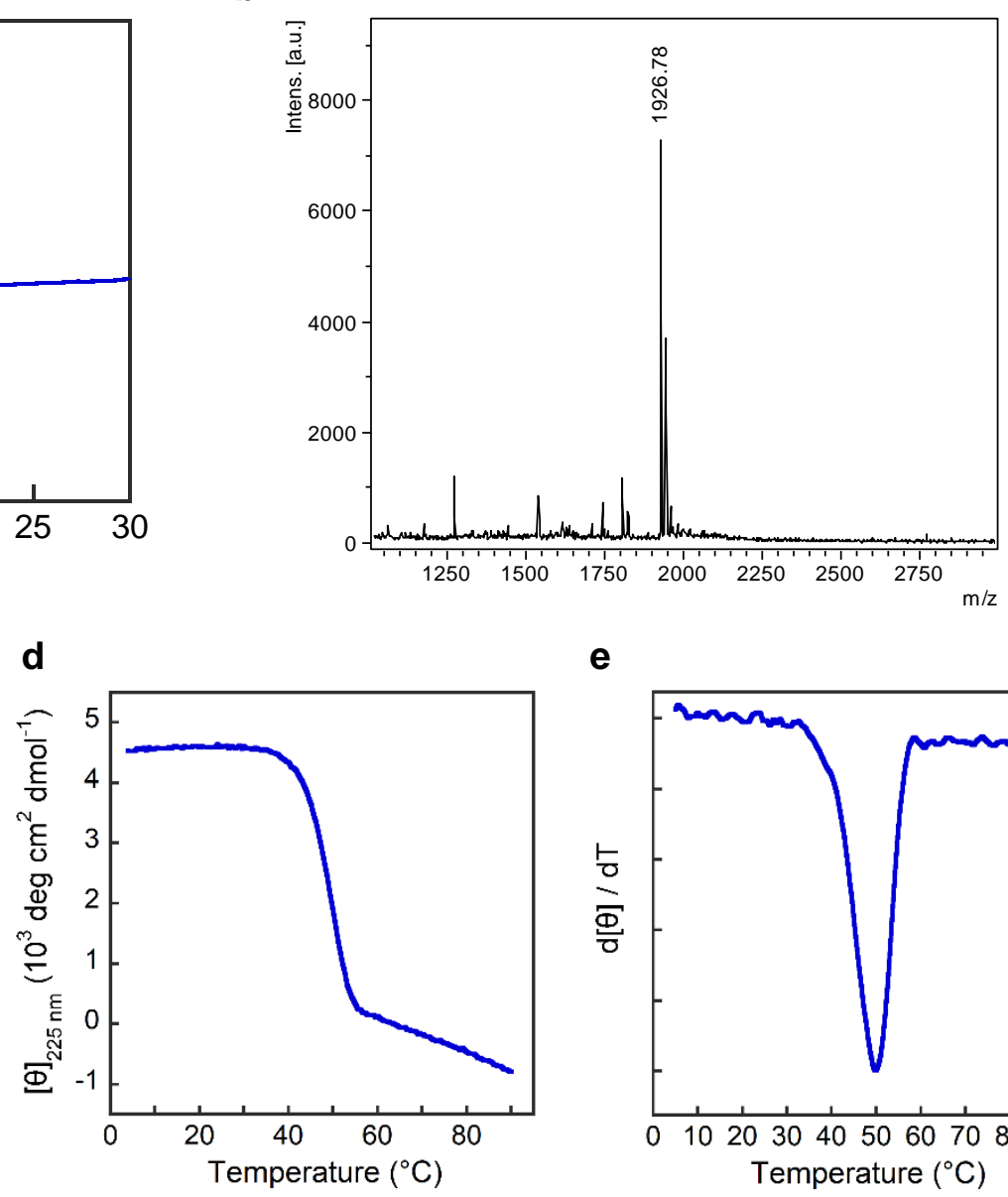

e

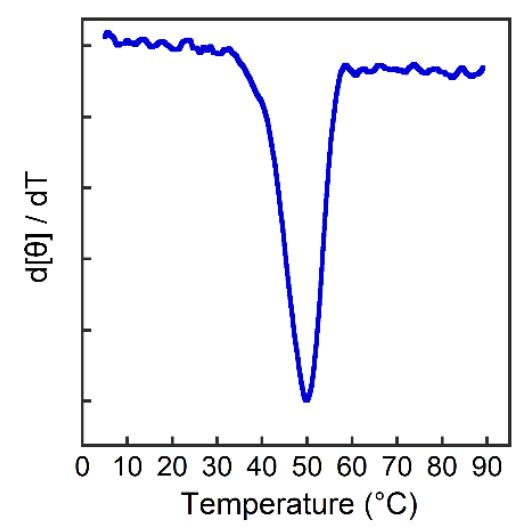

a, The HPLC chromatogram of purified peptide, $t_{R}=12.8 \mathrm{~min}$.

b, MALDI-MS, calculated: $1925.9[\mathrm{M}+\mathrm{Na}]^{+}$, observed: $1926.8[\mathrm{M}+\mathrm{Na}]^{+}$.

c, The CD spectrum in PBS buffer at $4{ }^{\circ} \mathrm{C}$.

d, The CD thermal melting curve in PBS buffer.

e, The first derivative of the melting curve, $T_{\mathrm{m}}=50^{\circ} \mathrm{C}$. 


\section{Nakn-CMP}

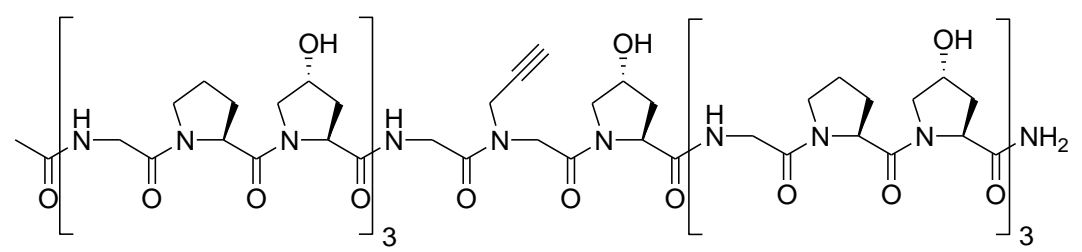

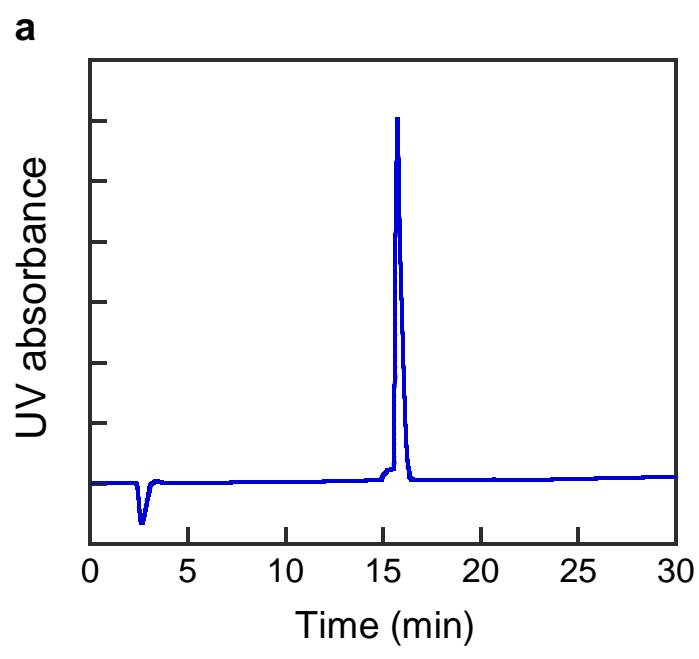

C

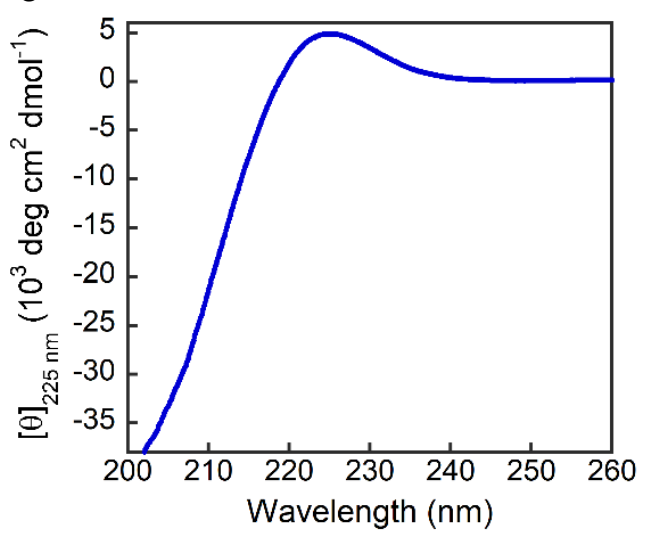

d b
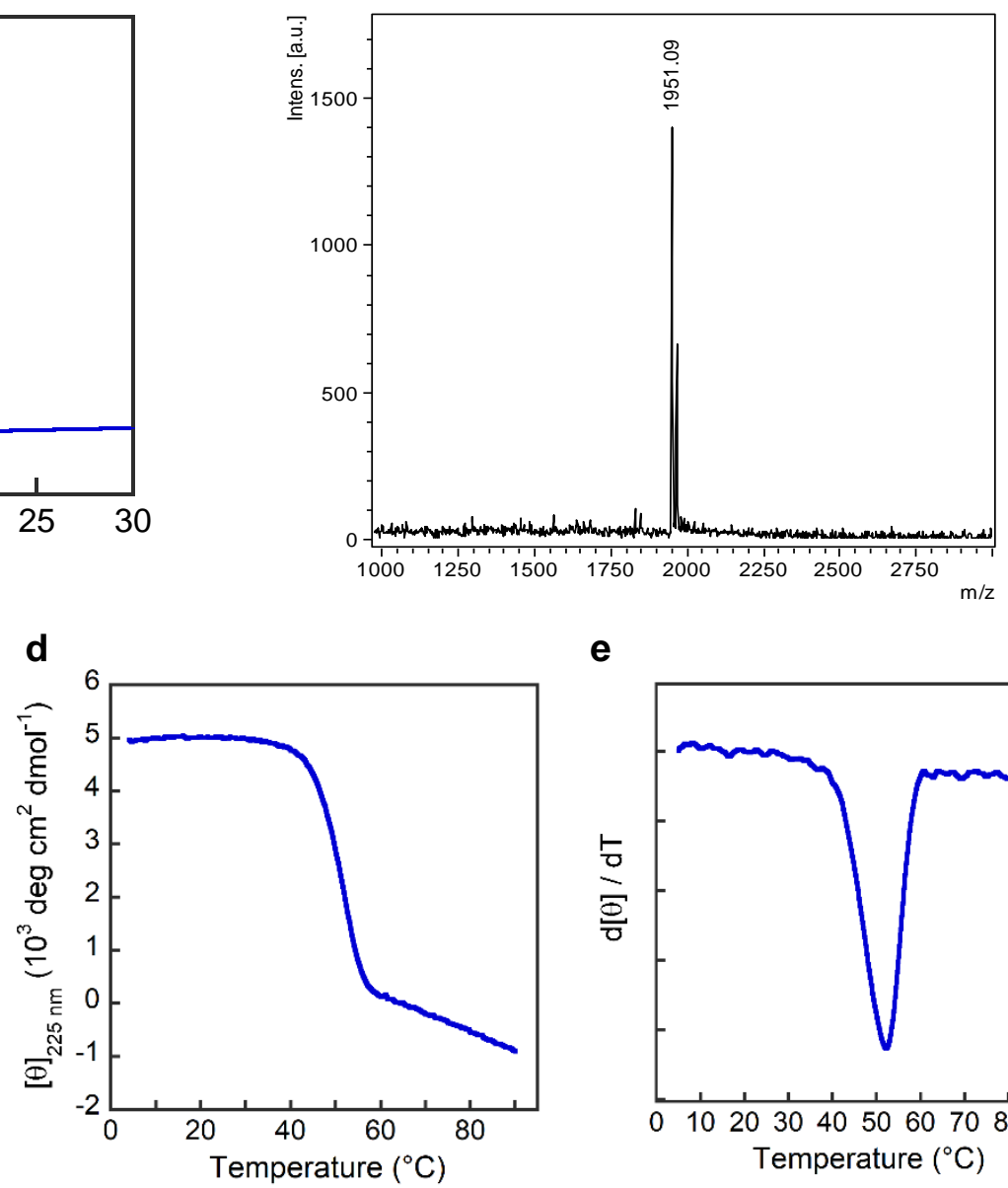

e

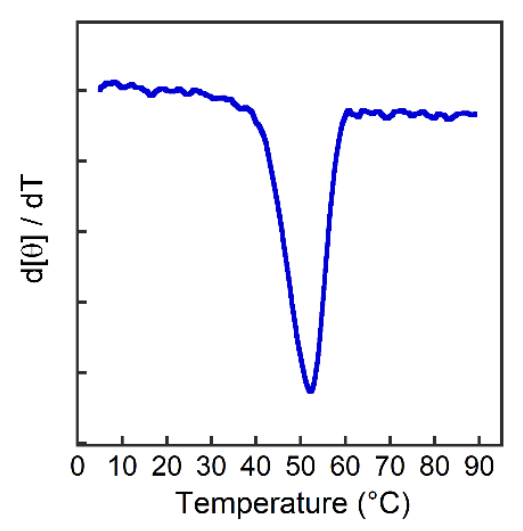

a, The HPLC chromatogram of purified peptide, $t_{R}=15.7 \mathrm{~min}$.

b, MALDI-MS, calculated: $1949.9[\mathrm{M}+\mathrm{Na}]^{+}$, observed: $1951.1[\mathrm{M}+\mathrm{Na}]^{+}$.

c, The CD spectrum in PBS buffer at $4{ }^{\circ} \mathrm{C}$.

d, The CD thermal melting curve in PBS buffer.

e, The first derivative of the melting curve, $T_{\mathrm{m}}=52{ }^{\circ} \mathrm{C}$. 


\section{Nakn-OH-CMP}

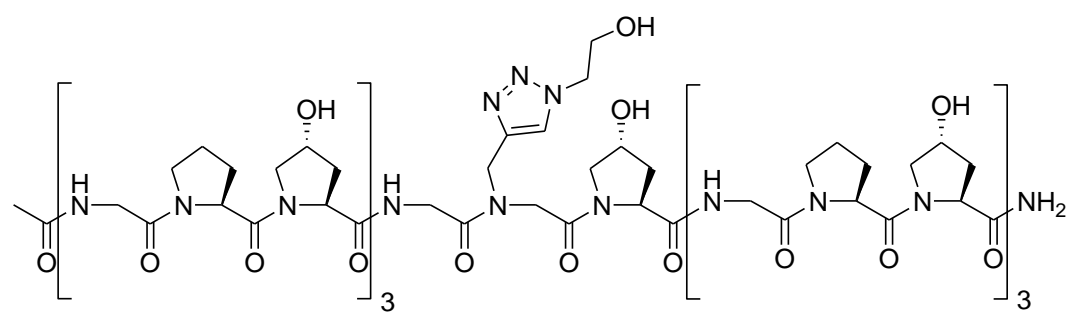

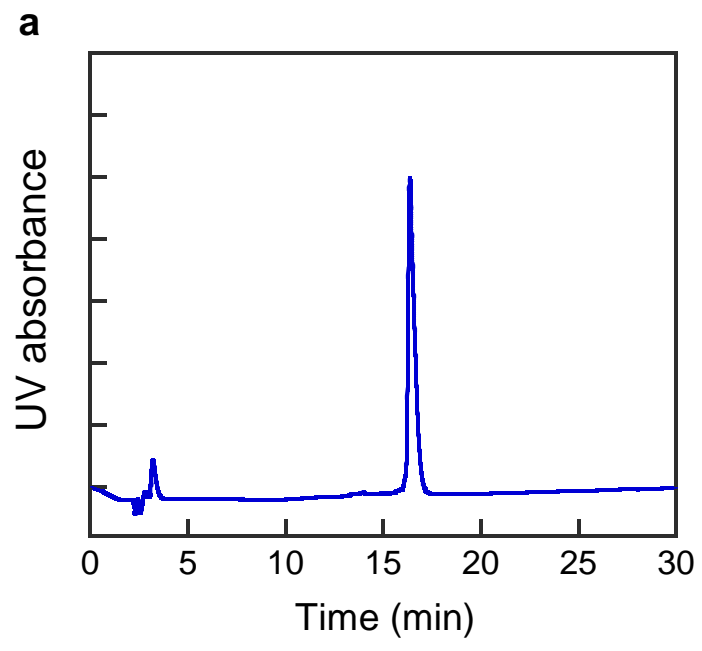

C

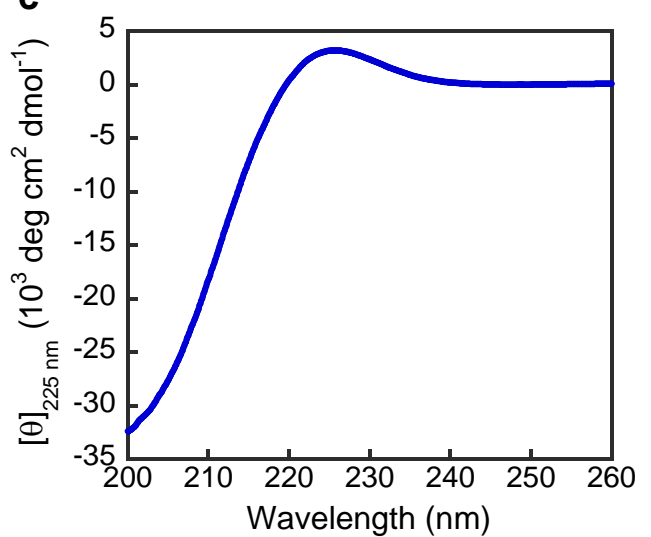

d b
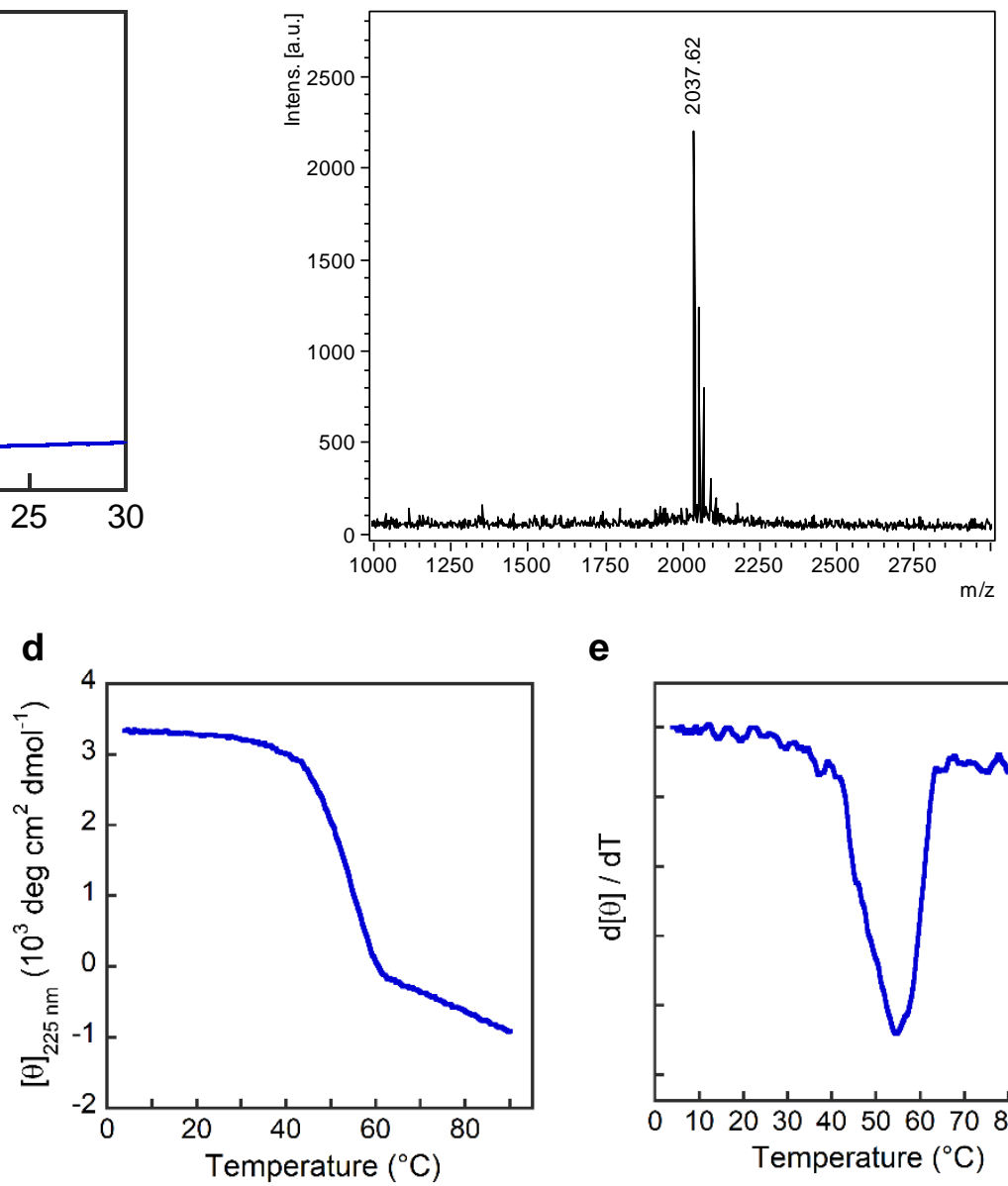

e

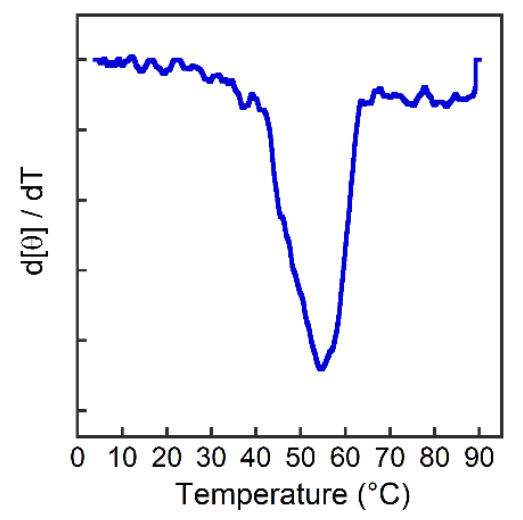

a, The HPLC chromatogram of purified peptide, $t_{R}=16.3 \mathrm{~min}$.

b, MALDI-MS, calculated: $2036.9[\mathrm{M}+\mathrm{Na}]^{+}$, observed: $2037.6[\mathrm{M}+\mathrm{Na}]^{+}$.

c, The CD spectrum in PBS buffer at $4{ }^{\circ} \mathrm{C}$.

d, The CD thermal melting curve in PBS buffer.

e, The first derivative of the melting curve, $T_{\mathrm{m}}=55^{\circ} \mathrm{C}$. 


\section{Nakn-man-CMP}

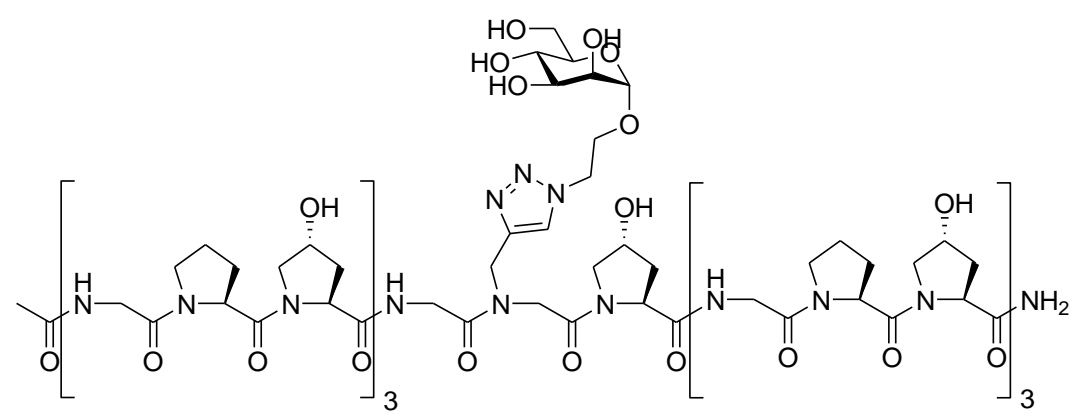

a

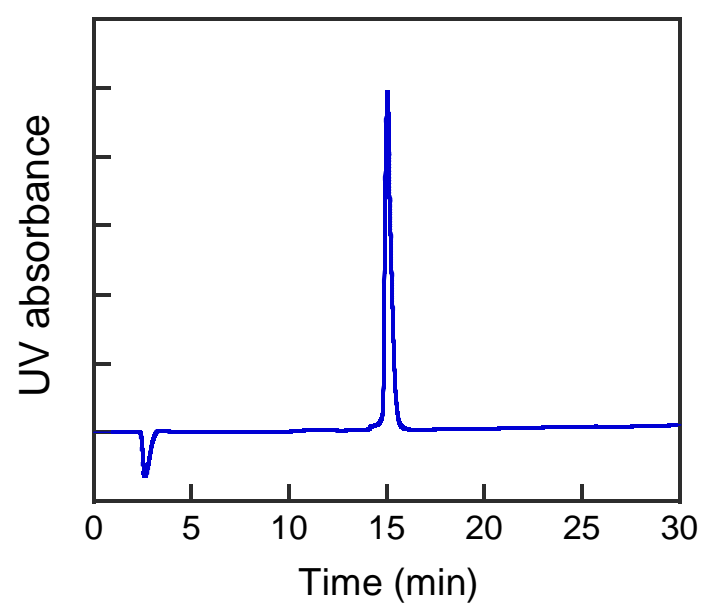

b

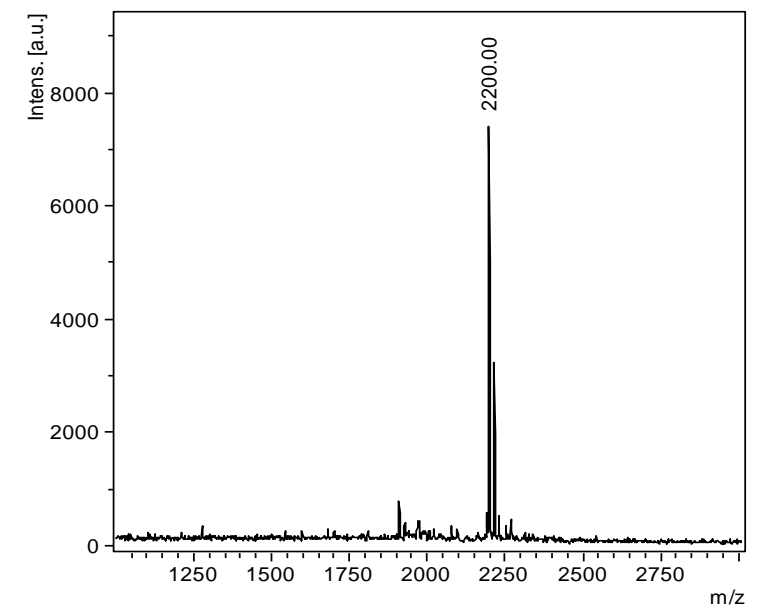

C

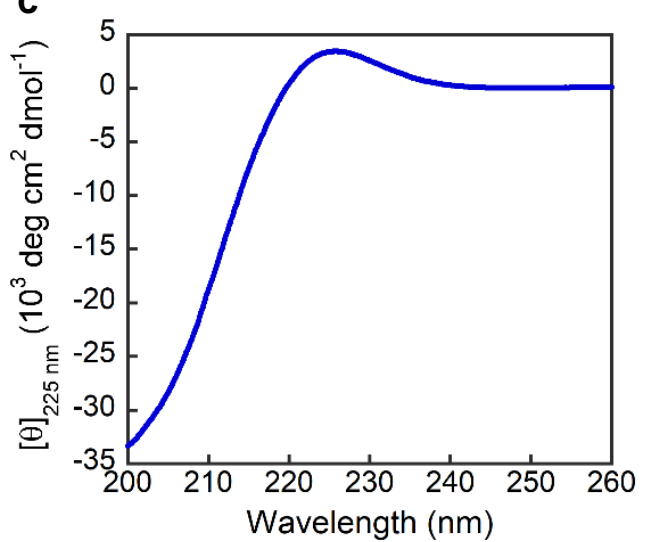

d

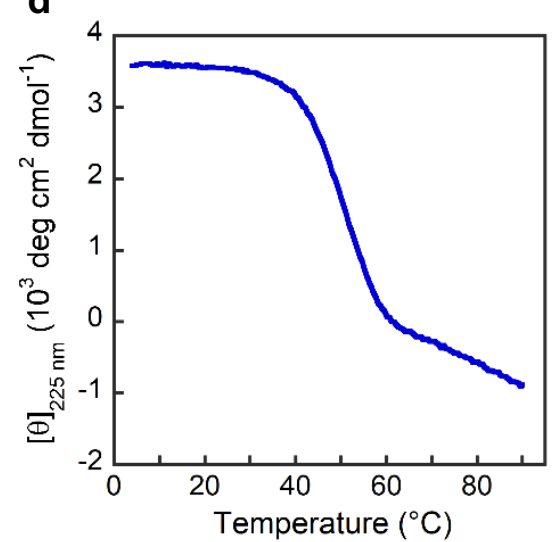

e

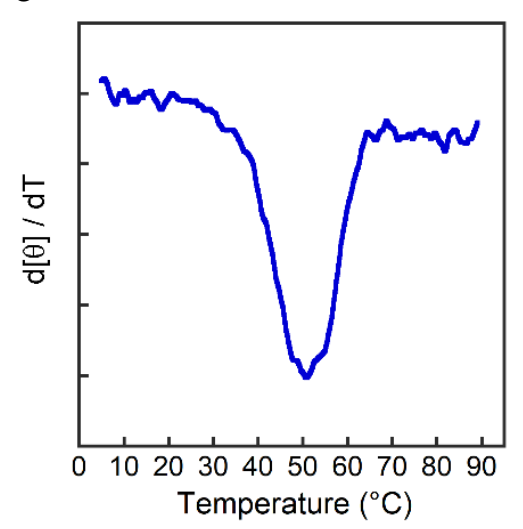

a, The HPLC chromatogram of purified peptide, $t_{R}=15.0 \mathrm{~min}$.

b, MALDI-MS, calculated: $2199.0[\mathrm{M}+\mathrm{Na}]^{+}$, observed: $2200.0[\mathrm{M}+\mathrm{Na}]^{+}$.

c, The CD spectrum in PBS buffer at $4{ }^{\circ} \mathrm{C}$.

d, The CD thermal melting curve in PBS buffer.

e, The first derivative of the melting curve, $T_{\mathrm{m}}=51{ }^{\circ} \mathrm{C}$. 


\section{Nasn-CMP}

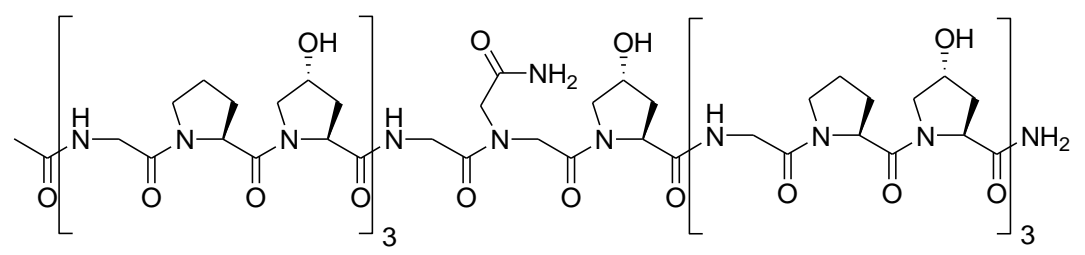

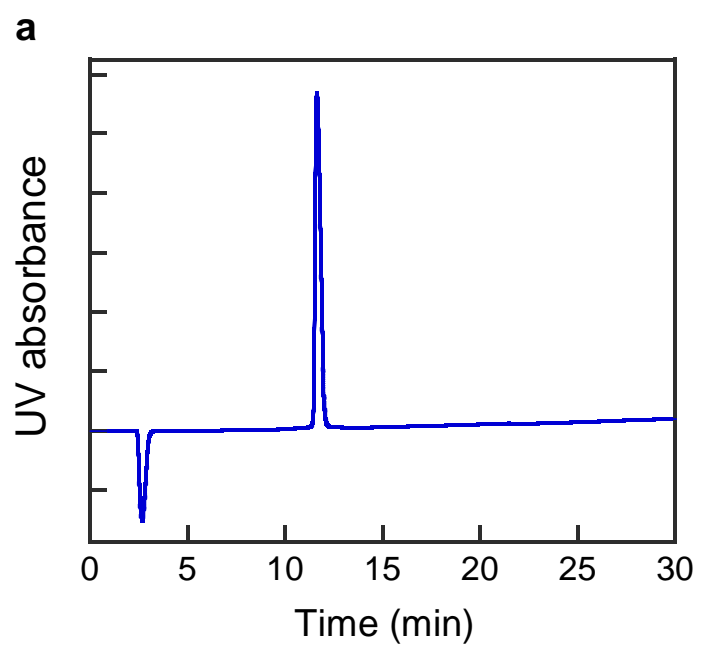

C

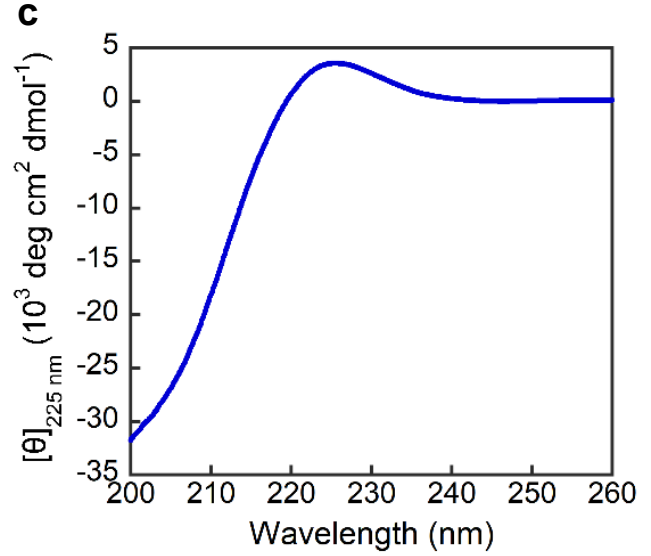

b

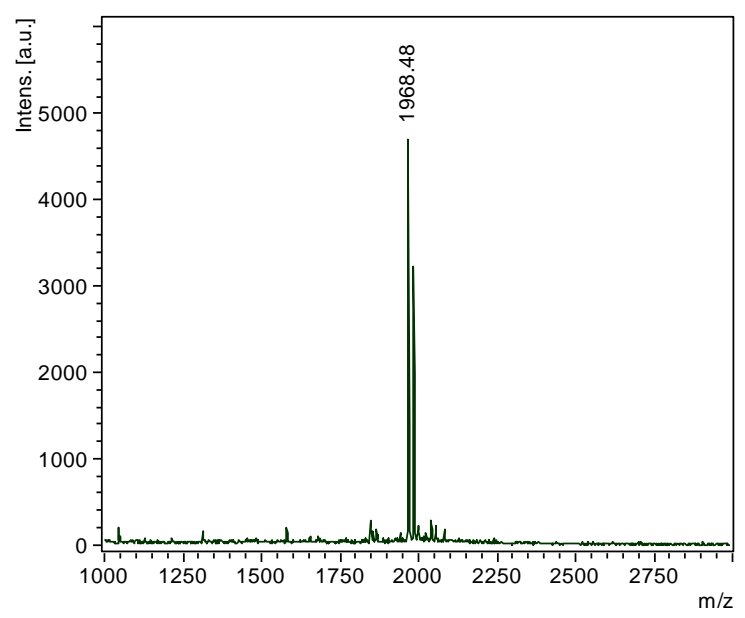

d

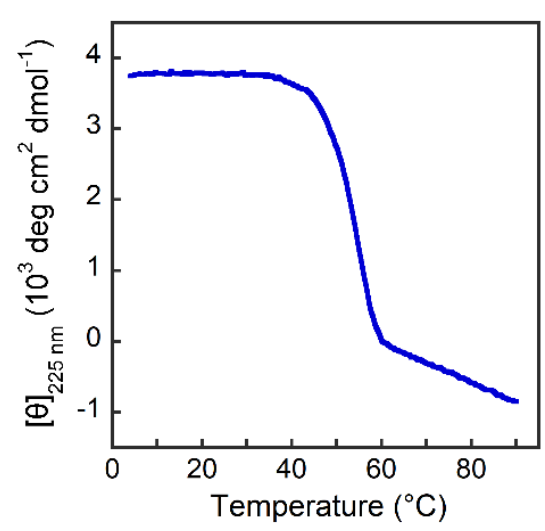

e

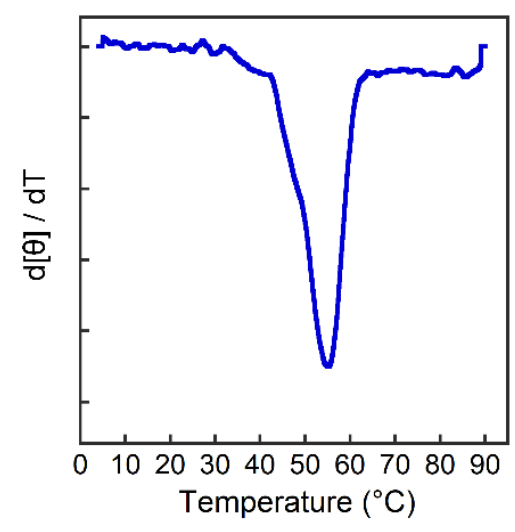

a, The HPLC chromatogram of purified peptide, $t_{R}=11.6 \mathrm{~min}$.

b, MALDI-MS, calculated: $1968.9[\mathrm{M}+\mathrm{Na}]^{+}$, observed: $1968.5[\mathrm{M}+\mathrm{Na}]^{+}$.

c, The CD spectrum in PBS buffer at $4{ }^{\circ} \mathrm{C}$.

d, The CD thermal melting curve in PBS buffer.

e, The first derivative of the melting curve, $T_{\mathrm{m}}=55^{\circ} \mathrm{C}$. 


\section{Nasp-CMP}

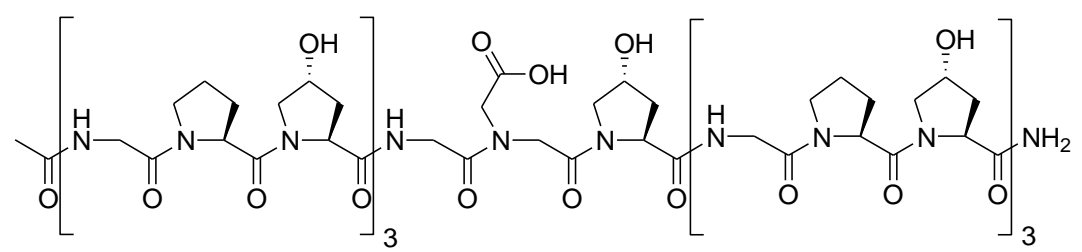

a

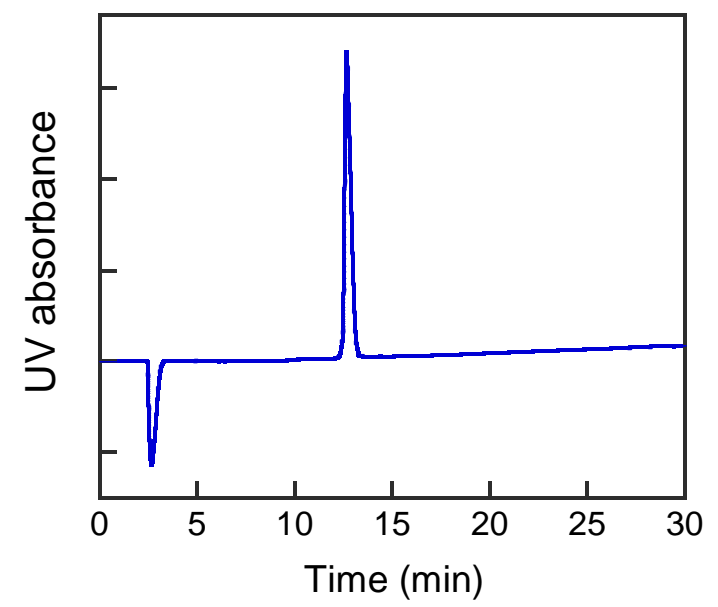

b

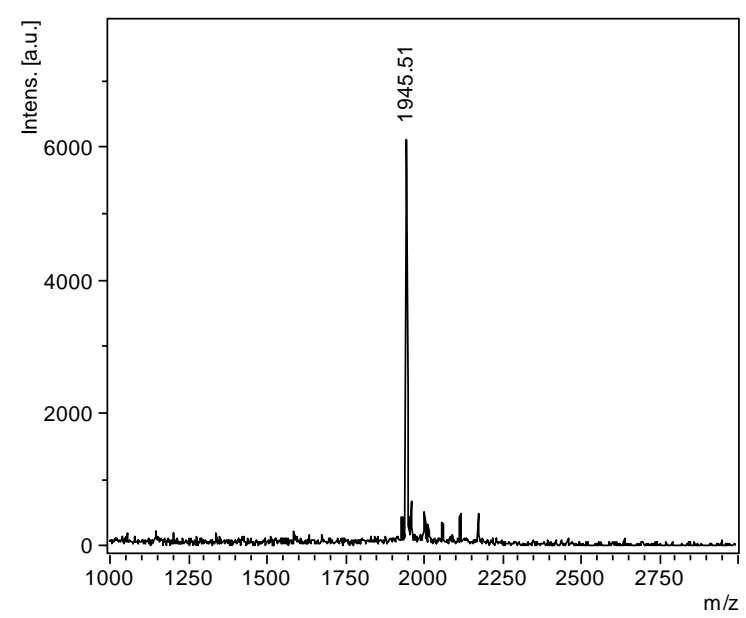

C

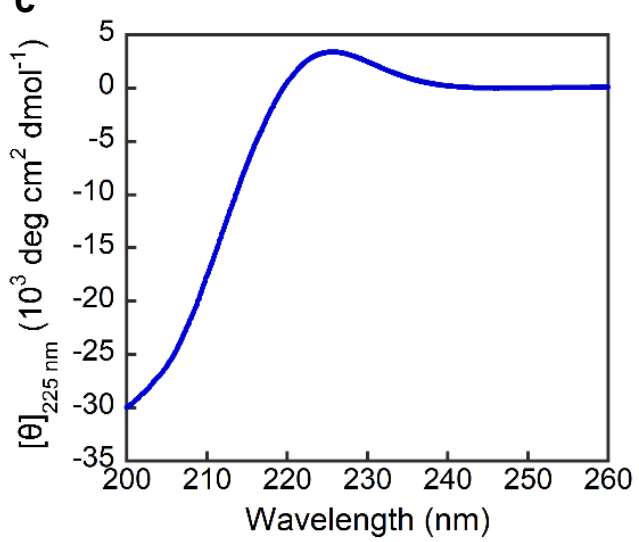

d

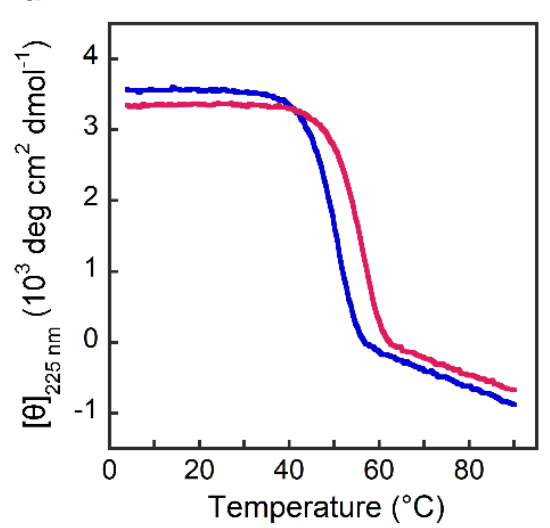

e

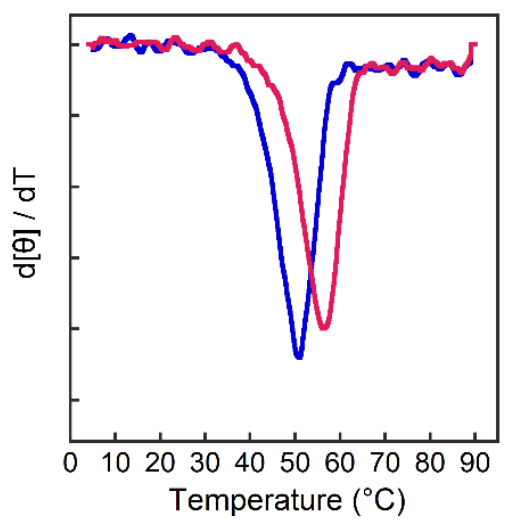

a, The HPLC chromatogram of purified peptide, $t_{R}=12.7$ min.

b, MALDI-MS, calculated: 1945.9 [M-H]', observed: 1945.5 [M-H]'.

c, The CD spectrum in PBS buffer at $4{ }^{\circ} \mathrm{C}$.

d, The CD thermal melting curves in PBS buffer (blue) and $15 \mathrm{mM} \mathrm{HCl}$ solution (pH 1.82, red).

e, The first derivatives of the melting curves, $T_{\mathrm{m}}=50{ }^{\circ} \mathrm{C}(\mathrm{PBS}$, blue $)$ or $56^{\circ} \mathrm{C}(\mathrm{HCl}$, red). 


\section{Nchx-CMP}
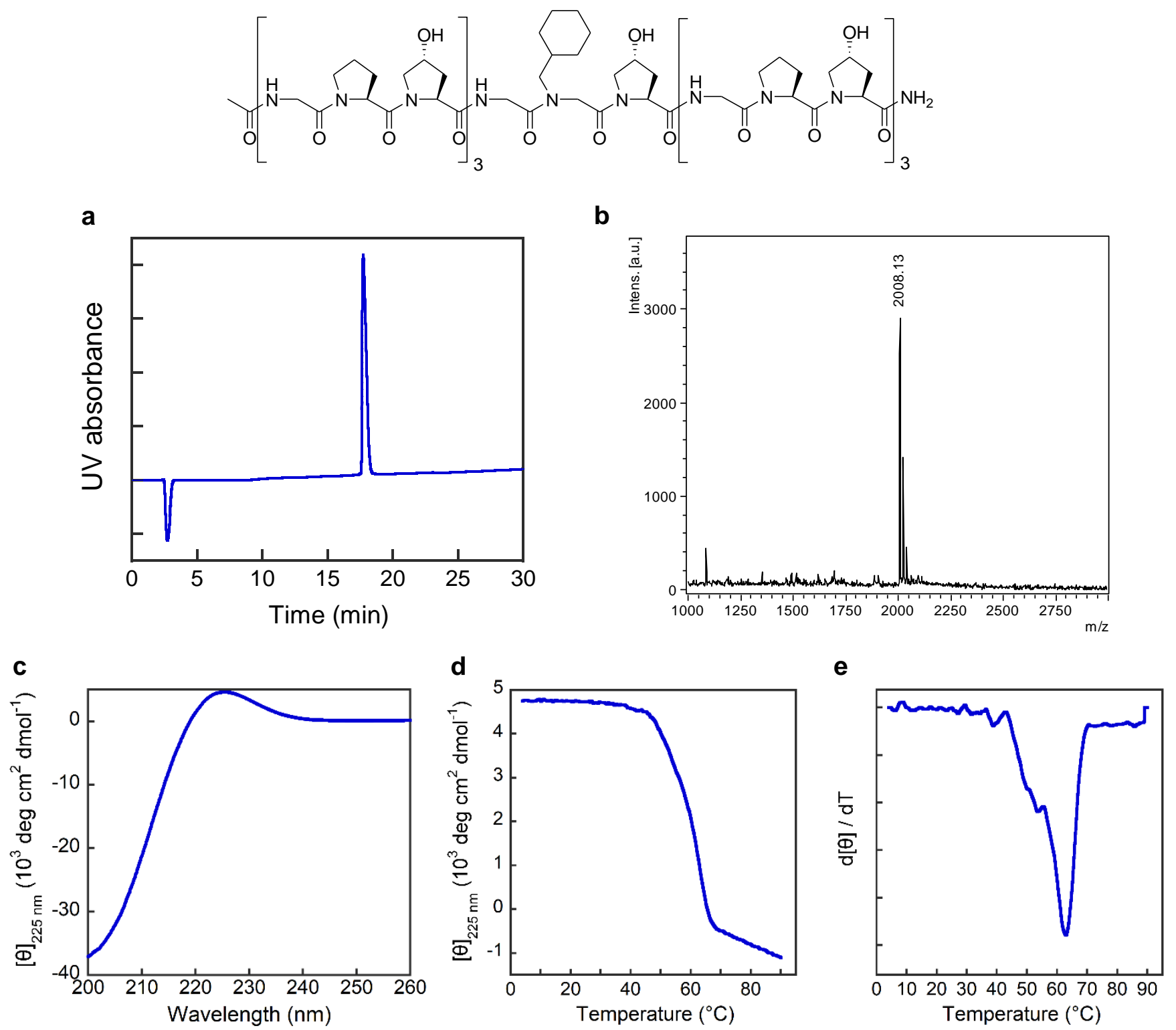
a, The HPLC chromatogram of purified peptide, $t_{R}=17.7 \mathrm{~min}$.
b, MALDI-MS, calculated: $2008.0[\mathrm{M}+\mathrm{Na}]^{+}$, observed: $2008.1[\mathrm{M}+\mathrm{Na}]^{+}, 2024.1[\mathrm{M}+\mathrm{K}]^{+}$.
c, The CD spectrum in PBS buffer at $4{ }^{\circ} \mathrm{C}$.
d, The CD thermal melting curve in PBS buffer.
e, The first derivative of the melting curve, $T_{\mathrm{m}}=63{ }^{\circ} \mathrm{C}$. 


\section{Ndxn-CMP}

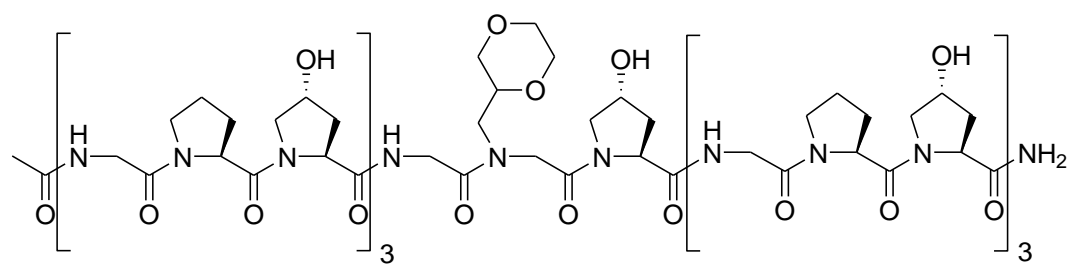

a

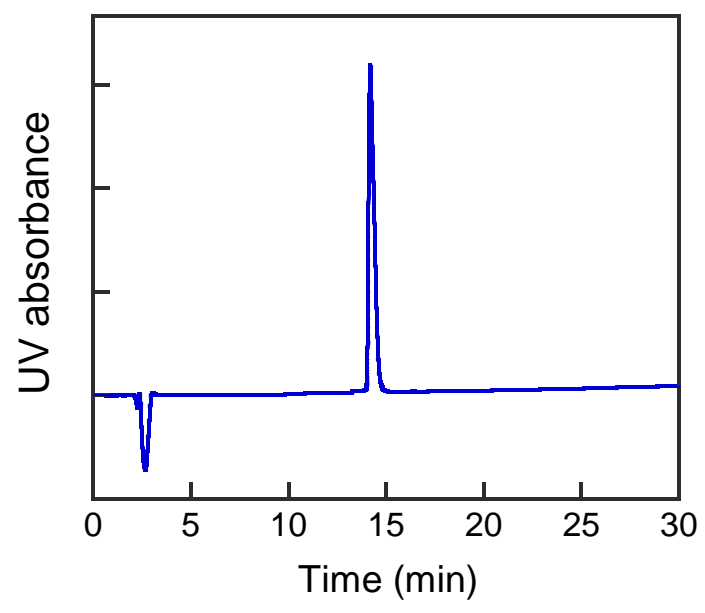

b

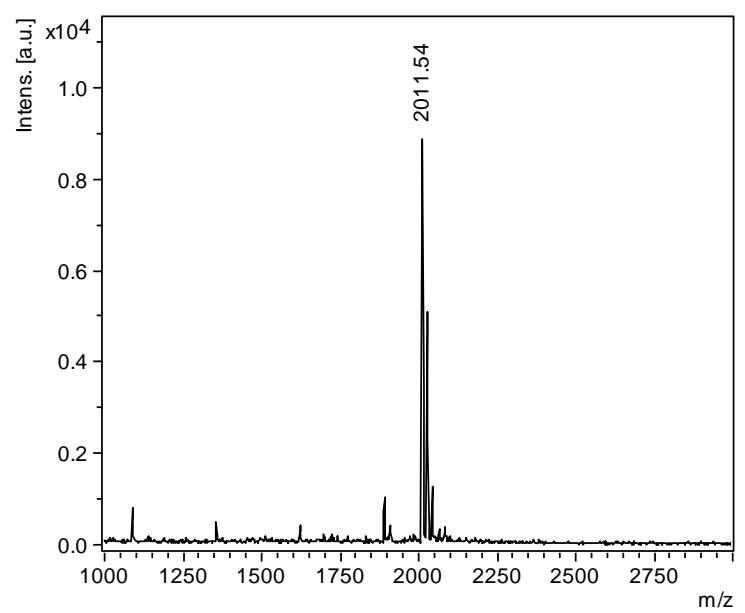

C

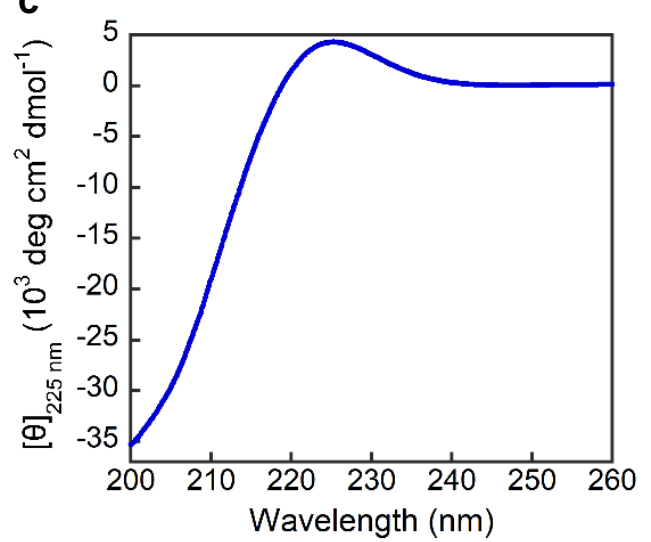

d

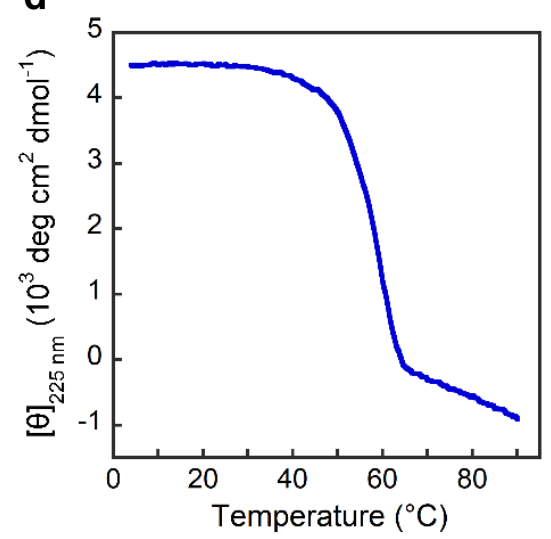

e

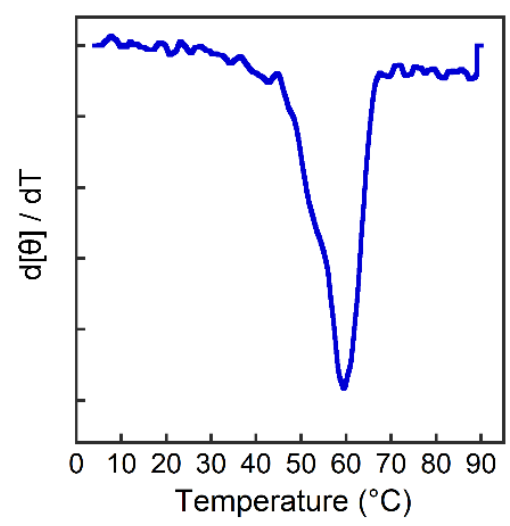

a, The HPLC chromatogram of purified peptide, $t_{R}=14.2$ min.

b, MALDI-MS, calculated: $2011.9[\mathrm{M}+\mathrm{Na}]^{+}$, observed: $2011.5[\mathrm{M}+\mathrm{Na}]^{+}, 2027.5[\mathrm{M}+\mathrm{K}]^{+}$.

c, The CD spectrum in PBS buffer at $4{ }^{\circ} \mathrm{C}$.

d, The CD thermal melting curve in PBS buffer.

e, The first derivative of the melting curve, $T_{\mathrm{m}}=59^{\circ} \mathrm{C}$. 


\section{NEt-CMP}

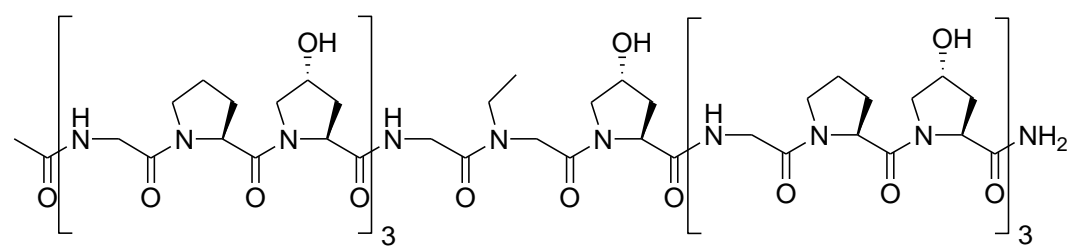

a

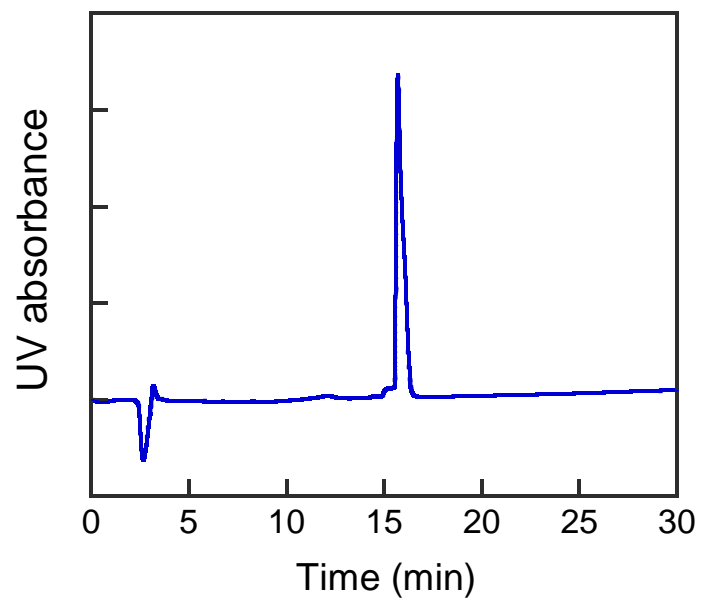

b

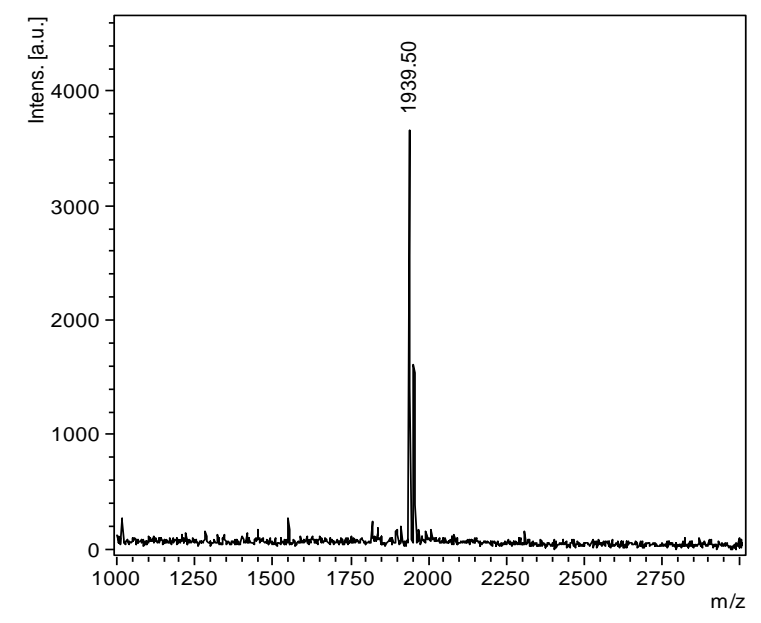

e

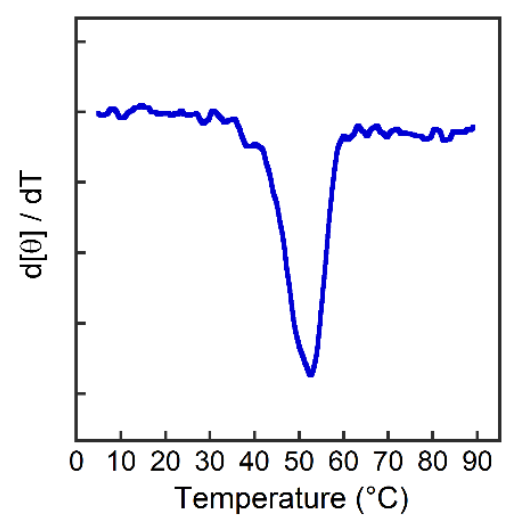

a, The HPLC chromatogram of purified peptide, $t_{R}=15.7 \mathrm{~min}$.

b, MALDI-MS, calculated: $1939.9[\mathrm{M}+\mathrm{Na}]^{+}$, observed: $1939.5[\mathrm{M}+\mathrm{Na}]^{+}$.

c, The CD spectrum in PBS buffer at $4{ }^{\circ} \mathrm{C}$.

d, The CD thermal melting curve in PBS buffer.

e, The first derivative of the melting curve, $T_{\mathrm{m}}=52{ }^{\circ} \mathrm{C}$. 


\section{Nhcy-CMP}

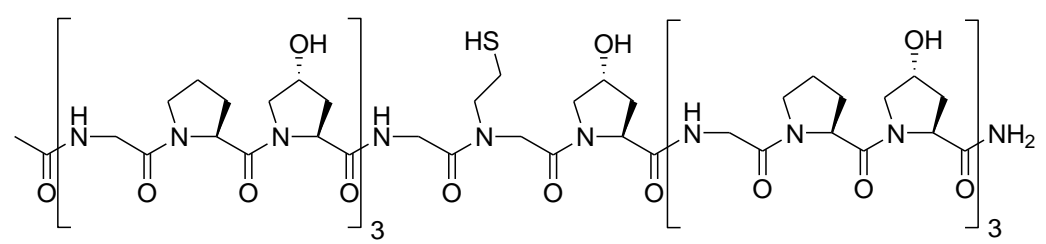

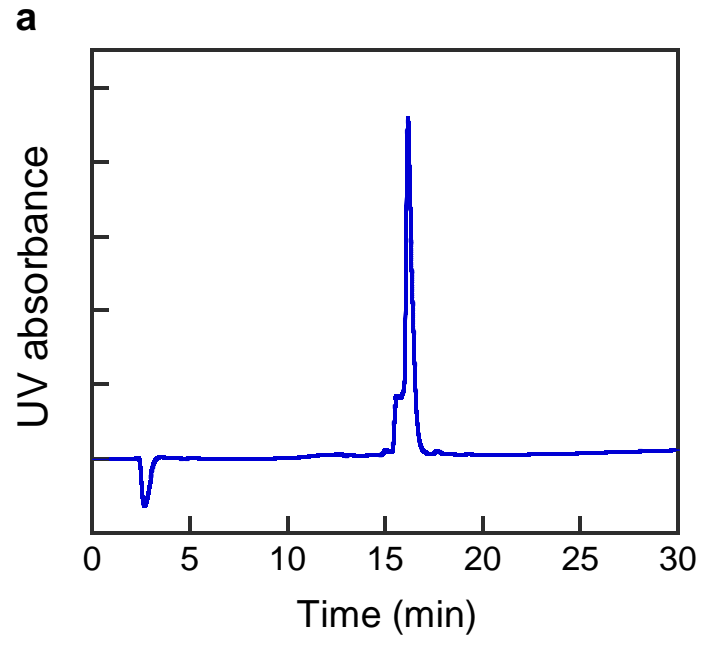

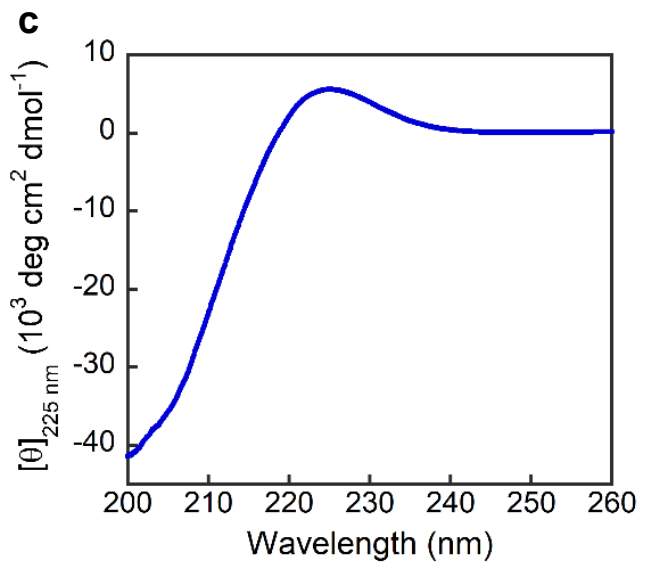

d b
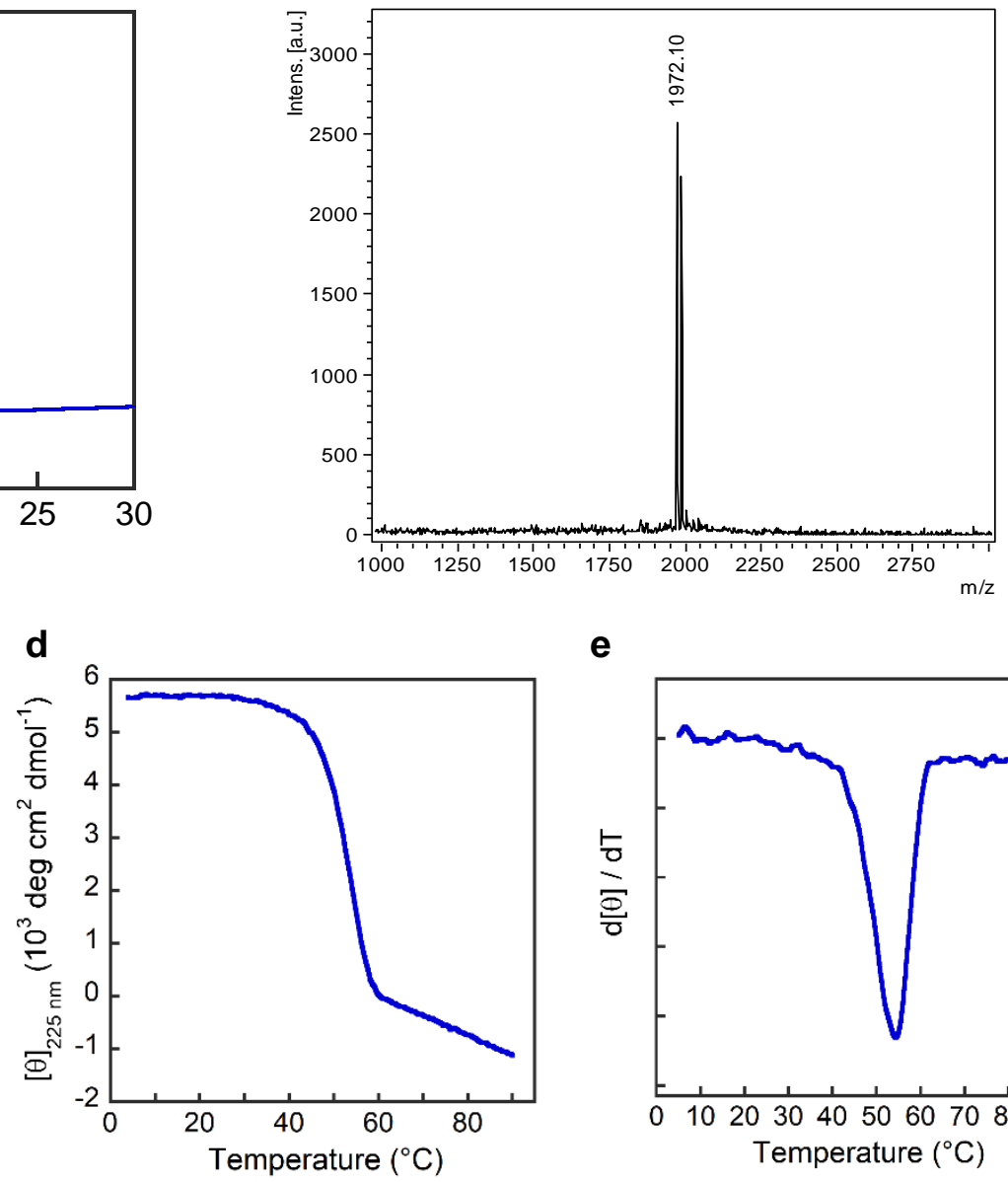

e

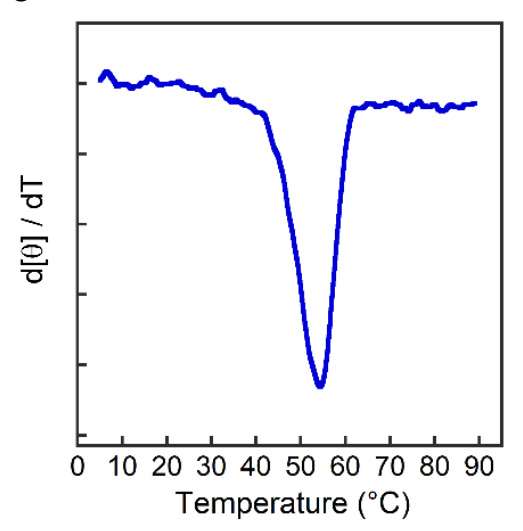

a, The HPLC chromatogram of purified peptide, $t_{R}=16.2 \mathrm{~min}$.

b, MALDI-MS, calculated: $1971.9[\mathrm{M}+\mathrm{Na}]^{+}$, observed: $1972.1[\mathrm{M}+\mathrm{Na}]^{+}$.

c, The CD spectrum in PBS buffer at $4{ }^{\circ} \mathrm{C}$.

d, The CD thermal melting curve in PBS buffer.

e, The first derivative of the melting curve, $T_{\mathrm{m}}=54{ }^{\circ} \mathrm{C}$. 


\section{Nleu-CMP}

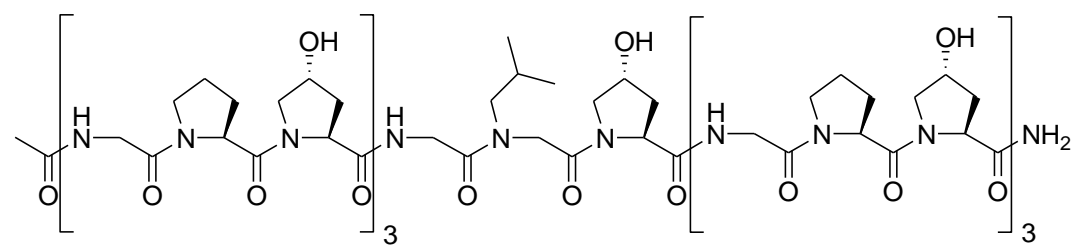

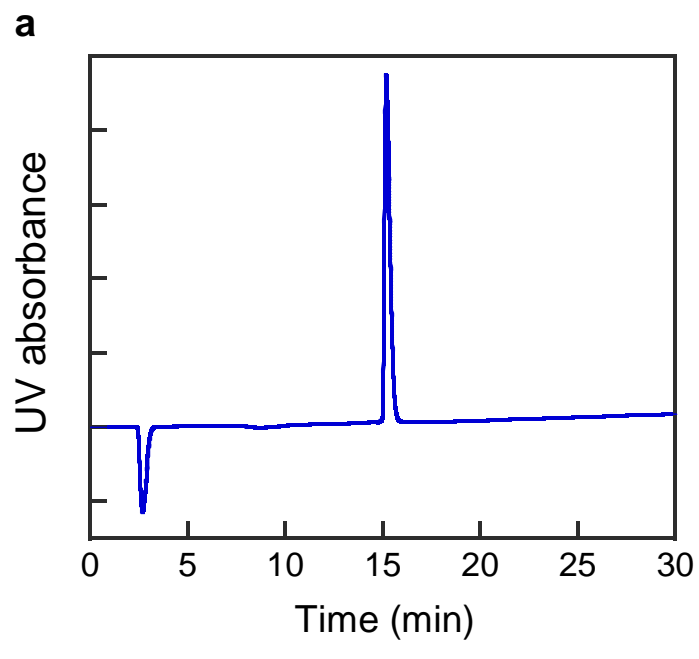

c

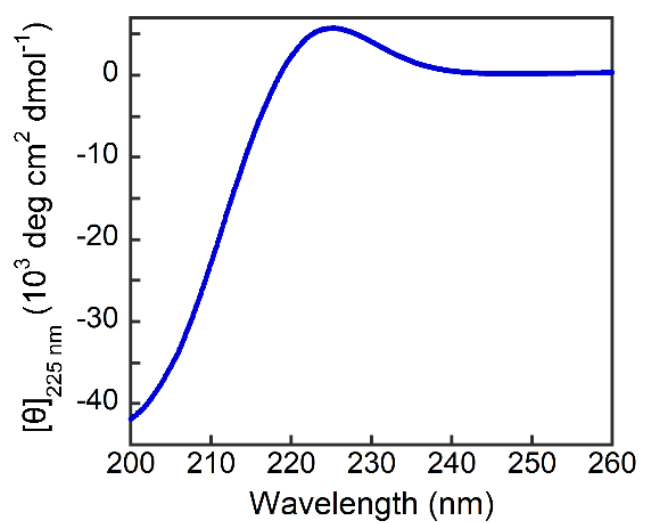

d b
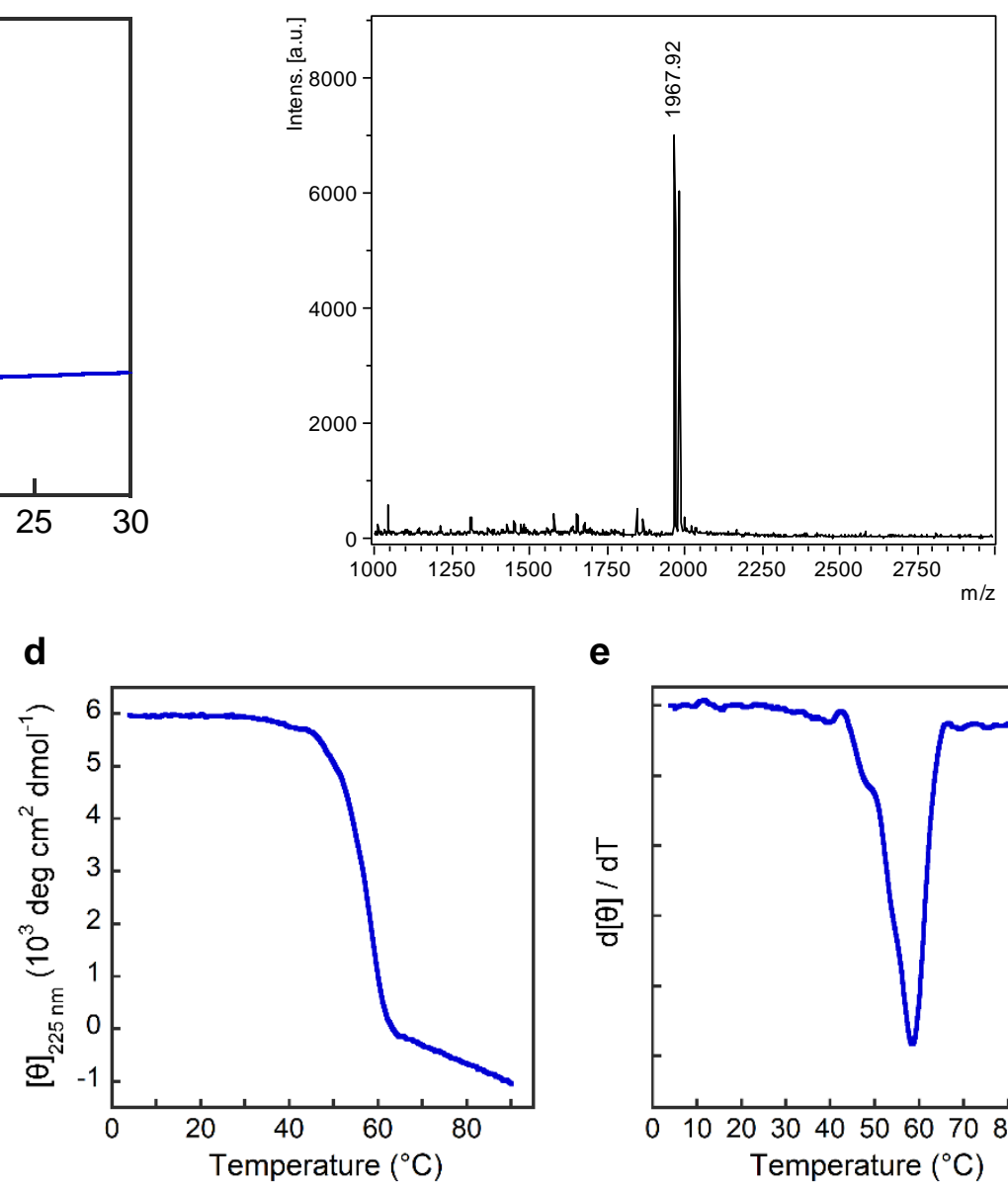

e

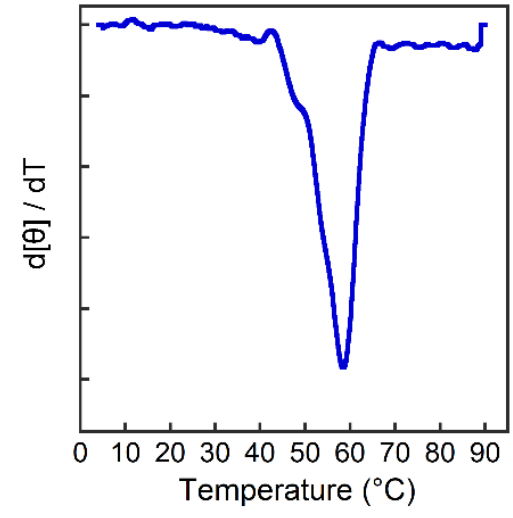

a, The HPLC chromatogram of purified peptide, $t_{R}=15.2 \mathrm{~min}$.

b, MALDI-MS, calculated: $1967.9[\mathrm{M}+\mathrm{Na}]^{+}$, observed: $1967.9[\mathrm{M}+\mathrm{Na}]^{+}, 1983.9[\mathrm{M}+\mathrm{K}]^{+}$.

c, The CD spectrum in PBS buffer at $4{ }^{\circ} \mathrm{C}$.

d, The CD thermal melting curve in PBS buffer.

e, The first derivative of the melting curve, $T_{\mathrm{m}}=58{ }^{\circ} \mathrm{C}$. 


\section{Nlys-CMP}

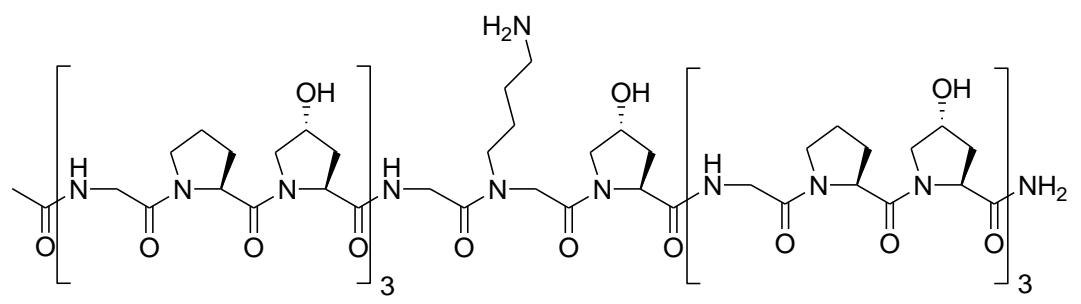

a

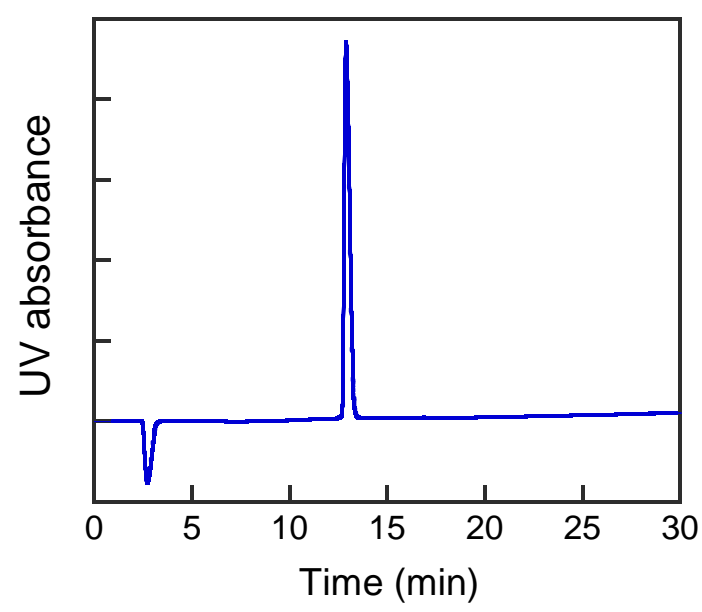

b

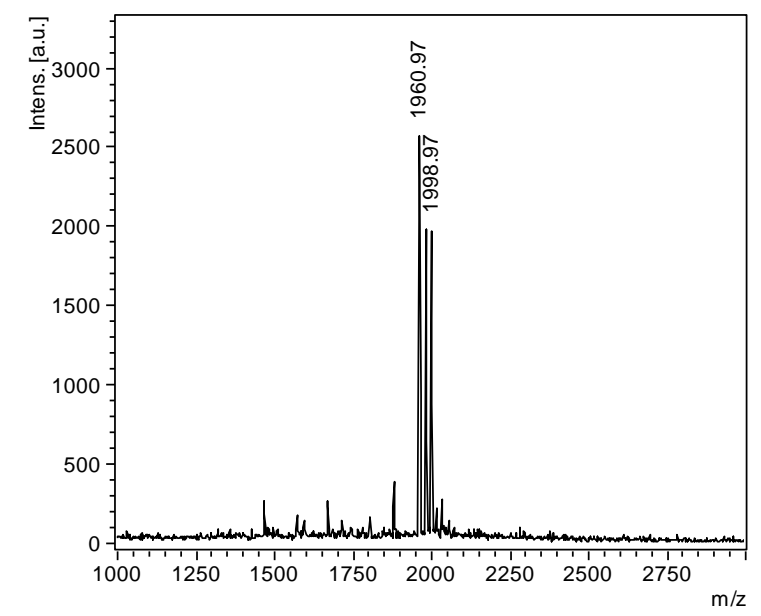

C

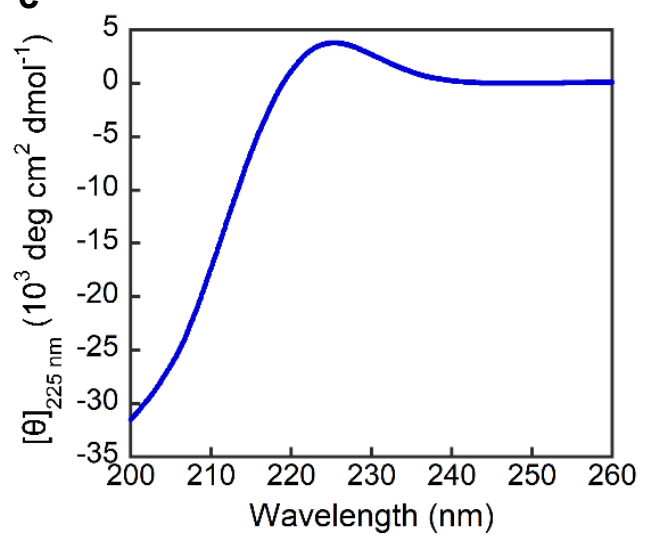

d

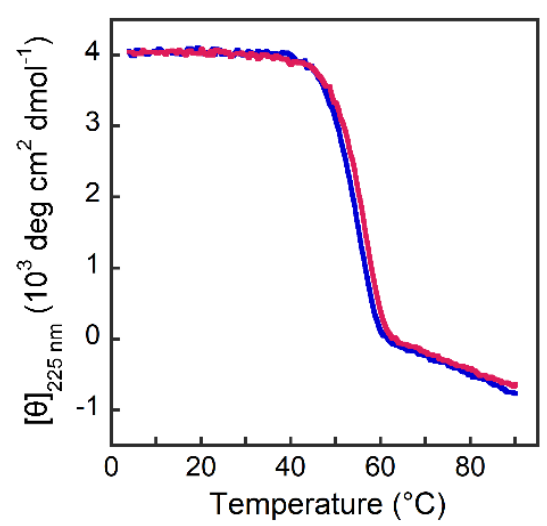

e

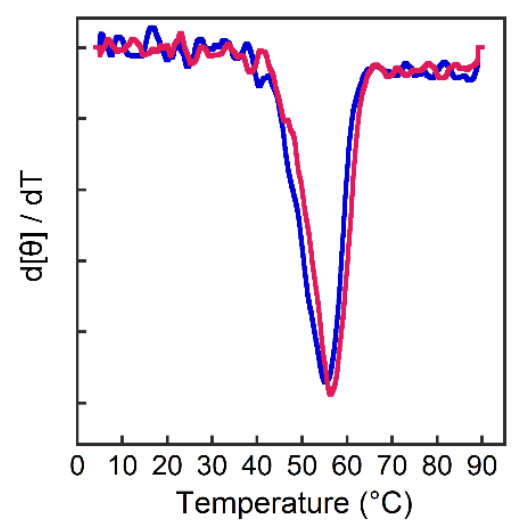

a, The HPLC chromatogram of purified peptide, $t_{R}=12.9$ min.

b, MALDI-MS, calculated: $1960.9[\mathrm{M}+\mathrm{H}]^{+}$, observed: $1961.0[\mathrm{M}+\mathrm{H}]^{+}, 1983.0[\mathrm{M}+\mathrm{Na}]^{+}, 1999.0[\mathrm{M}+\mathrm{K}]^{+}$.

c, The CD spectrum in PBS buffer at $4{ }^{\circ} \mathrm{C}$.

d, The CD thermal melting curves in PBS buffer (blue) and $35 \mathrm{mM} \mathrm{NaOH}$ solution (pH 12.54, red).

e, The first derivatives of the melting curves, $T_{\mathrm{m}}=55^{\circ} \mathrm{C}(\mathrm{PBS}$, blue $)$ or $56{ }^{\circ} \mathrm{C}(\mathrm{NaOH}$, red). 


\section{NMe-Ala-CMP}

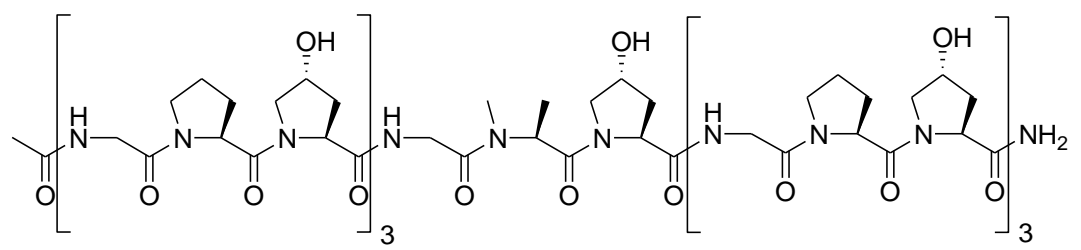

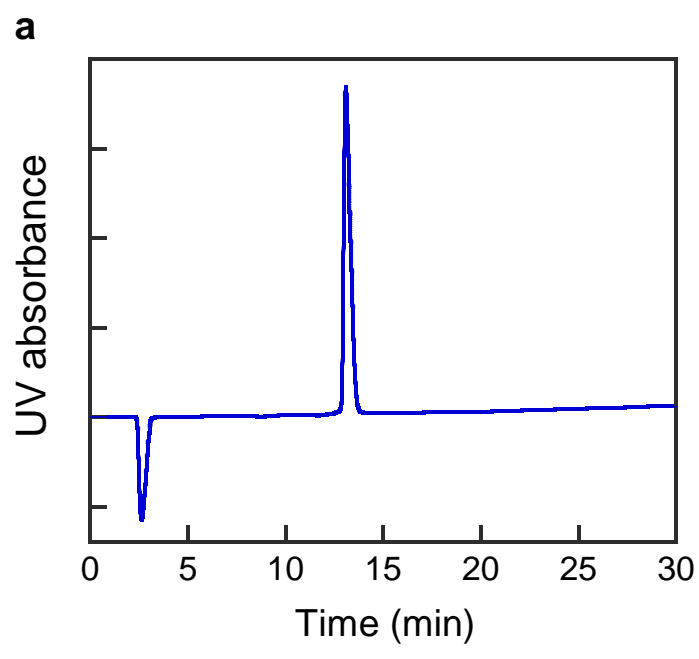

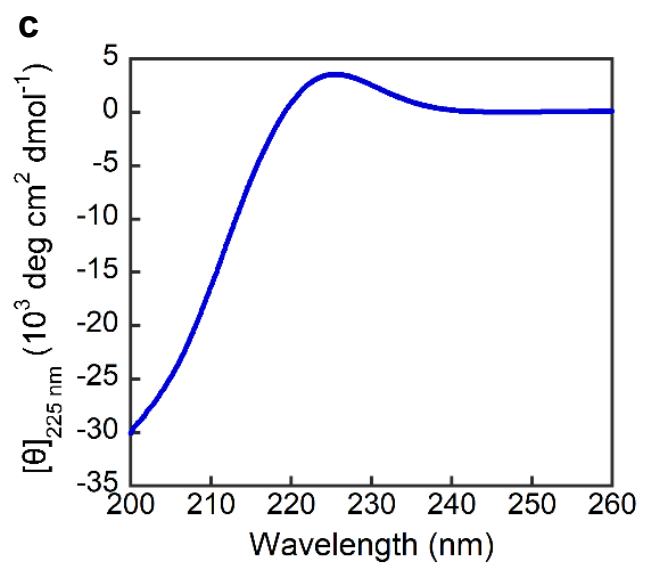

d b
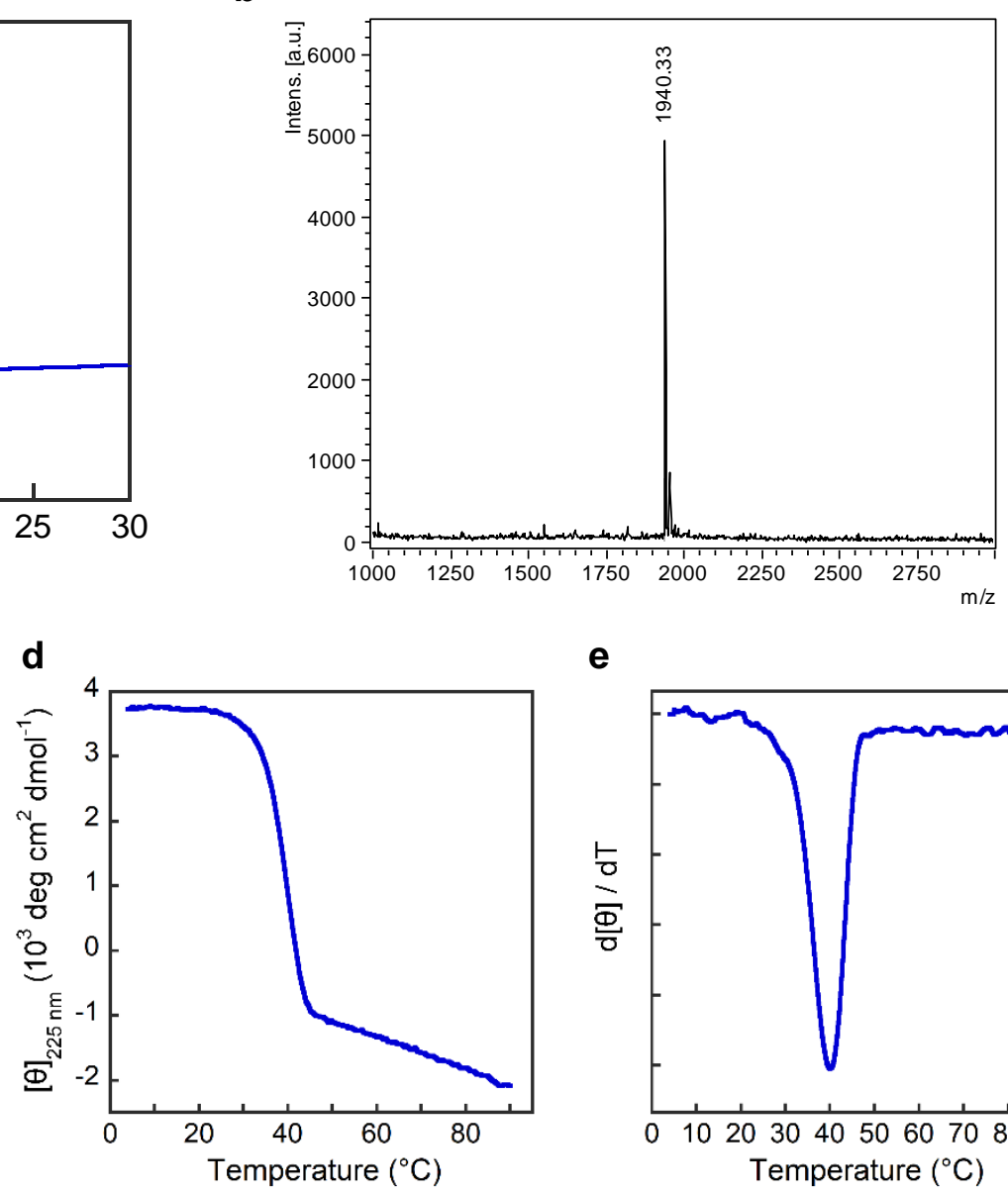

e

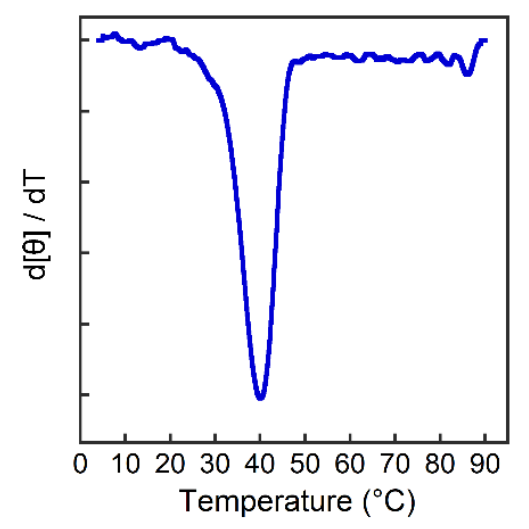

a, The HPLC chromatogram of purified peptide, $t_{R}=13.1 \mathrm{~min}$.

b, MALDI-MS, calculated: $1939.9[\mathrm{M}+\mathrm{Na}]^{+}$, observed: $1940.3[\mathrm{M}+\mathrm{Na}]^{+}$.

c, The CD spectrum in PBS buffer at $4{ }^{\circ} \mathrm{C}$.

d, The CD thermal melting curve of in PBS buffer.

e, The first derivative of the melting curve, $T_{\mathrm{m}}=40{ }^{\circ} \mathrm{C}$. 


\section{Nmet-CMP}

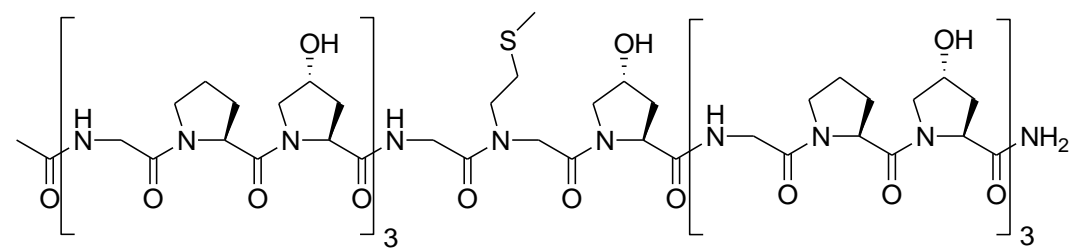

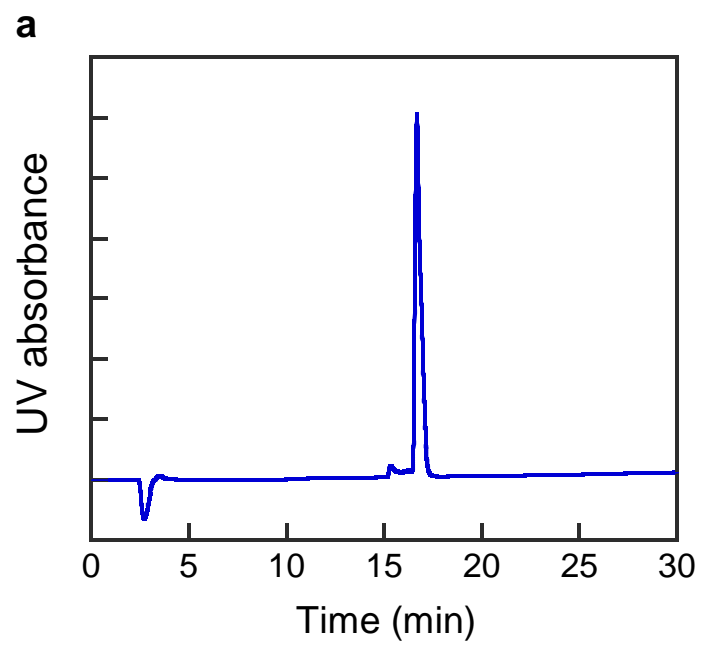

C

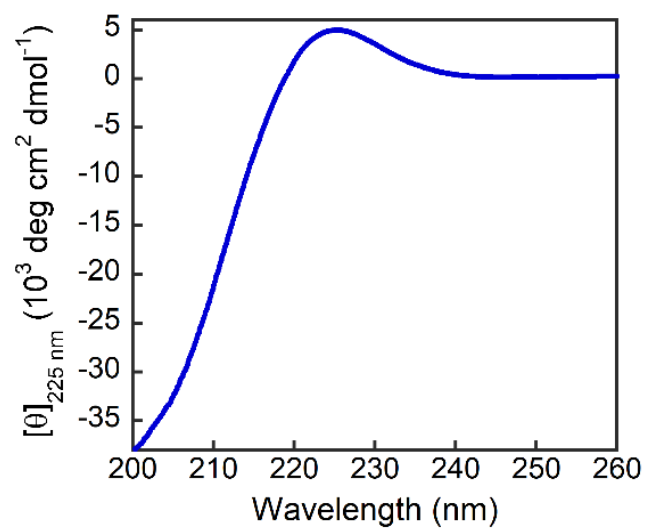

b

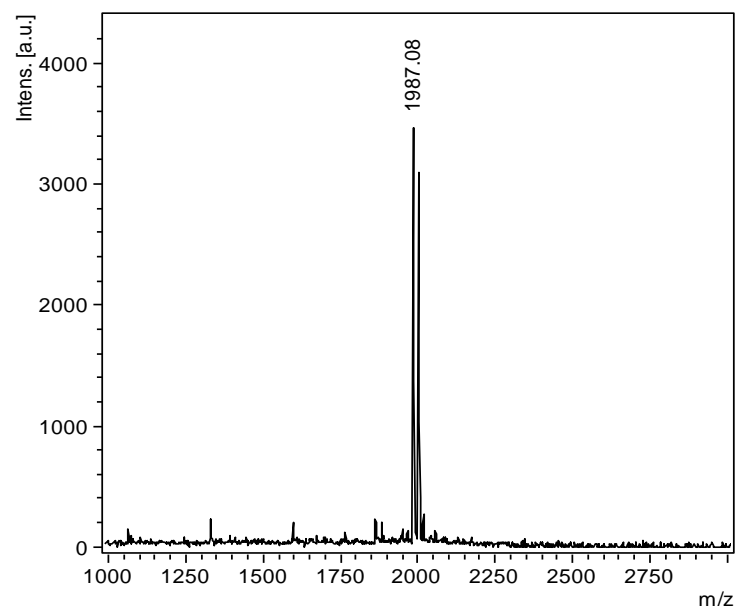

e

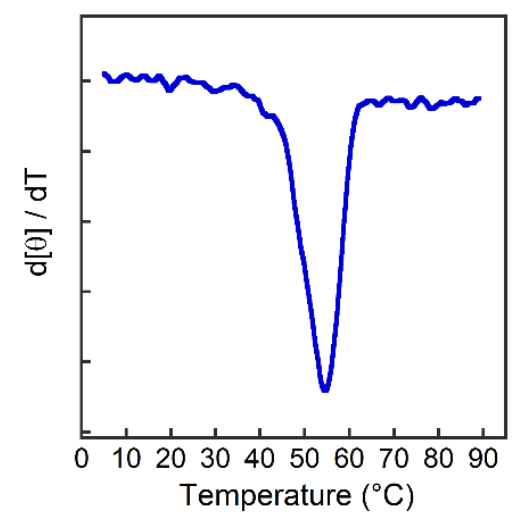

a, The HPLC chromatogram of purified peptide, $t_{R}=16.7 \mathrm{~min}$.

b, MALDI-MS, calculated: $1986.9[\mathrm{M}+\mathrm{Na}]^{+}$, observed: $1987.1[\mathrm{M}+\mathrm{Na}]^{+}$.

c, The CD spectrum in PBS buffer at $4{ }^{\circ} \mathrm{C}$.

d, The CD thermal melting curve in PBS buffer.

e, The first derivative of the melting curve, $T_{\mathrm{m}}=55^{\circ} \mathrm{C}$. 


\section{Nnbz-CMP}

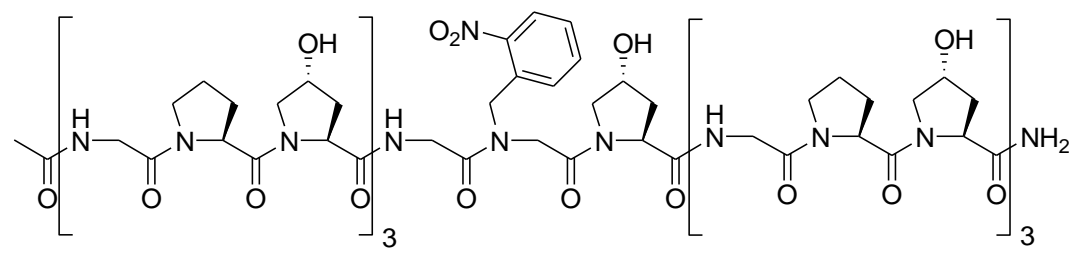

a

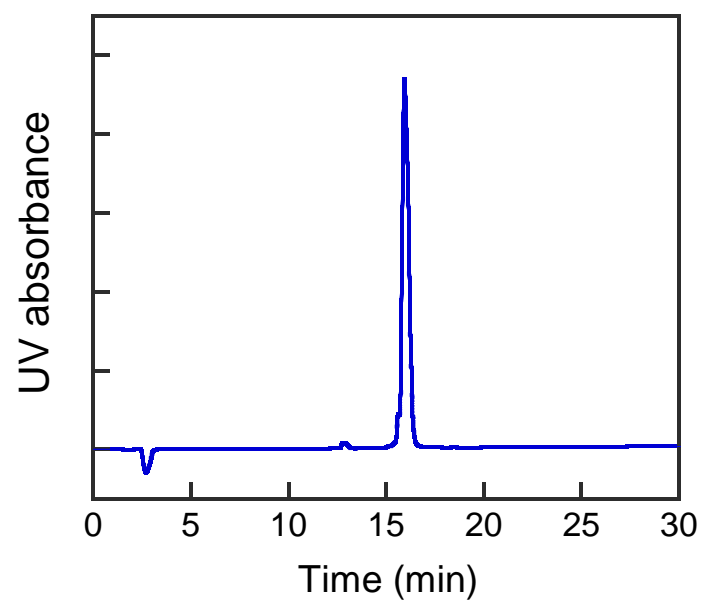

b

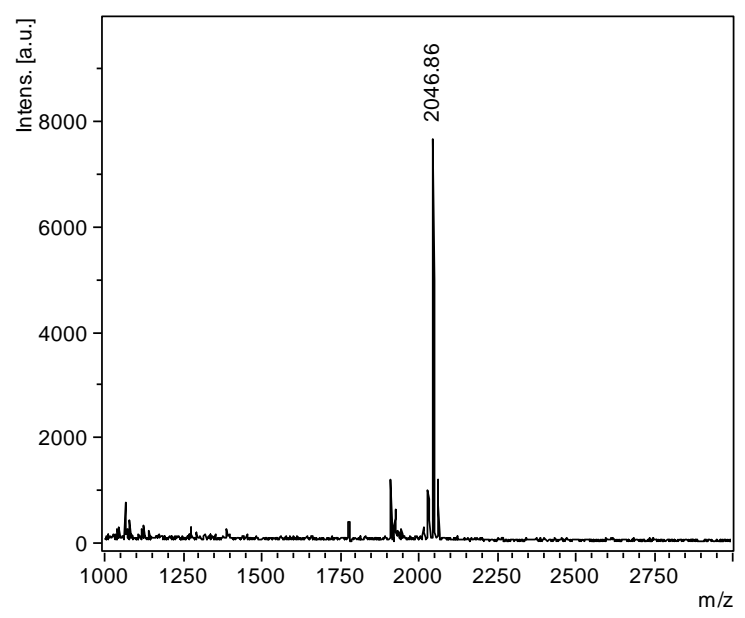

C

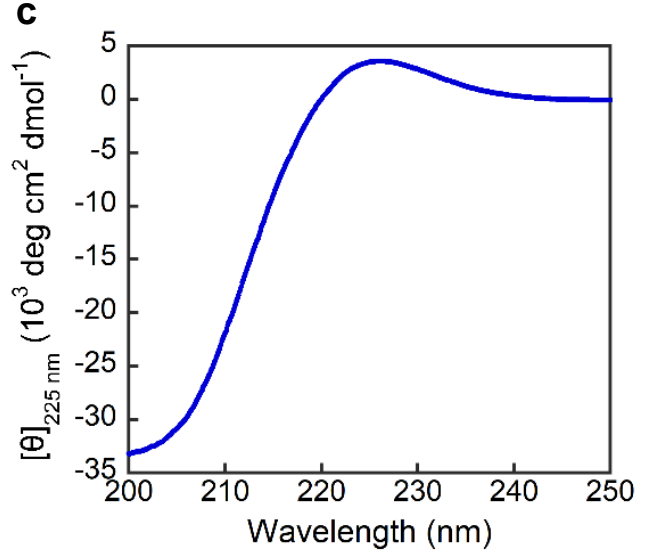

d

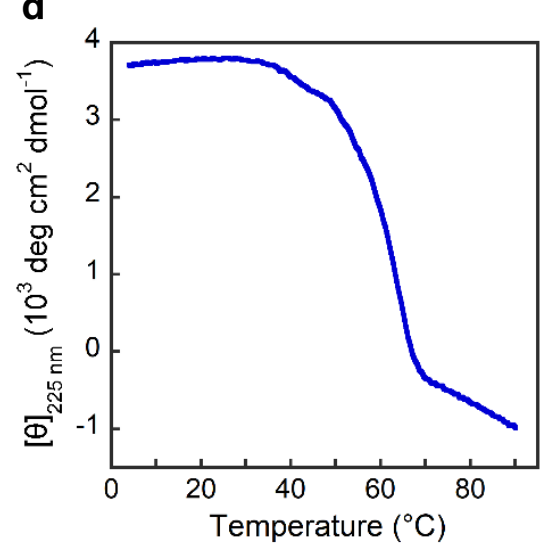

e

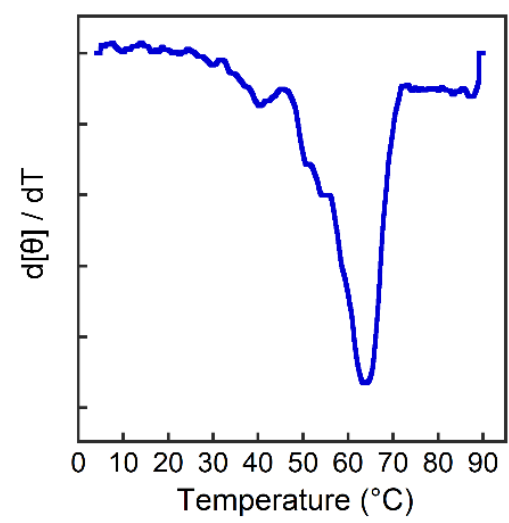

a, The HPLC chromatogram of purified peptide, $t_{R}=15.9$ min.

b, MALDI-MS, calculated: 2046.9 [M+Na] $]^{+}$, observed: $2046.9[\mathrm{M}+\mathrm{Na}]^{+}$.

c, The CD spectrum in PBS buffer at $4{ }^{\circ} \mathrm{C}$.

d, The CD thermal melting curve in PBS buffer.

e, The first derivative of the melting curve, $T_{\mathrm{m}}=62{ }^{\circ} \mathrm{C}$. 


\section{Nnbz2-CMP}

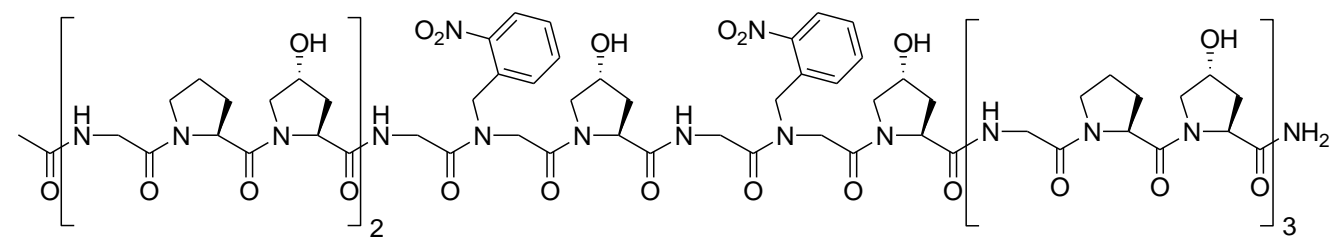

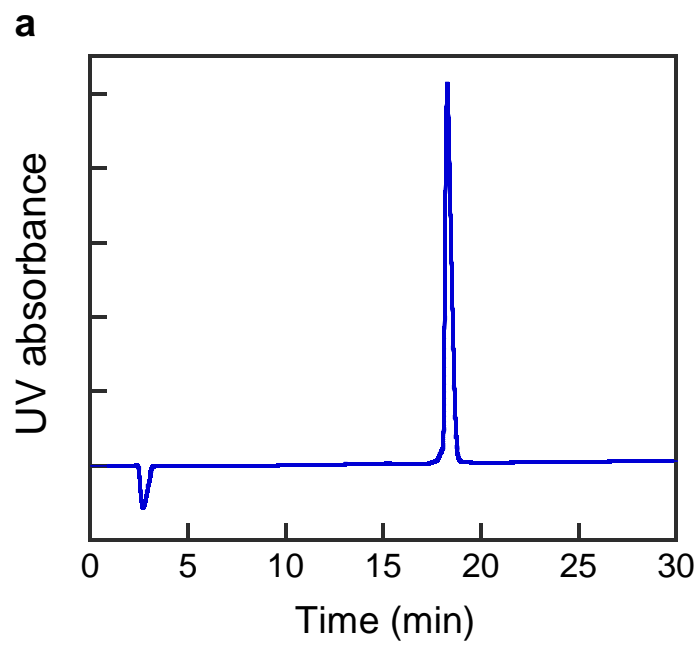

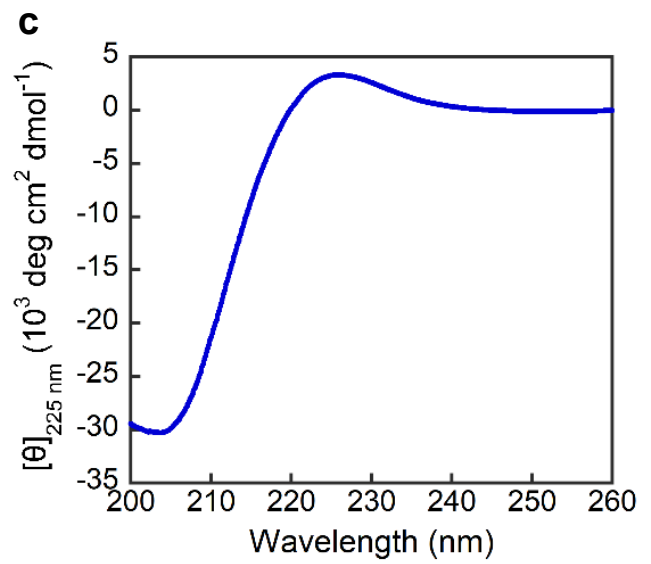

b

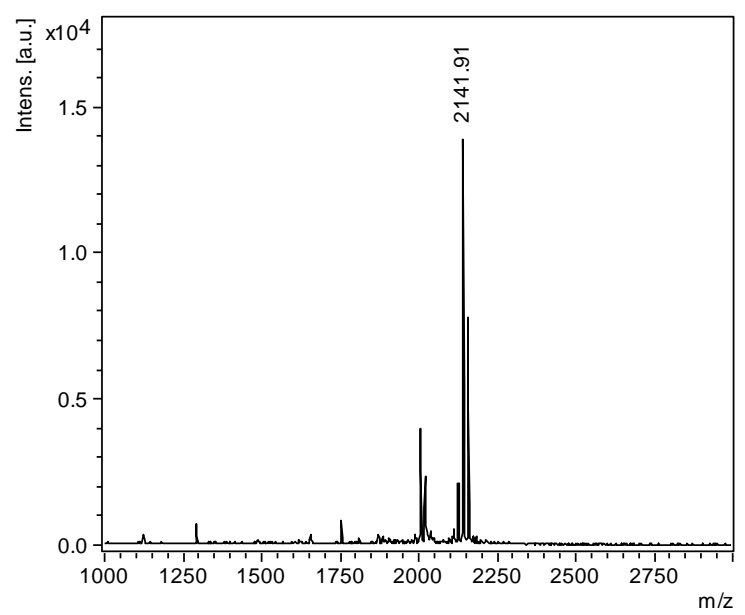

d

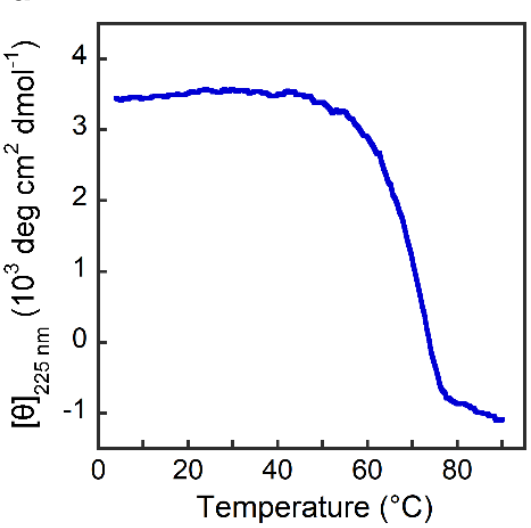

e

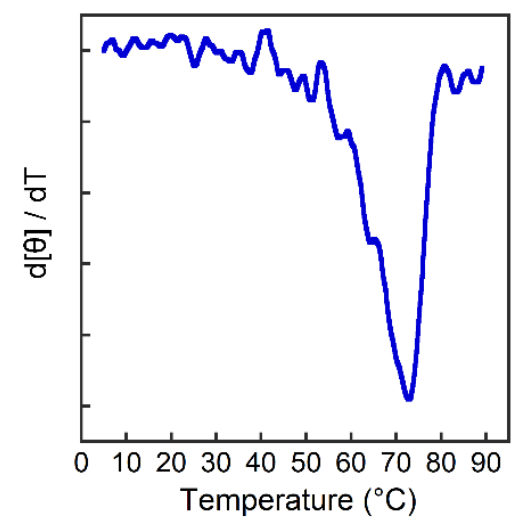

a, The HPLC chromatogram of purified peptide, $t_{R}=18.3 \mathrm{~min}$.

b, MALDI-MS, calculated: $2141.9[\mathrm{M}+\mathrm{Na}]^{+}$, observed: $2141.9[\mathrm{M}+\mathrm{Na}]^{+}$.

c, The CD spectrum in PBS buffer at $4{ }^{\circ} \mathrm{C}$.

d, The CD thermal melting curve in PBS buffer.

e, The first derivative of the melting curve, $T_{\mathrm{m}}=73{ }^{\circ} \mathrm{C}$. 


\section{Nnbz3-CMP}

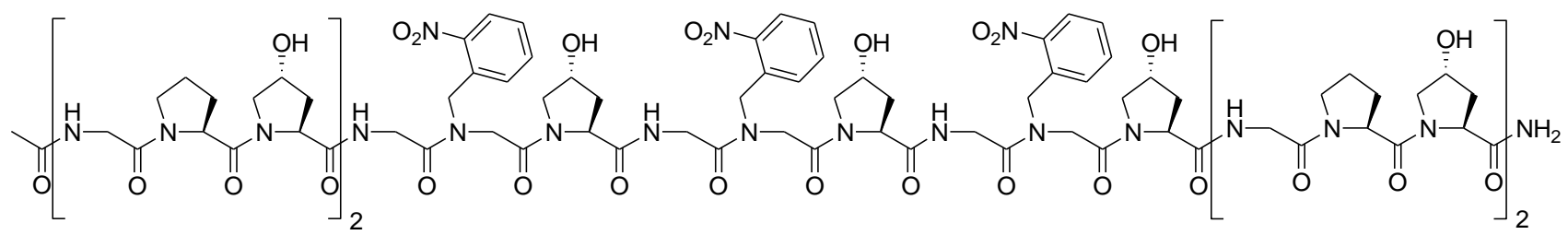

a

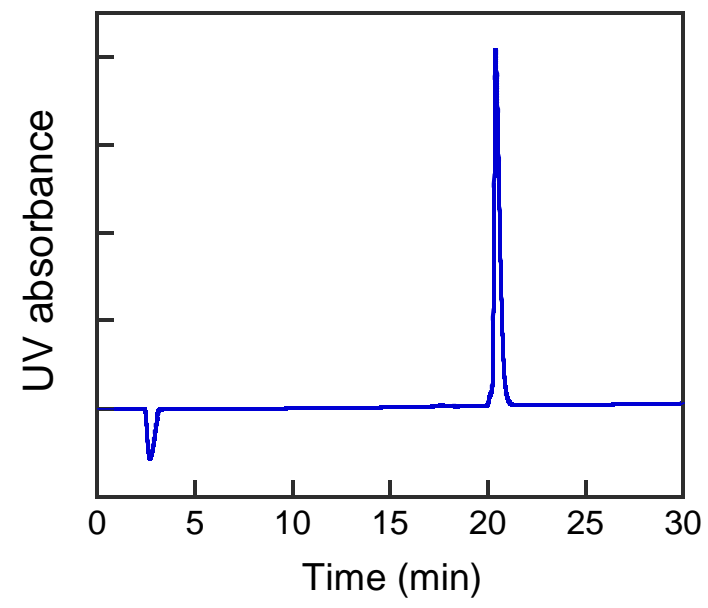

b

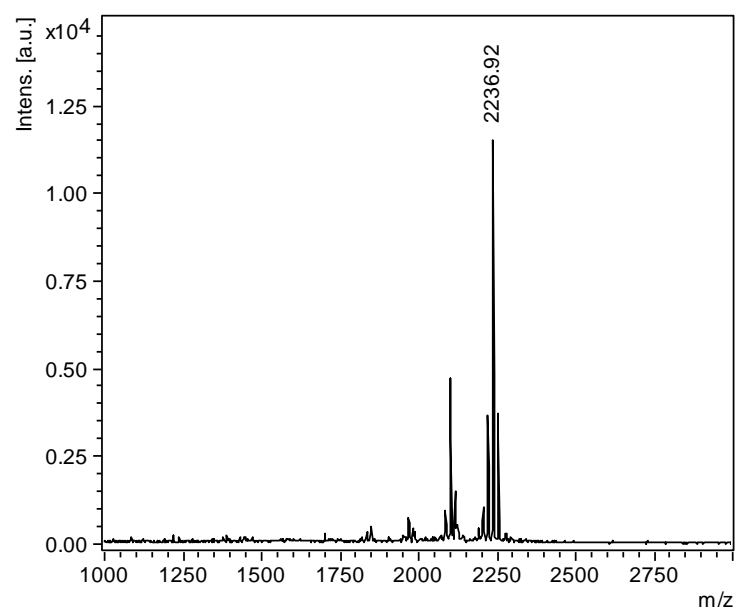

C

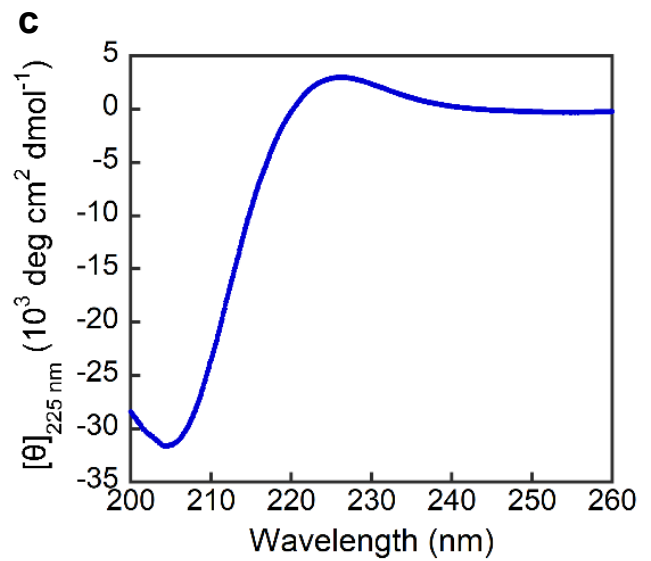

d

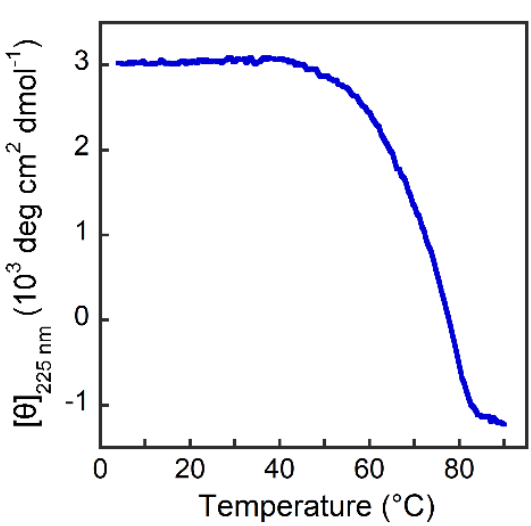

e

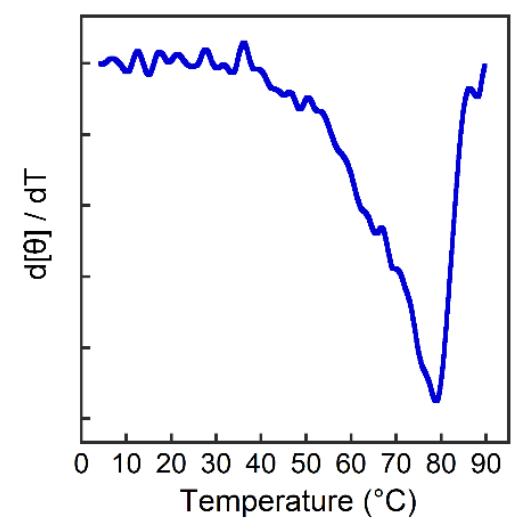

a, The HPLC chromatogram of purified peptide, $t_{R}=20.4 \mathrm{~min}$.

b, MALDI-MS, calculated: $2236.9[\mathrm{M}+\mathrm{Na}]^{+}$, observed: $2236.9[\mathrm{M}+\mathrm{Na}]^{+}$.

c, The CD spectrum in PBS buffer at $4{ }^{\circ} \mathrm{C}$.

d, The CD thermal melting curve in PBS buffer.

e, The first derivative of the melting curve, $T_{\mathrm{m}}=79^{\circ} \mathrm{C}$. 


\section{Nphe-CMP}

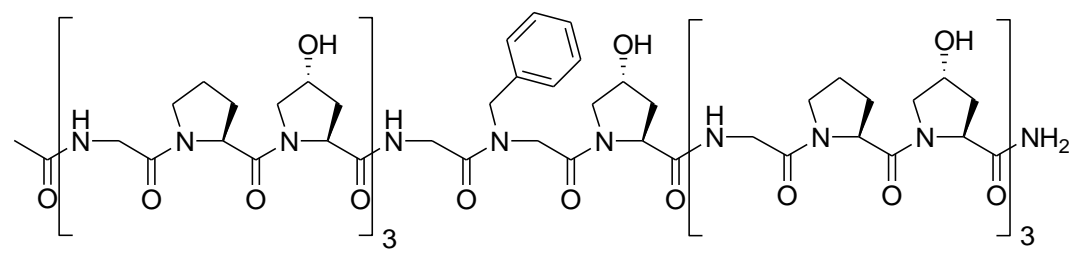

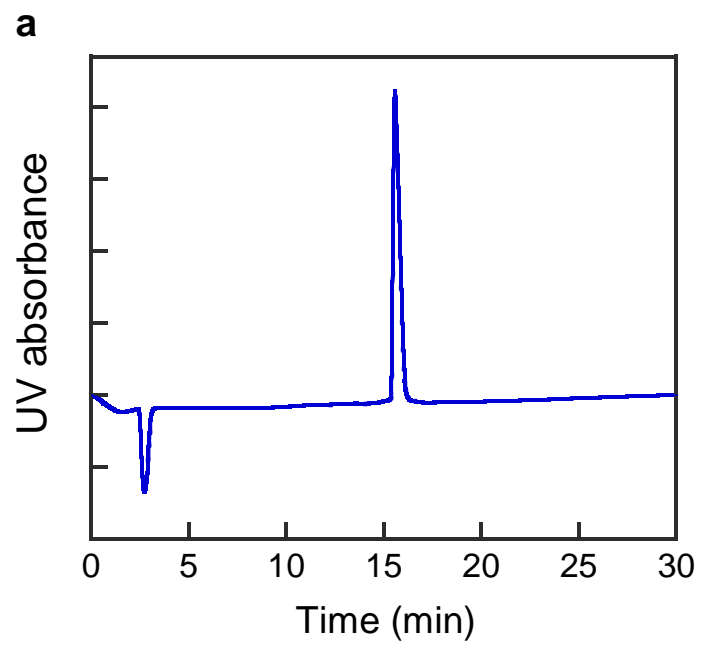

C

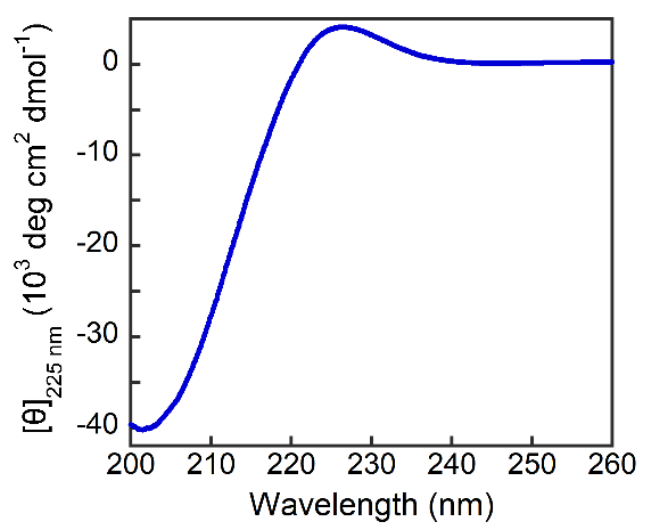

b

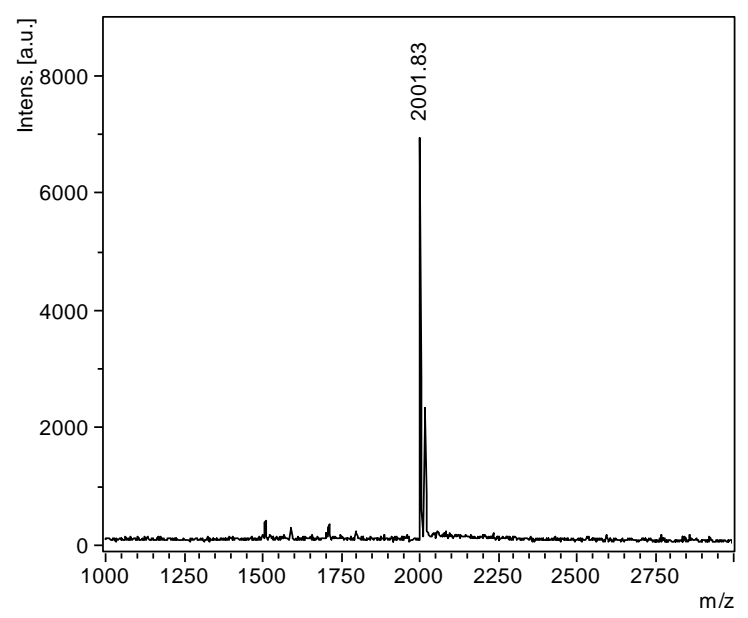

d

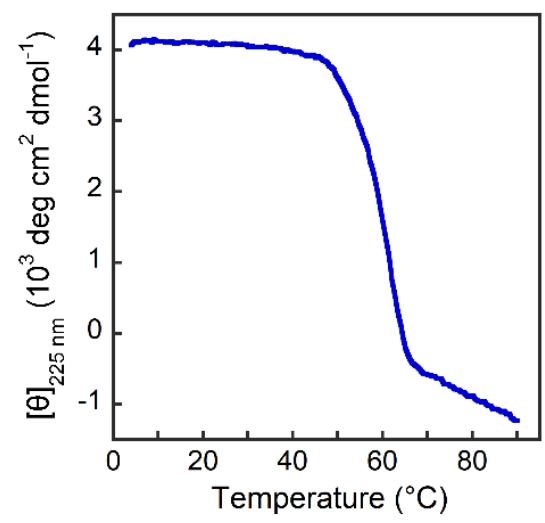

e

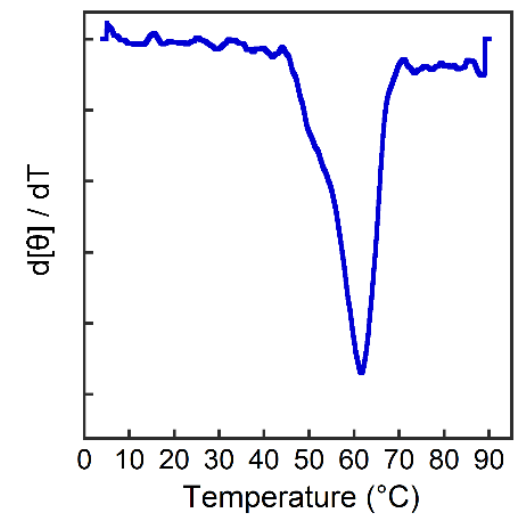

a, The HPLC chromatogram of purified peptide, $t_{R}=15.6$ min.

b, MALDI-MS, calculated: $2001.9[\mathrm{M}+\mathrm{Na}]^{+}$, observed: $2001.8[\mathrm{M}+\mathrm{Na}]^{+}, 2017.8[\mathrm{M}+\mathrm{K}]^{+}$.

c, The CD spectrum in PBS buffer at $4{ }^{\circ} \mathrm{C}$.

d, The CD thermal melting curve in PBS buffer.

e, The first derivative of the melting curve, $T_{\mathrm{m}}=62^{\circ} \mathrm{C}$. 


\section{Nphe-Ile-CMP}

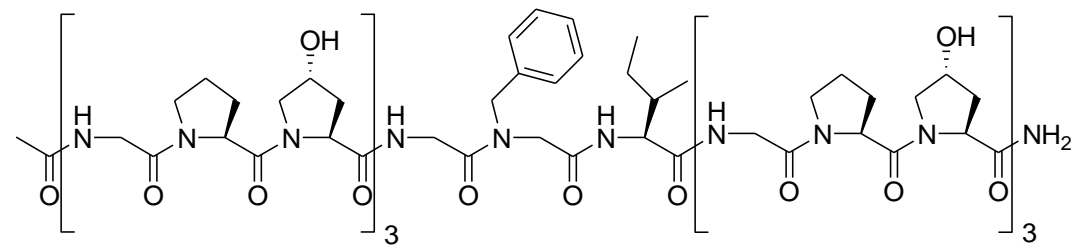

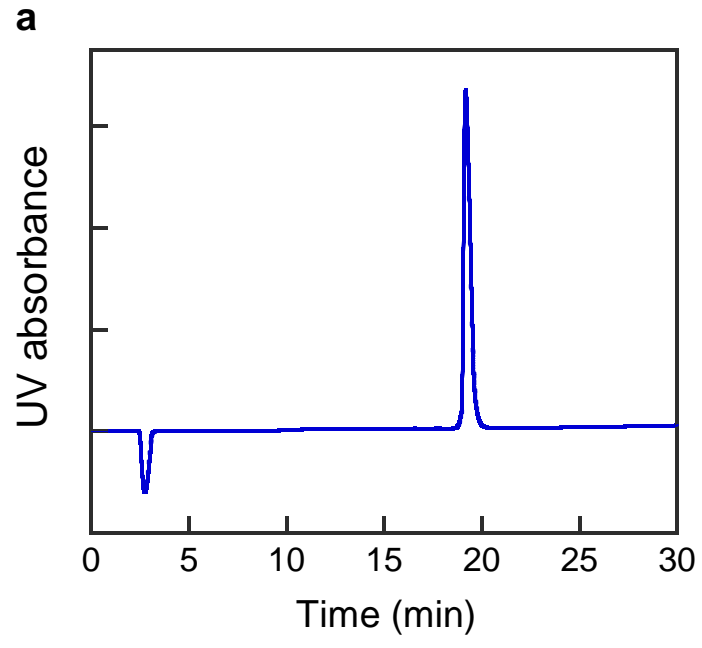

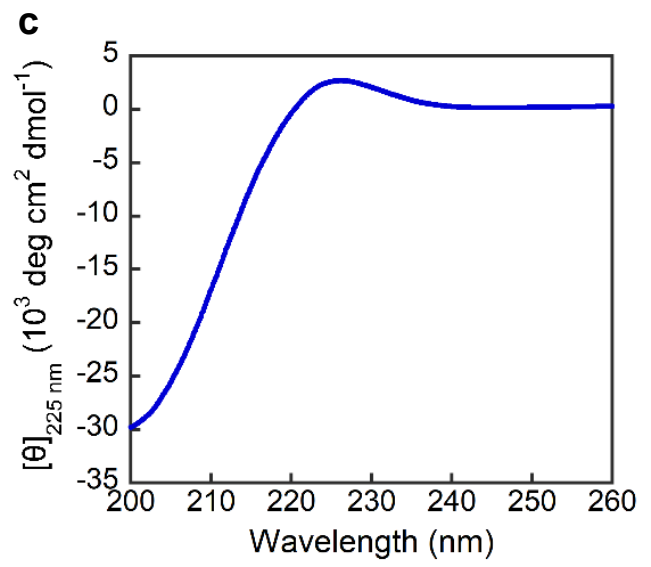

d b
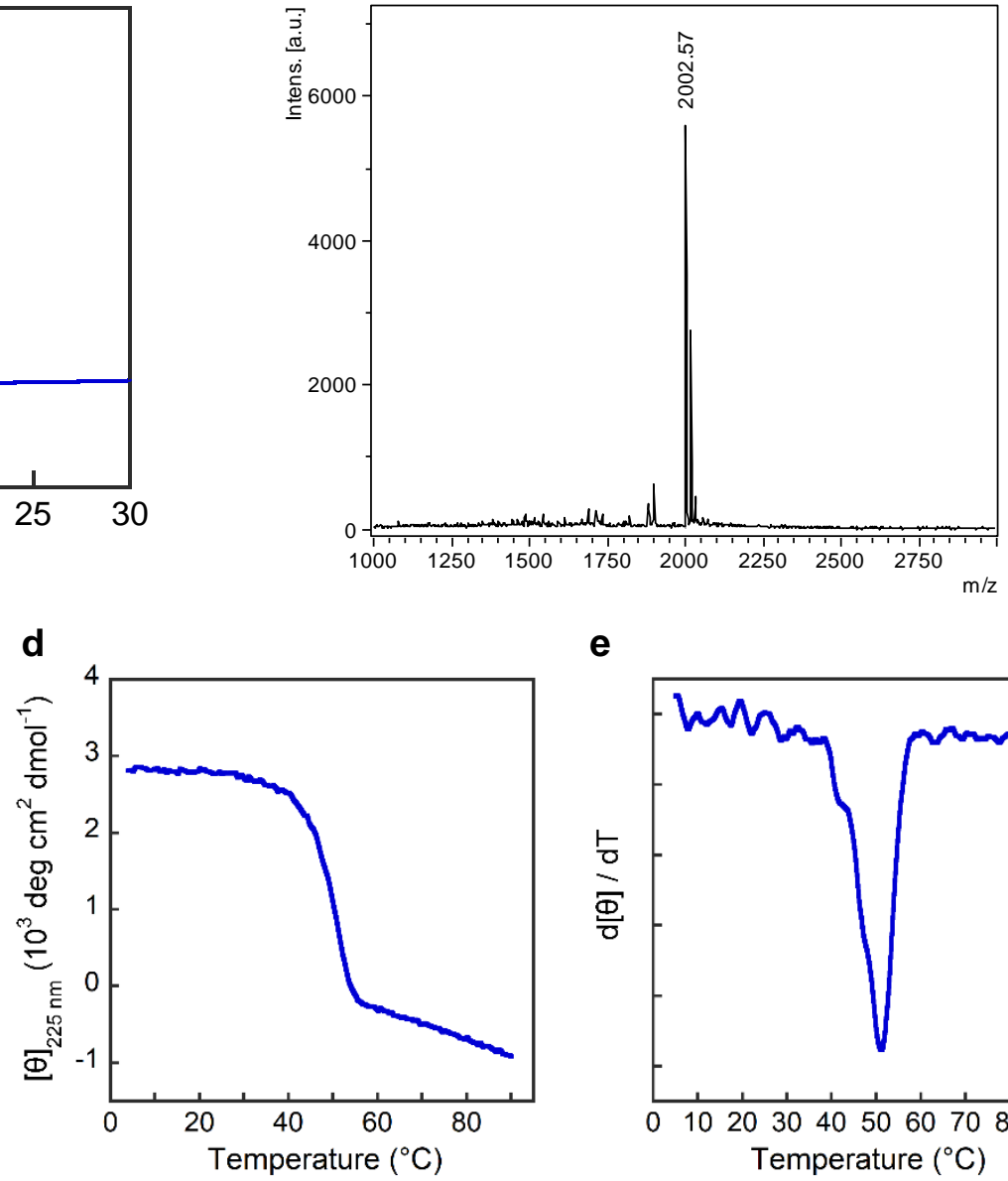

e

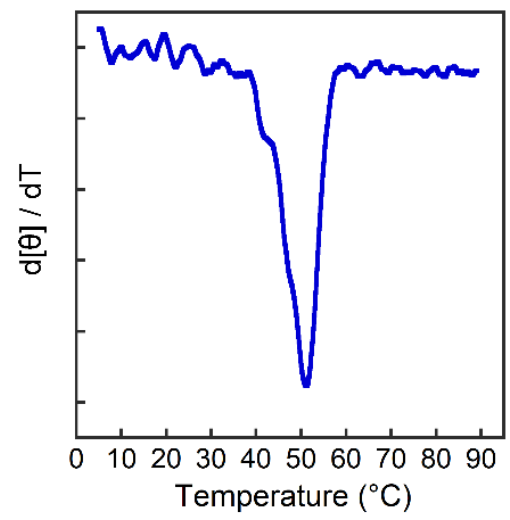

a, The HPLC chromatogram of purified peptide, $t_{R}=19.2 \mathrm{~min}$.

b, MALDI-MS, calculated: $2001.9[\mathrm{M}+\mathrm{Na}]^{+}$, observed: $2002.6[\mathrm{M}+\mathrm{Na}]^{+}$.

c, The CD spectrum -Ile in PBS buffer at $4{ }^{\circ} \mathrm{C}$.

d, The CD thermal melting curve in PBS buffer.

e, The first derivative of the melting curve, $T_{\mathrm{m}}=51^{\circ} \mathrm{C}$. 


\section{Nrpe-CMP}

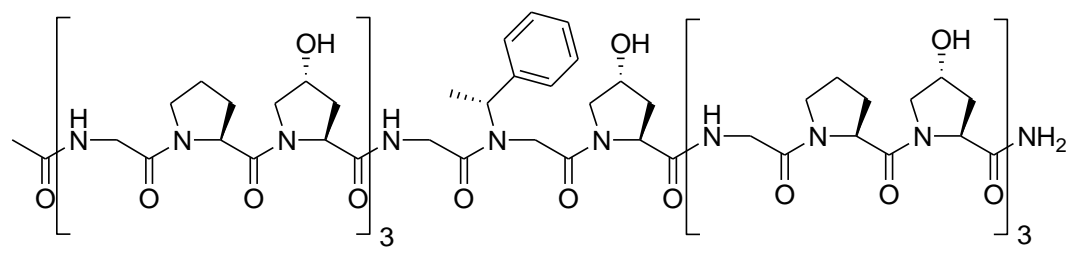

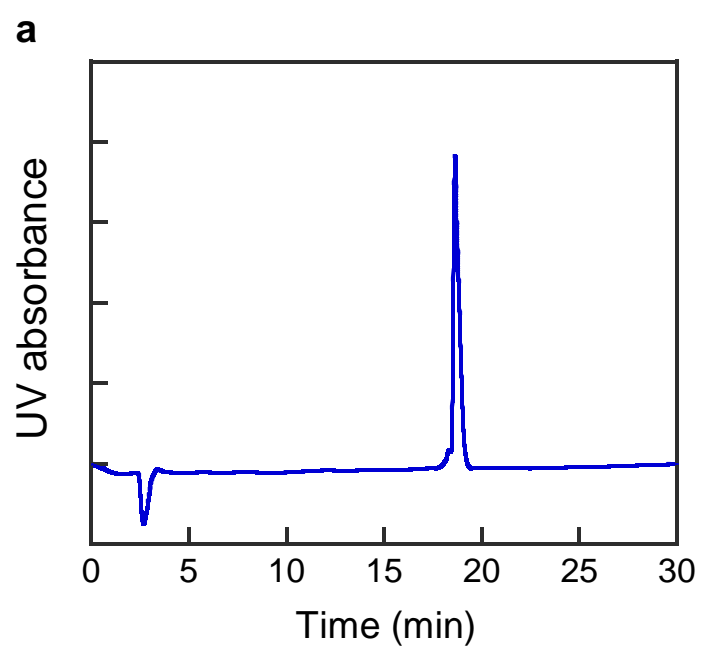

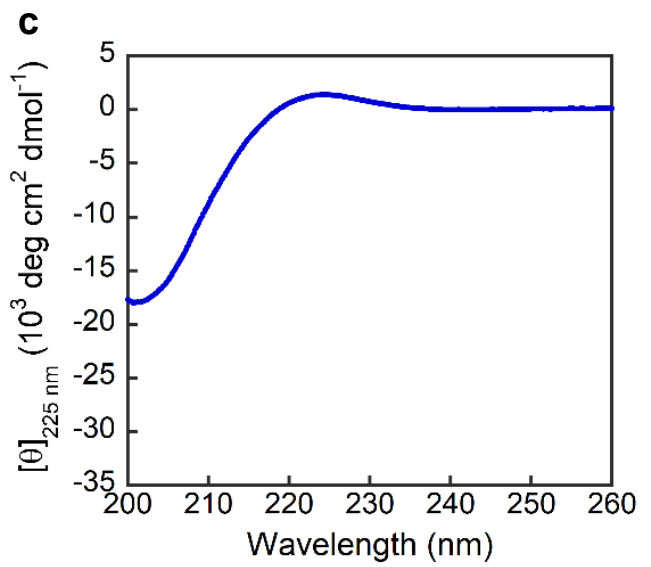

d b
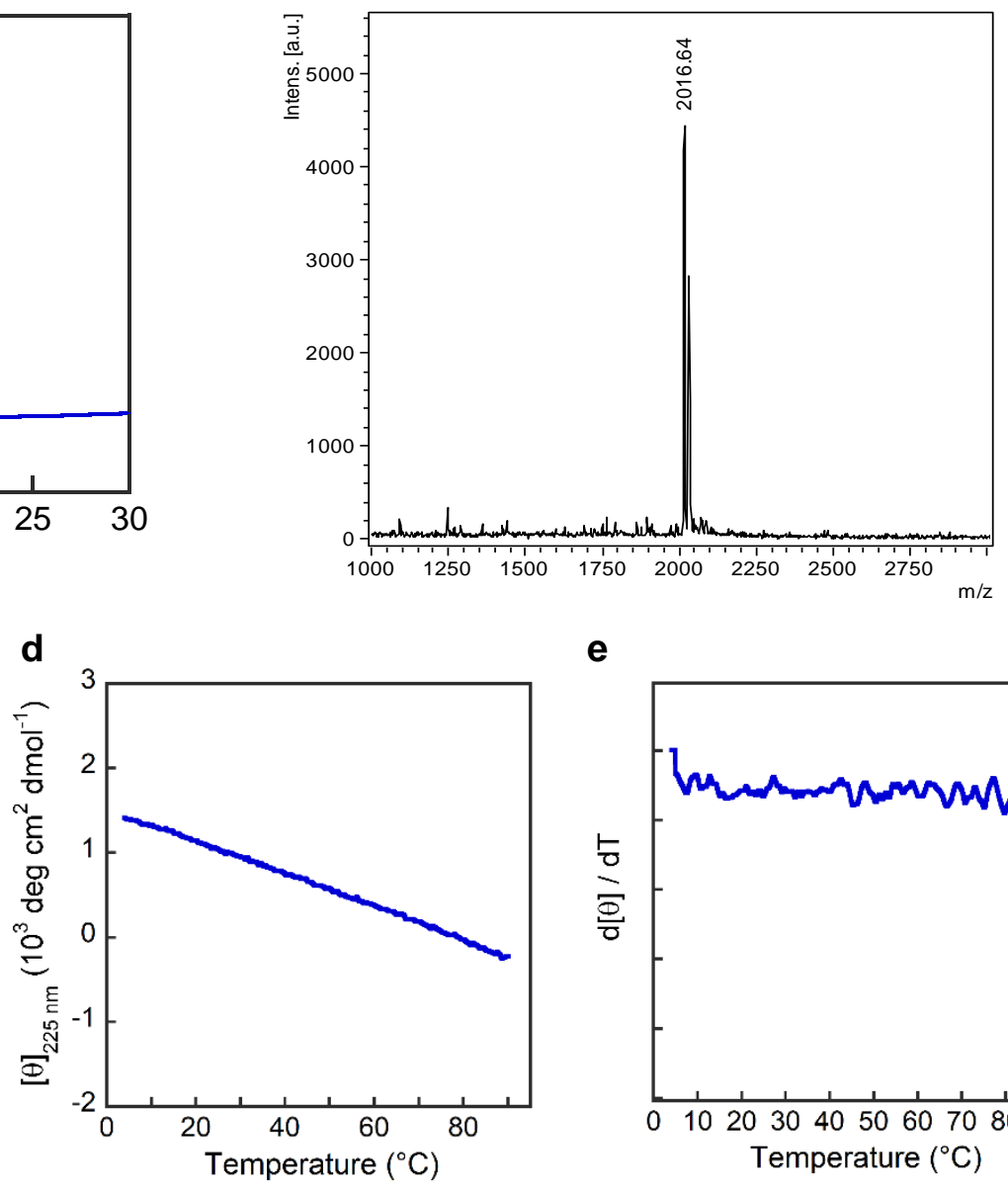

e

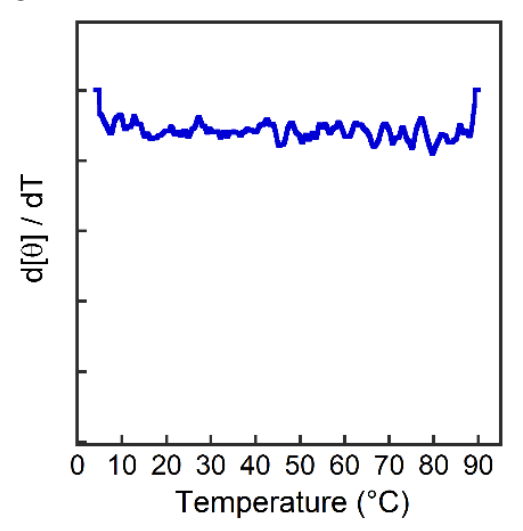

a, The HPLC chromatogram of purified peptide, $t_{R}=18.6 \mathrm{~min}$.

b, MALDI-MS, calculated: $2015.9[\mathrm{M}+\mathrm{Na}]^{+}$, observed: $2016.6[\mathrm{M}+\mathrm{Na}]^{+}$.

c, The CD spectrum in PBS buffer at $4{ }^{\circ} \mathrm{C}$.

d, The CD thermal melting curve in PBS buffer.

e, The first derivative of the melting curve. 


\section{Nspe-CMP}
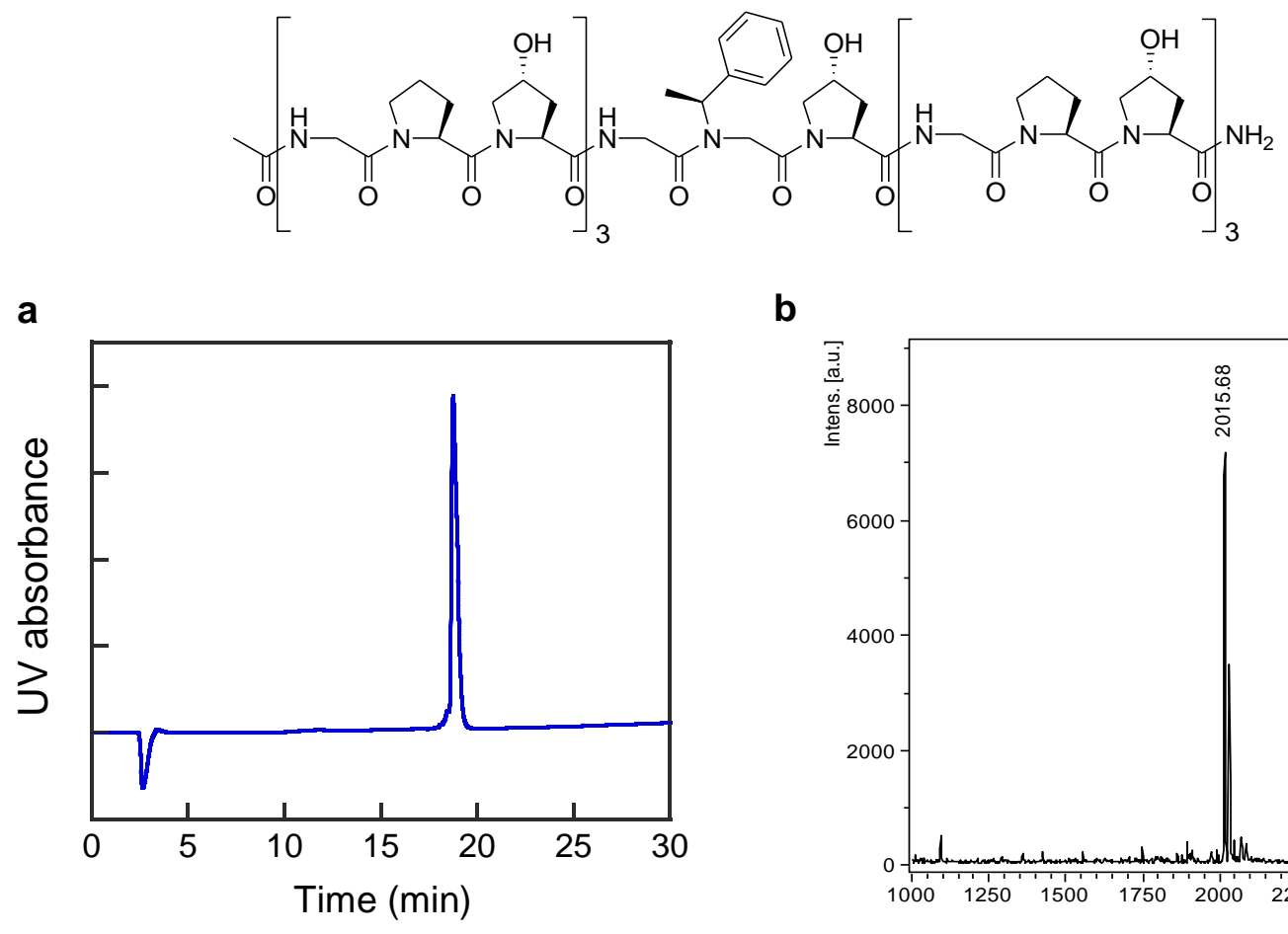

b
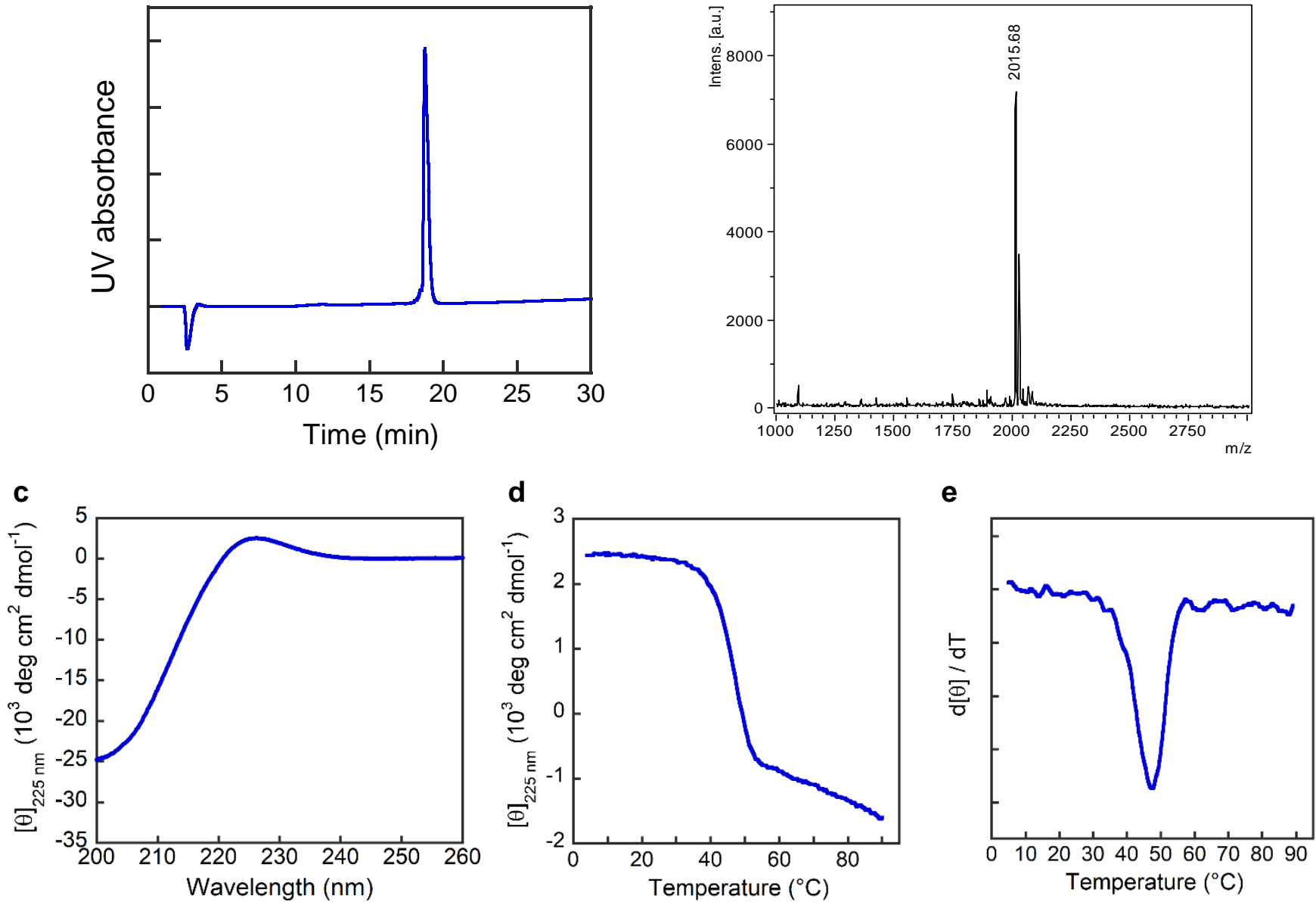
a, The HPLC chromatogram of purified peptide, $t_{R}=18.7 \mathrm{~min}$.
b, MALDI-MS, calculated: $2015.9[\mathrm{M}+\mathrm{Na}]^{+}$, observed: $2015.7[\mathrm{M}+\mathrm{Na}]^{+}$.
c, The CD spectrum in PBS buffer at $4{ }^{\circ} \mathrm{C}$.
d, The CD thermal melting curve in PBS buffer.
e, The first derivative of the melting curve, $T_{\mathrm{m}}=48{ }^{\circ} \mathrm{C}$. 


\section{Ntyr-CMP}

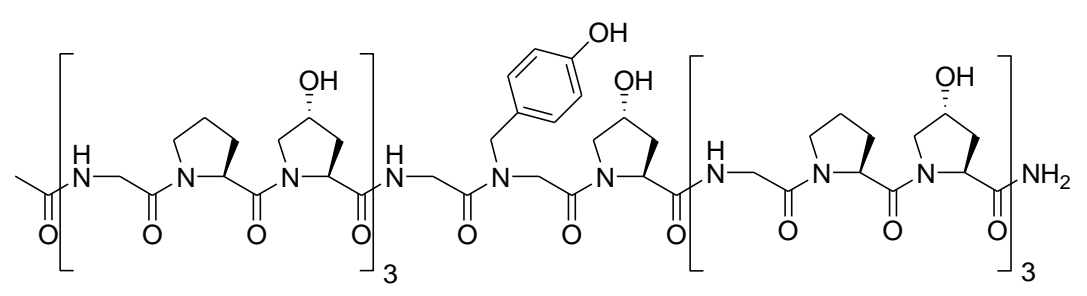

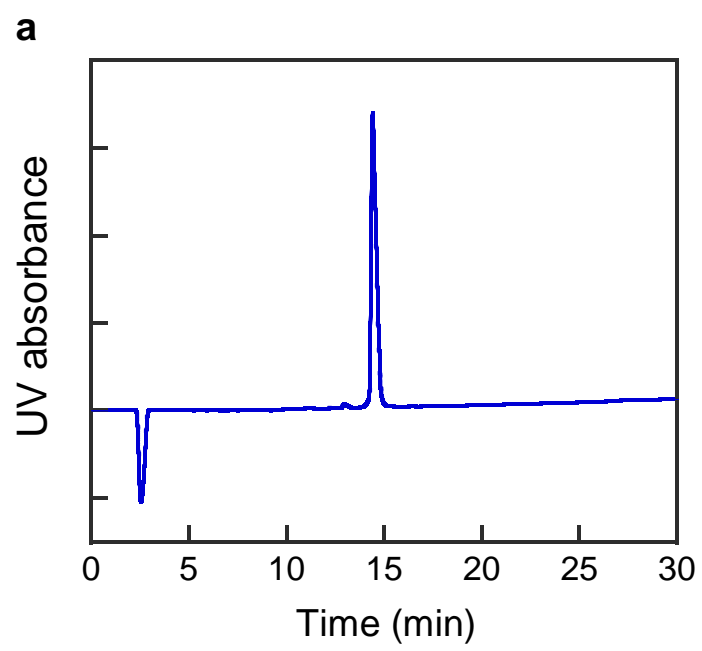

C

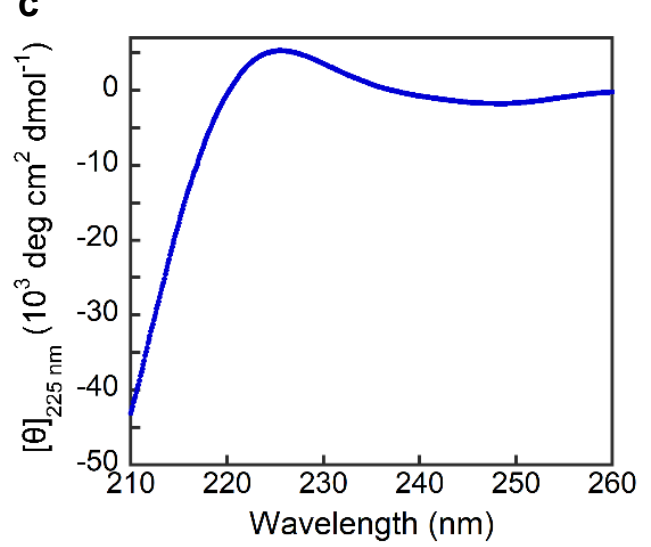

d b
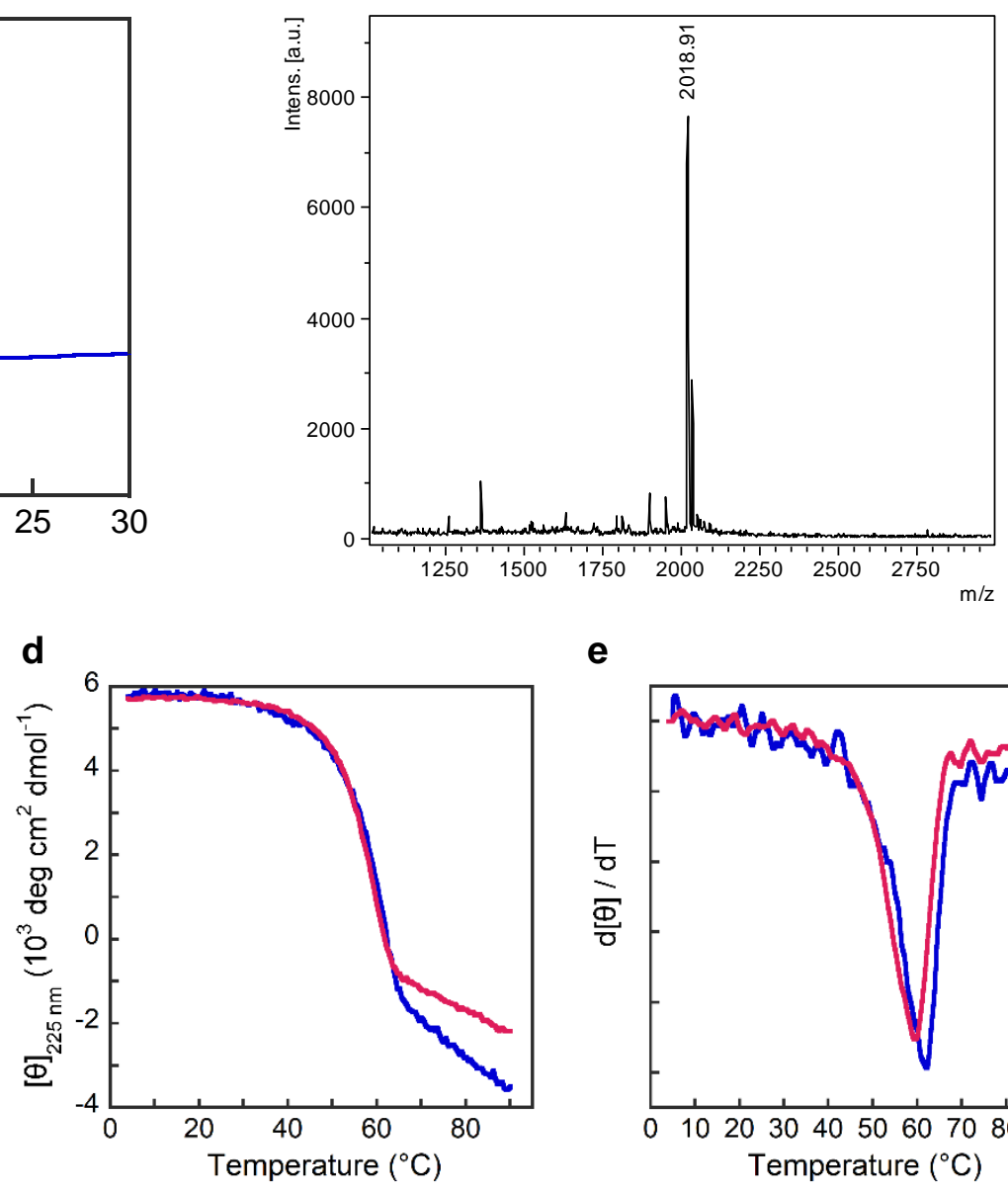

e

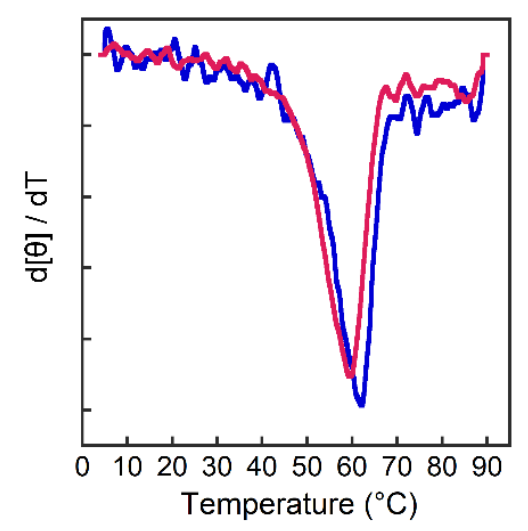

a, The HPLC chromatogram of purified peptide, $t_{R}=14.4 \mathrm{~min}$.

b, MALDI-MS, calculated: $2017.9[\mathrm{M}+\mathrm{Na}]^{+}$, observed: $2018.9[\mathrm{M}+\mathrm{Na}]^{+}$.

c, The $\mathrm{CD}$ spectrum in $10 \mathrm{mM} \mathrm{NaOH}$ solution $(\mathrm{pH} 12)$ at $4{ }^{\circ} \mathrm{C}$.

d, The CD thermal melting curves in PBS buffer (blue) and $10 \mathrm{mM} \mathrm{NaOH}$ solution (pH 12, red).

e, The first derivatives of the melting curves, $T_{\mathrm{m}}=61{ }^{\circ} \mathrm{C}(\mathrm{PBS}$, blue $)$ or $59{ }^{\circ} \mathrm{C}(\mathrm{NaOH}$, red $)$. 
Nval-CMP

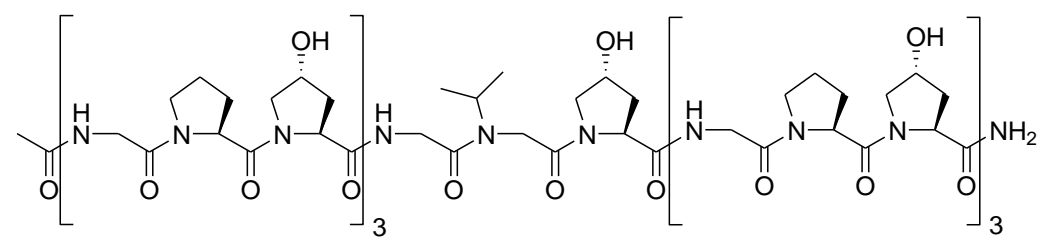

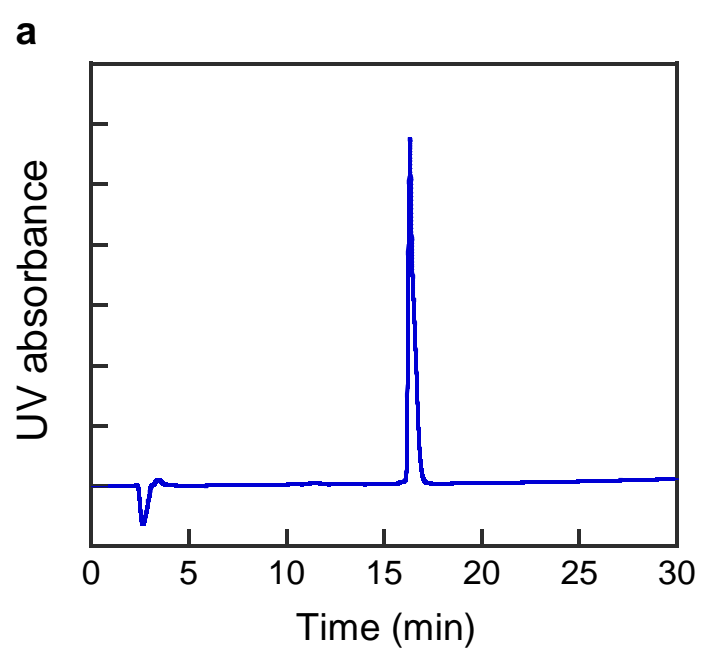

C

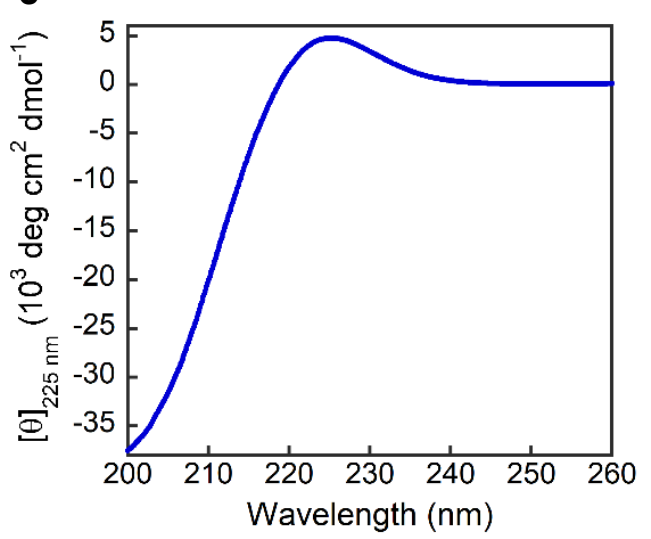

d b
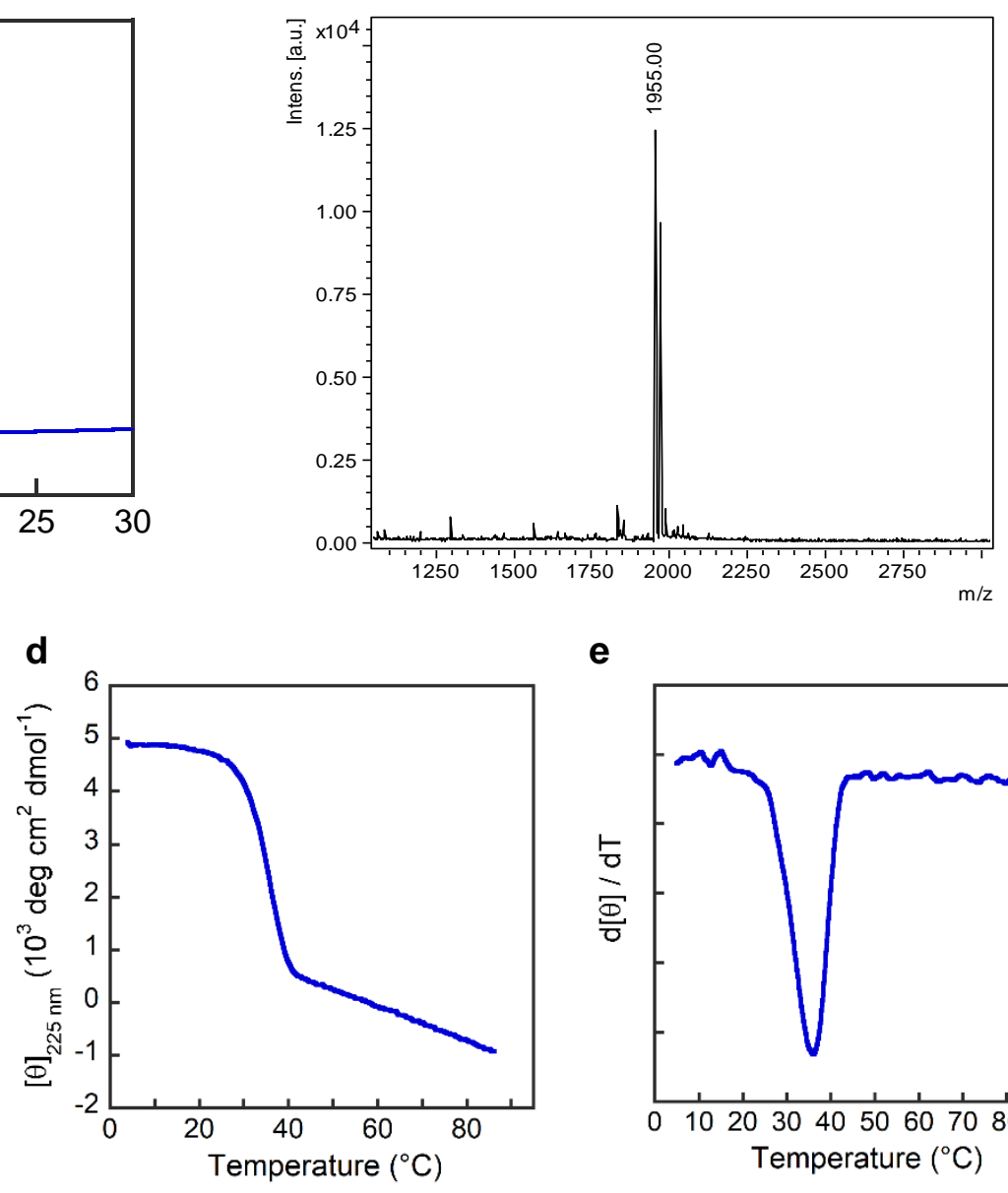

e

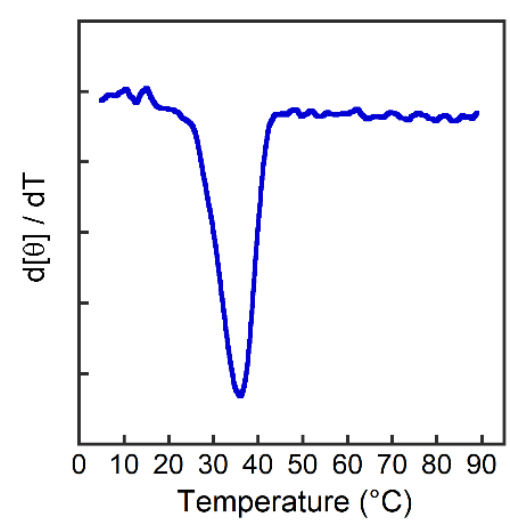

a, The HPLC chromatogram of purified peptide, $t_{R}=16.3 \mathrm{~min}$.

b, MALDI-MS, calculated: $1953.9[\mathrm{M}+\mathrm{Na}]^{+}$, observed: $1955.0[\mathrm{M}+\mathrm{Na}]^{+}$.

c, The CD spectrum in PBS buffer at $4{ }^{\circ} \mathrm{C}$.

d, The CD thermal melting curve in PBS buffer.

e, The first derivative of the melting curve, $T_{\mathrm{m}}=36^{\circ} \mathrm{C}$. 


\section{X7-CMP}

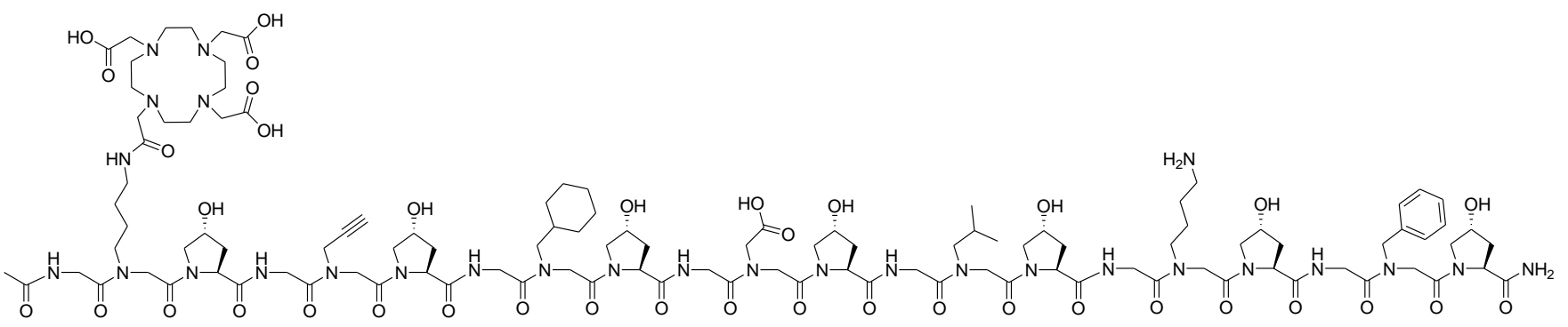

a

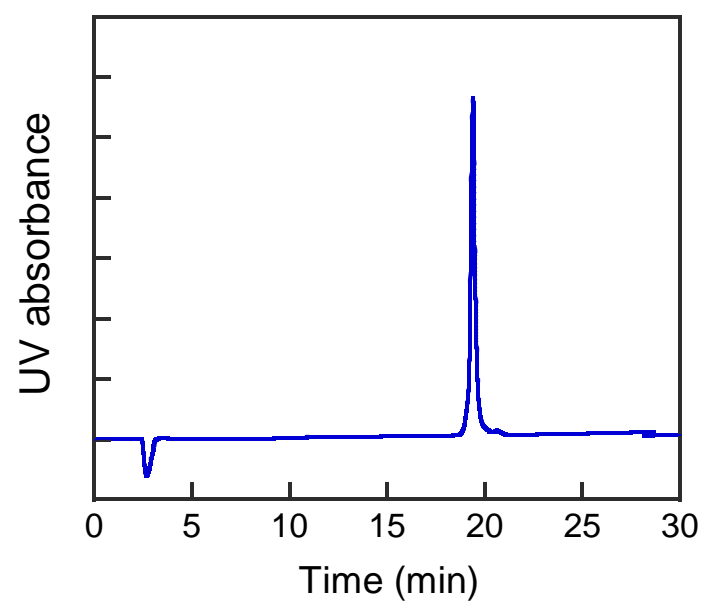

C

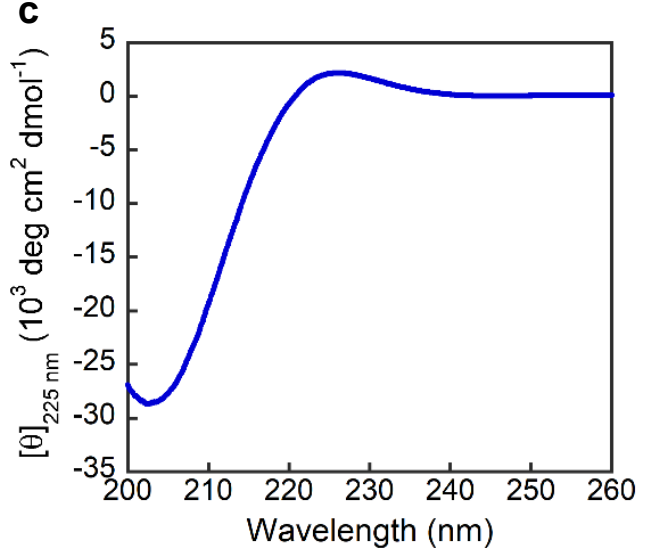

d b
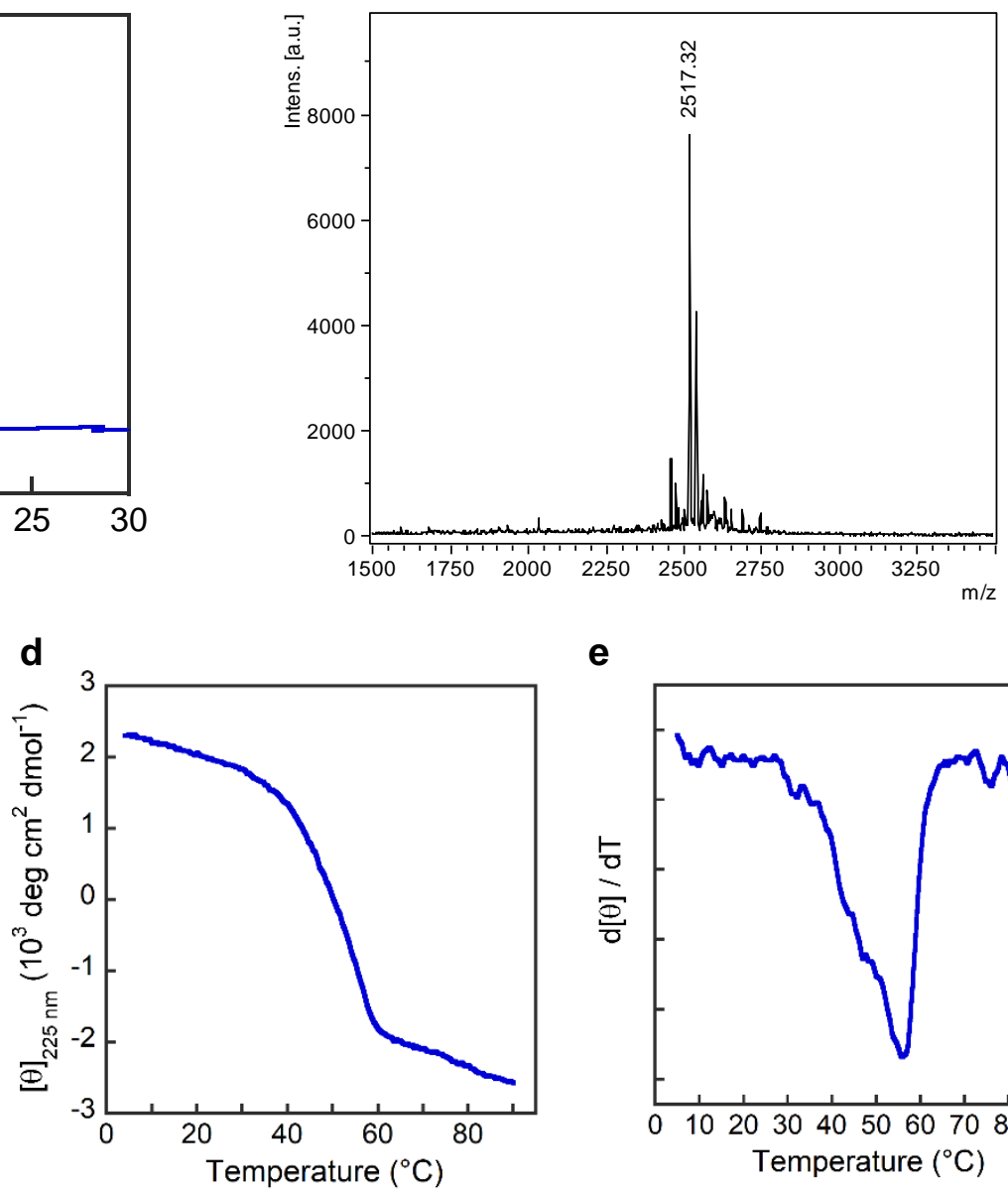

e

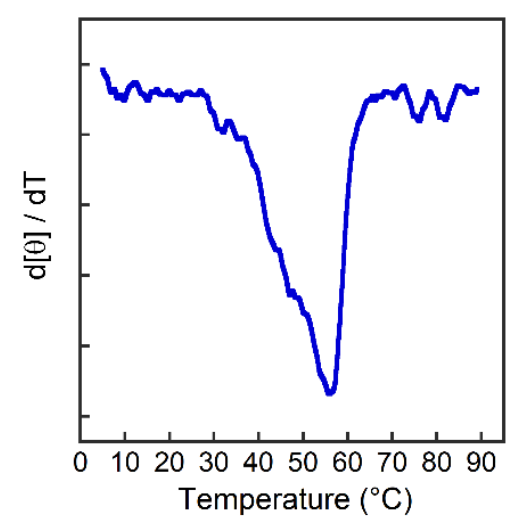

a, The HPLC chromatogram of purified peptide, $t_{R}=19.4 \mathrm{~min}$.

b, MALDI-MS, calculated: $2516.2[\mathrm{M}+\mathrm{H}]^{+}$, observed: $2517.3[\mathrm{M}+\mathrm{H}]^{+}$.

c, The CD spectrum in PBS buffer at $4{ }^{\circ} \mathrm{C}$.

d, The CD thermal melting curve in PBS buffer.

e, The first derivative of the melting curve, $T_{\mathrm{m}}=56{ }^{\circ} \mathrm{C}$. 


\section{X-PP5 peptides}

\section{Pro-PP5}
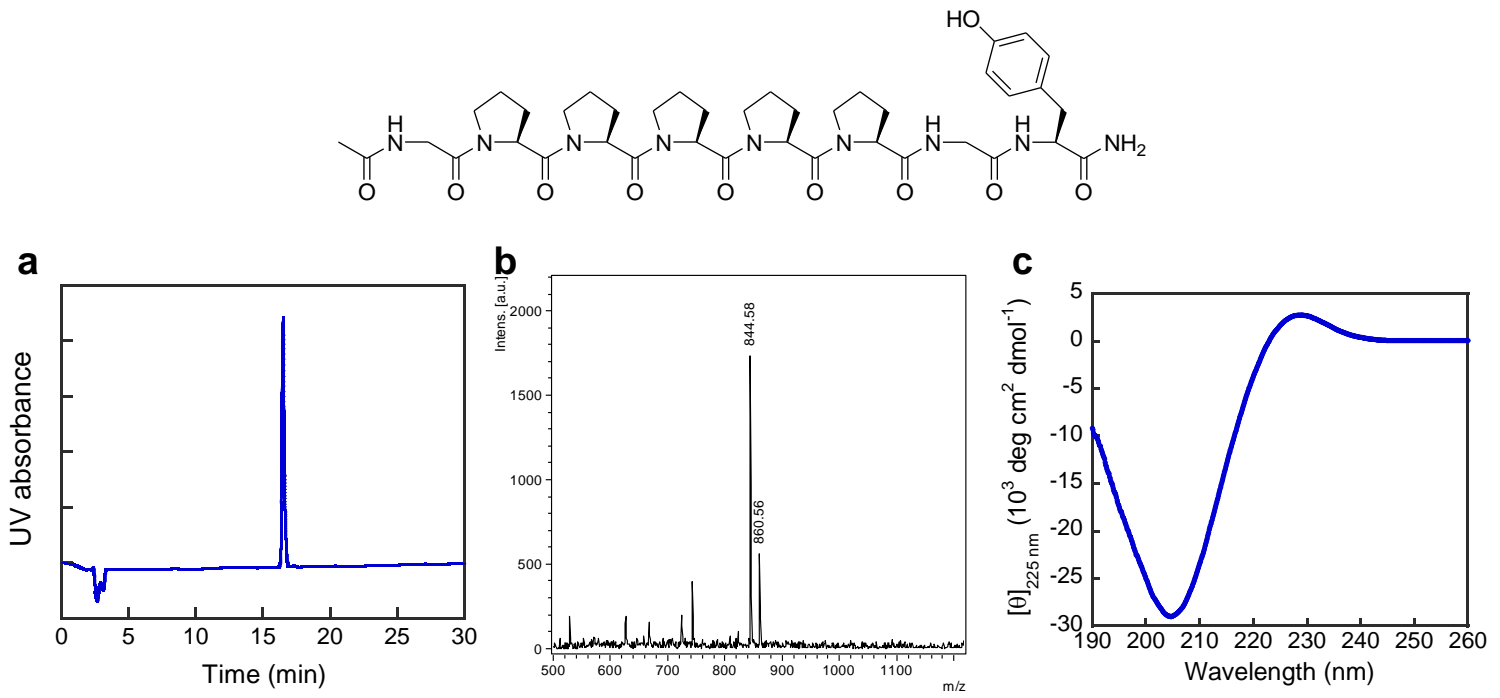

a, The HPLC chromatogram of purified peptide, $t_{R}=16.5 \mathrm{~min}$.

b, MALDI-MS, calculated: $844.4[\mathrm{M}+\mathrm{Na}]^{+}$, observed: $844.6[\mathrm{M}+\mathrm{Na}]^{+}$.

c, The $\mathrm{CD}$ spectrum in $5 \mathrm{mM}$ phosphate buffer at $25^{\circ} \mathrm{C}$.

\section{Gly-PP5}
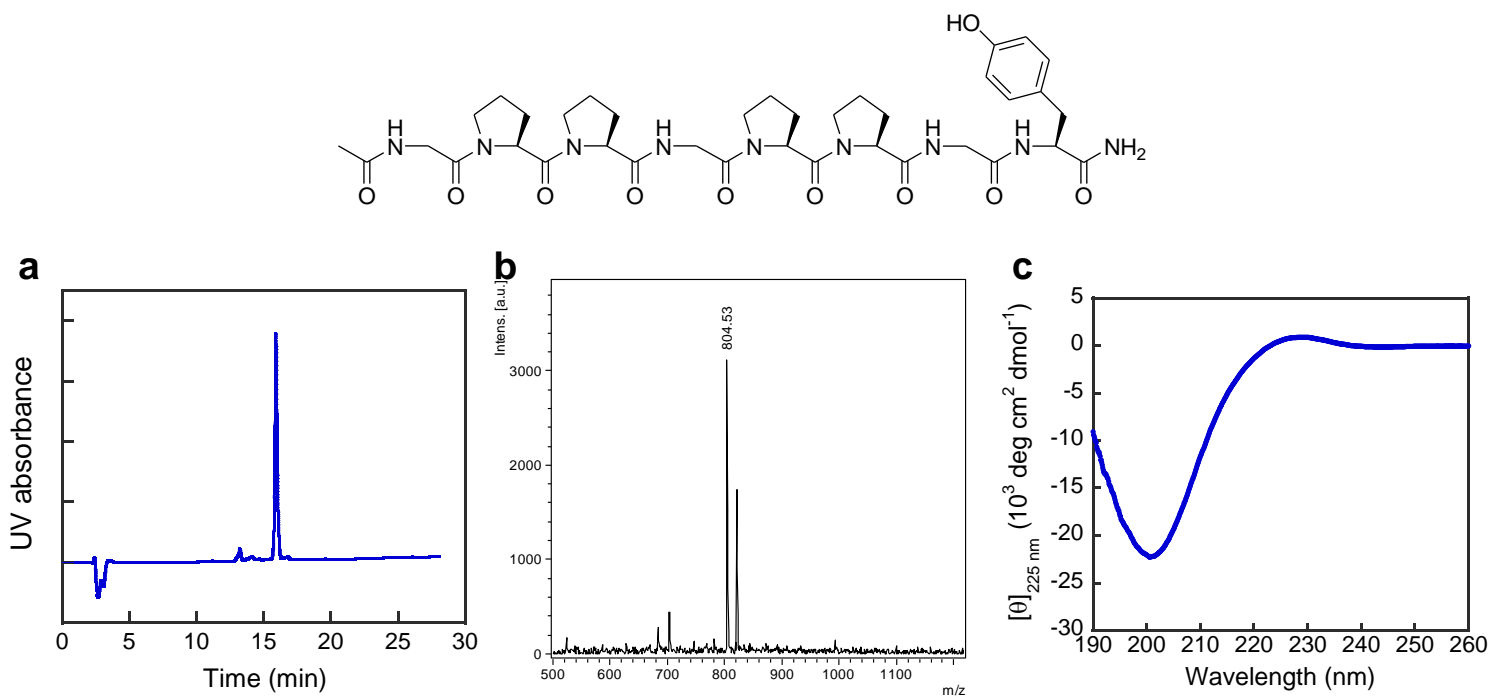

a, The HPLC chromatogram of purified peptide, $t_{R}=15.9 \mathrm{~min}$.

b, MALDI-MS, calculated: $804.4[\mathrm{M}+\mathrm{Na}]^{+}$, observed: $804.5[\mathrm{M}+\mathrm{Na}]^{+}$.

c, The $\mathrm{CD}$ spectrum in $5 \mathrm{mM}$ phosphate buffer at $25^{\circ} \mathrm{C}$. 


\section{Hyp-PP5}
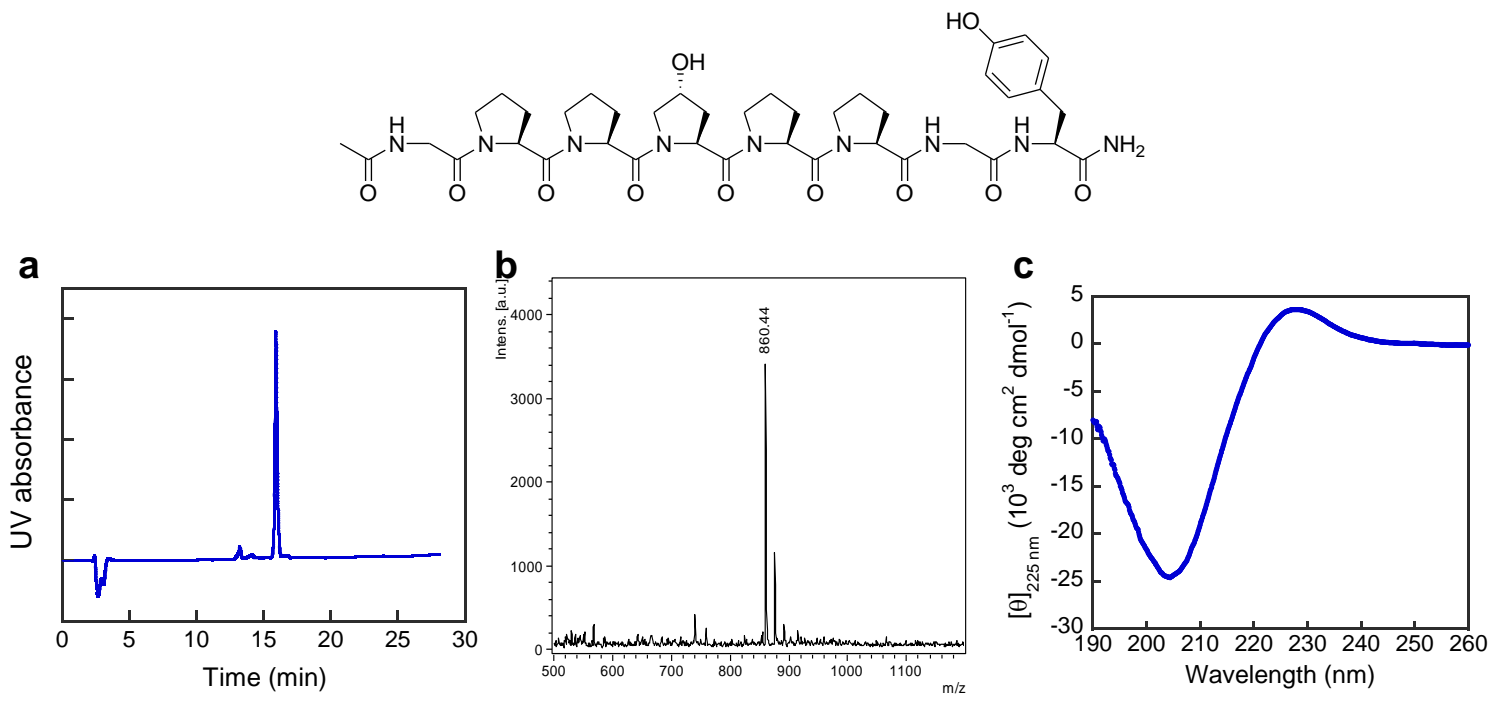

a, The HPLC chromatogram of purified peptide, $t_{R}=15.9 \mathrm{~min}$.

b, MALDI-MS, calculated: $860.4[\mathrm{M}+\mathrm{Na}]^{+}$, observed: $860.4[\mathrm{M}+\mathrm{Na}]^{+}$.

c, The CD spectrum in $5 \mathrm{mM}$ phosphate buffer at $25^{\circ} \mathrm{C}$.

\section{Sar-PP5}
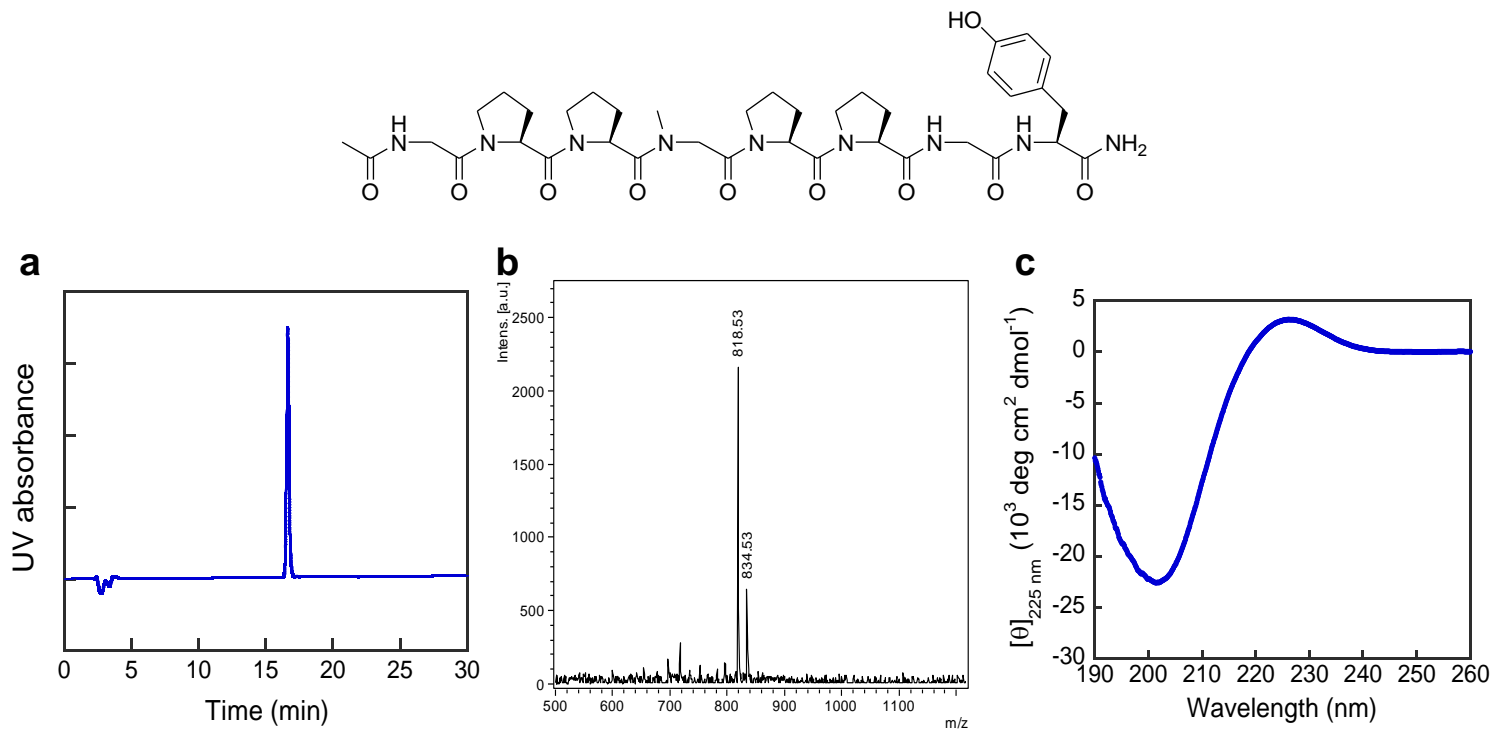

a, The HPLC chromatogram of purified peptide, $t_{R}=16.6 \mathrm{~min}$.

b, MALDI-MS, calculated: $818.4[\mathrm{M}+\mathrm{Na}]^{+}$, observed: $818.5[\mathrm{M}+\mathrm{Na}]^{+}, 834.5[\mathrm{M}+\mathrm{K}]^{+}$.

c, The CD spectrum in $5 \mathrm{mM}$ phosphate buffer at $25^{\circ} \mathrm{C}$. 


\section{Nasn-PP5}
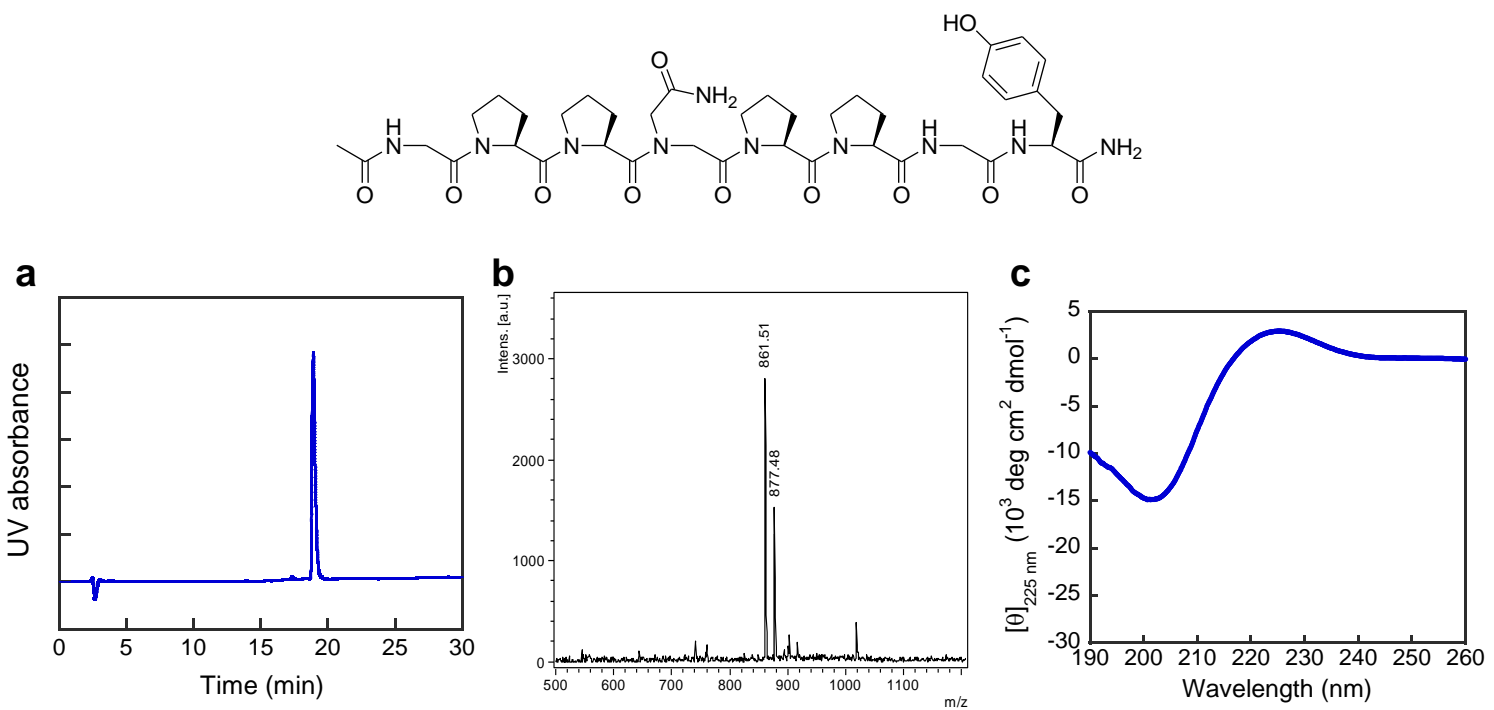

a, The HPLC chromatogram of purified peptide, $t_{R}=18.9 \mathrm{~min}$.

b, MALDI-MS, calculated: $861.4[\mathrm{M}+\mathrm{Na}]^{+}$, observed: $861.5[\mathrm{M}+\mathrm{Na}]^{+}, 877.5[\mathrm{M}+\mathrm{K}]^{+}$.

c, The CD spectrum in $5 \mathrm{mM}$ phosphate buffer at $25^{\circ} \mathrm{C}$.

\section{Nasp-PP5}
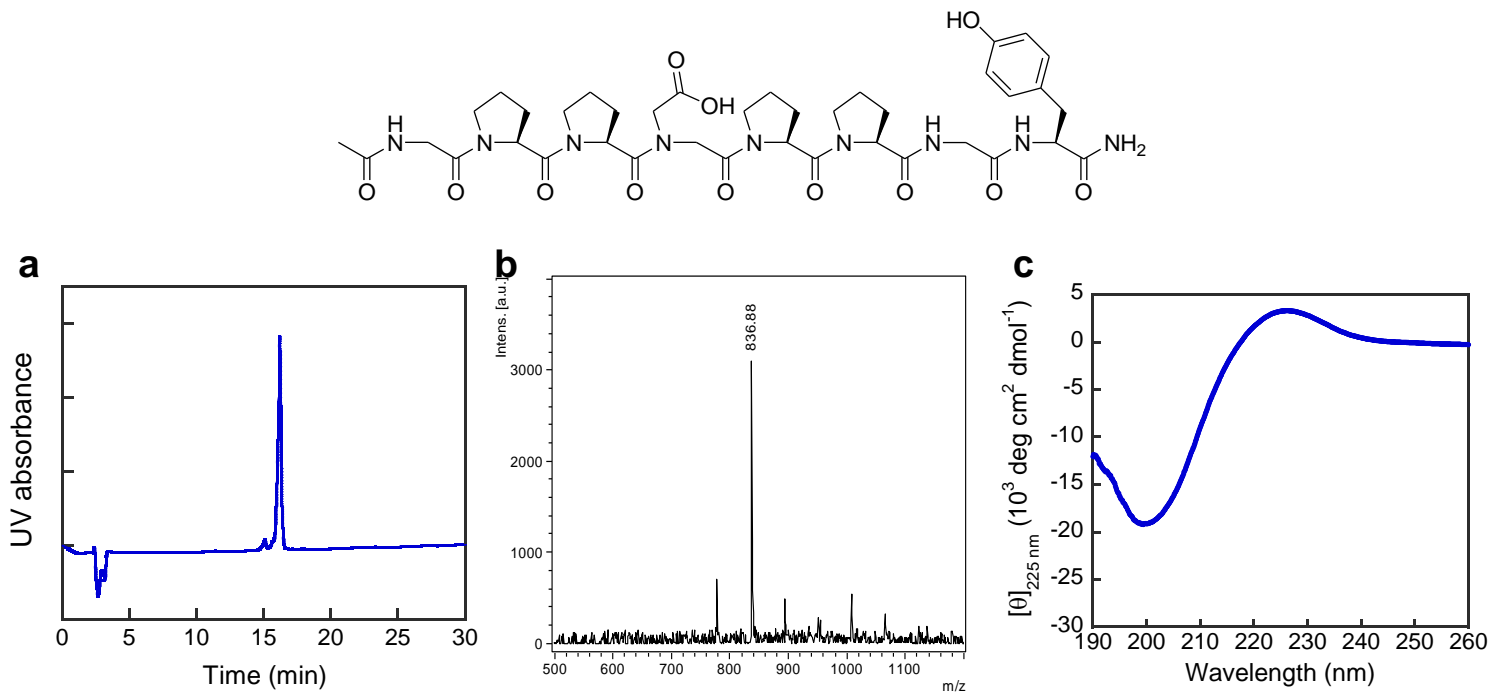

a, The HPLC chromatogram of purified peptide, $t_{R}=16.2 \mathrm{~min}$.

b, MALDI-MS, calculated: 838.4 [M-H]', observed: 836.9 [M-H]'.

c, The $\mathrm{CD}$ spectrum in $5 \mathrm{mM}$ phosphate buffer at $25^{\circ} \mathrm{C}$. 


\section{Nleu-PP5}
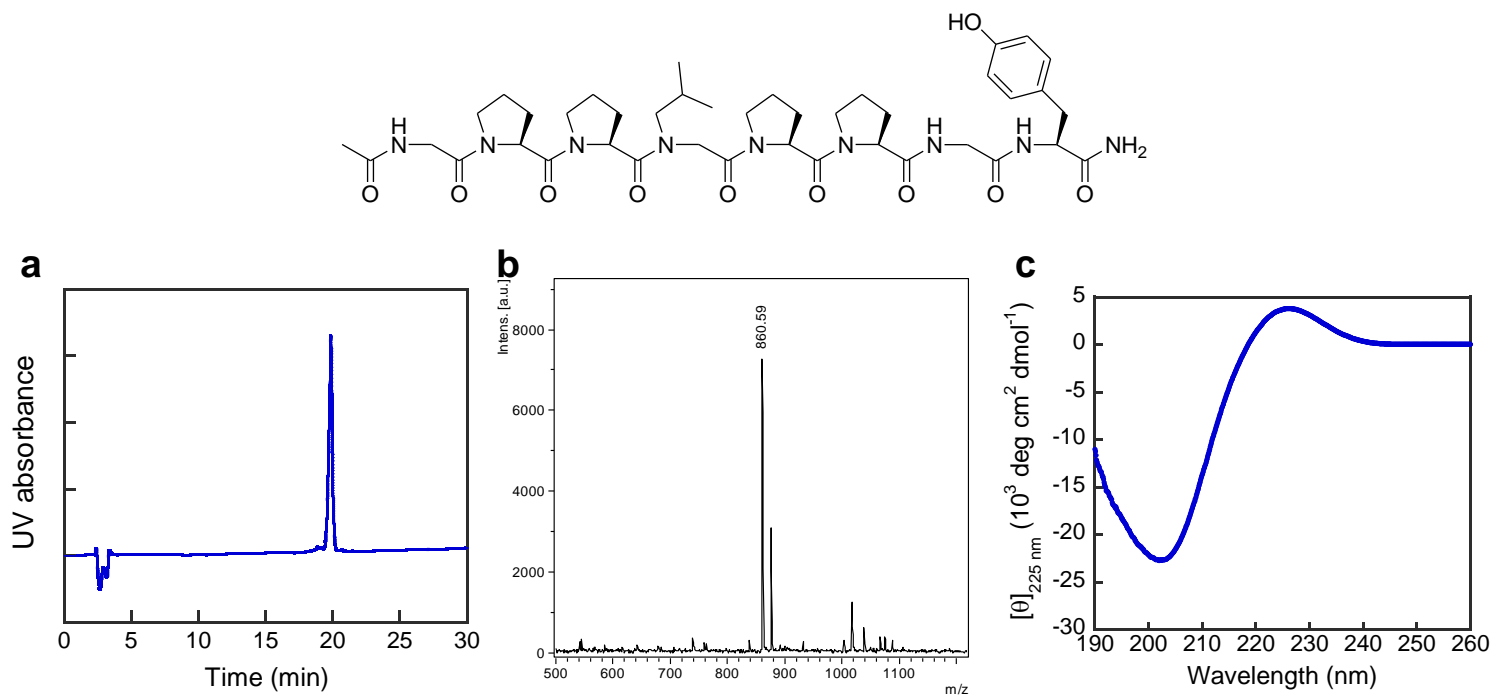

a, The HPLC chromatogram of purified peptide, $t_{R}=19.9$ min.

b, MALDI-MS, calculated: $860.4[\mathrm{M}+\mathrm{Na}]^{+}$, observed: $860.6[\mathrm{M}+\mathrm{Na}]^{+}$.

c, The $\mathrm{CD}$ spectrum in $5 \mathrm{mM}$ phosphate buffer at $25^{\circ} \mathrm{C}$.

\section{Nlys-PP5}
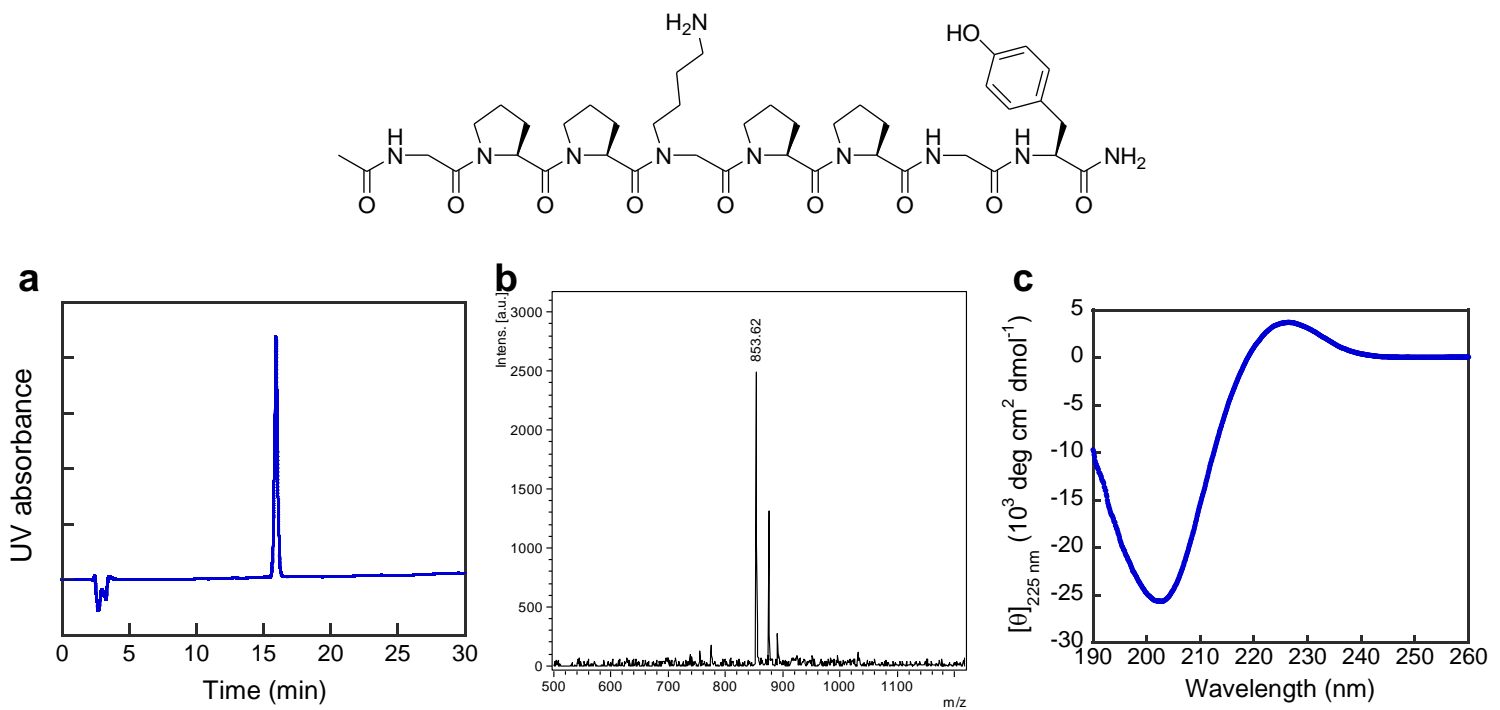

a, The HPLC chromatogram of purified peptide, $t_{R}=15.9$ min.

b, MALDI-MS, calculated: $853.4[\mathrm{M}+\mathrm{H}]^{+}$, observed: $853.6[\mathrm{M}+\mathrm{H}]^{+}, 875.4[\mathrm{M}+\mathrm{Na}]^{+}$.

c, The $\mathrm{CD}$ spectrum in $5 \mathrm{mM}$ phosphate buffer at $25^{\circ} \mathrm{C}$. 


\section{NMe-Ala-PP5}
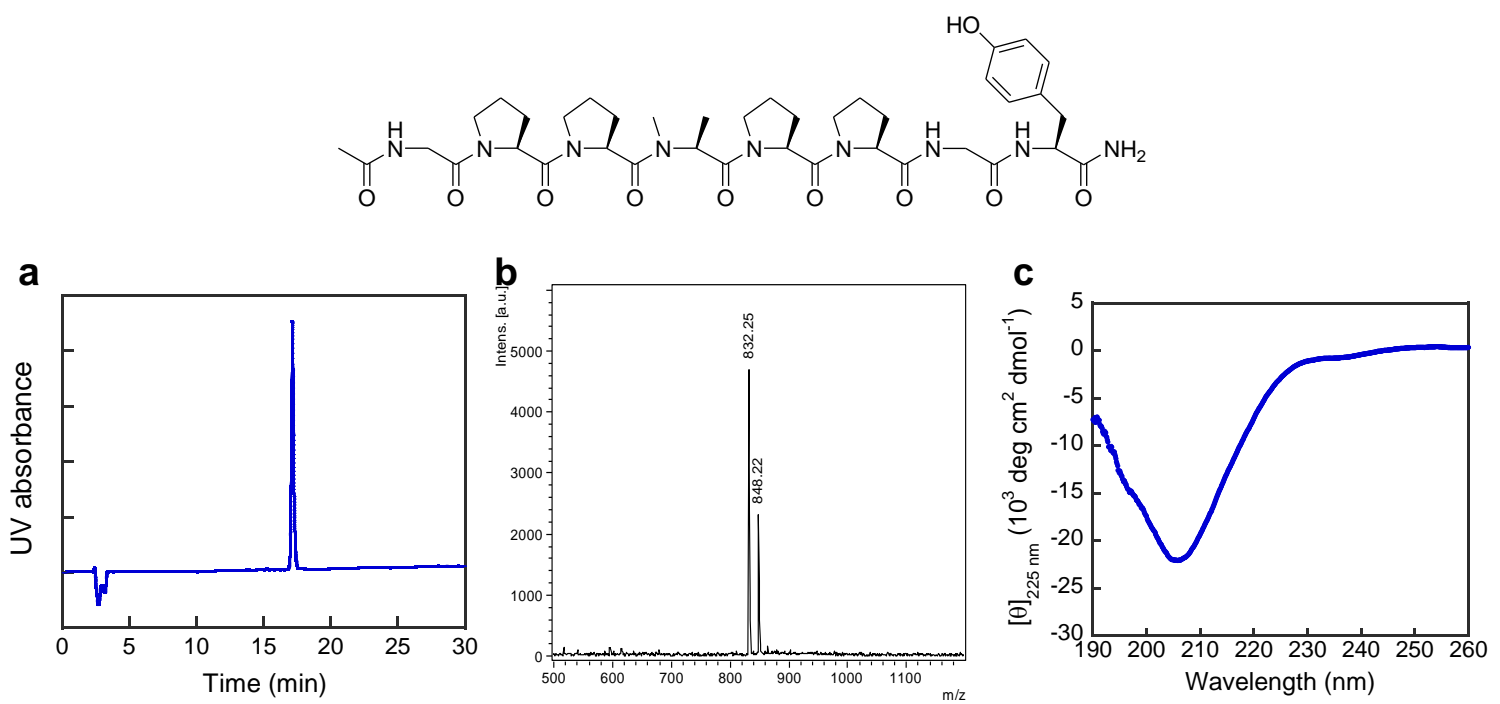

a, The HPLC chromatogram of purified peptide, $t_{R}=17.1 \mathrm{~min}$.

b, MALDI-MS, calculated: $832.4[\mathrm{M}+\mathrm{Na}]^{+}$, observed: $832.3[\mathrm{M}+\mathrm{Na}]^{+}, 848.2[\mathrm{M}+\mathrm{K}]^{+}$.

c, The $\mathrm{CD}$ spectrum in $5 \mathrm{mM}$ phosphate buffer at $25^{\circ} \mathrm{C}$.

\section{Nphe-PP5}
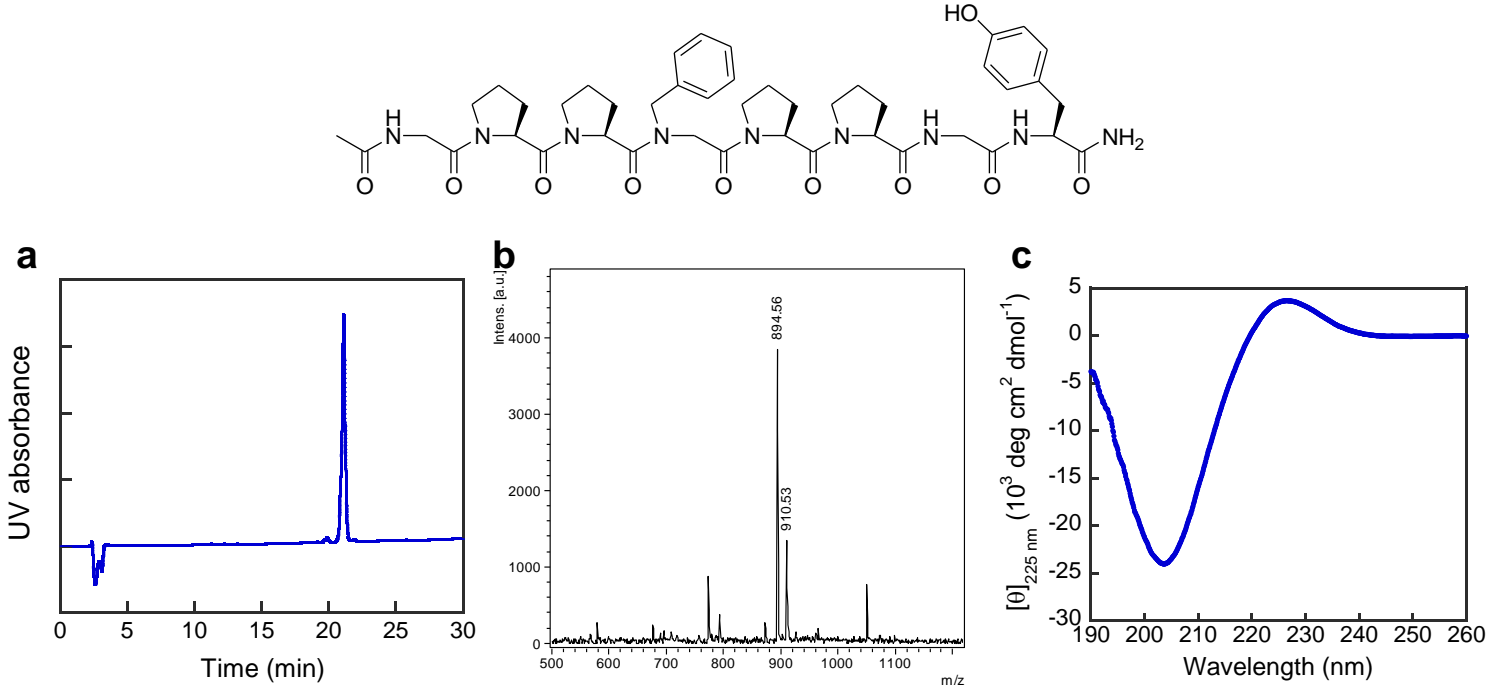

a, The HPLC chromatogram of purified peptide, $t_{R}=21.1 \mathrm{~min}$.

b, MALDI-MS, calculated: $894.4[\mathrm{M}+\mathrm{Na}]^{+}$, observed: $894.6[\mathrm{M}+\mathrm{Na}]^{+}$.

c, The $\mathrm{CD}$ spectrum in $5 \mathrm{mM}$ phosphate buffer at $25^{\circ} \mathrm{C}$. 


\section{Nval-PP5}
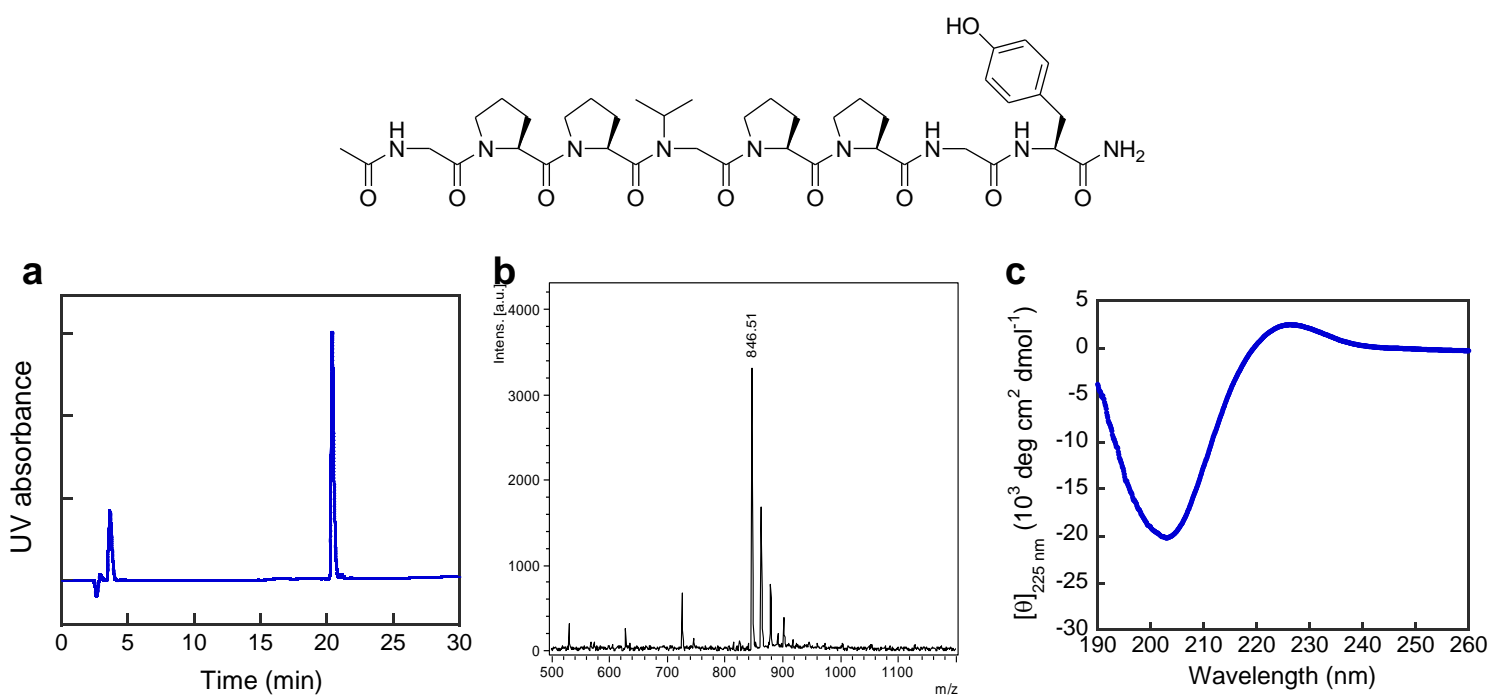

a, The HPLC chromatogram of purified peptide, $t_{R}=21.0 \mathrm{~min}$.

b, MALDI-MS, calculated: $846.4[\mathrm{M}+\mathrm{Na}]^{+}$, observed: $846.5[\mathrm{M}+\mathrm{Na}]^{+}$.

c, The CD spectrum in $5 \mathrm{mM}$ phosphate buffer at $25^{\circ} \mathrm{C}$. 


\section{References}

(1) Erdmann, R. S.; Wennemers, H. Functionalizable Collagen Model Peptides. J. Am. Chem. Soc. 2010, 132 (40), 13957-13959.

(2) Zuckermann, R. N.; Kerr, J. M.; Moosf, W. H.; Kent, S. B. H. Efficient Method for the Preparation of Peptoids [Oligo(N-Substituted Glycines)] by Submonomer Solid-Phase Synthesis. J. Am. Chem. Soc. 1992, 114 (26), 10646-10647.

(3) Li, Y.; Foss, C. a.; Summerfield, D. D.; Doyle, J. J.; Torok, C. M.; Dietz, H. C.; Pomper, M. G.; Yu, S. M. Targeting Collagen Strands by Photo-Triggered Triple-Helix Hybridization. Proc. Natl. Acad. Sci. 2012, 109 (37), 14767-14772.

(4) Li, Y.; San, B. H.; Kessler, J. L.; Kim, J. H.; Xu, Q.; Hanes, J.; Yu, S. M. Non-Covalent Photo-Patterning of Gelatin Matrices Using Caged Collagen Mimetic Peptides. Macromol. Biosci. 2015, 15, 52-62.

(5) Otwinowski, Z.; Minor, W. Processing of X-Ray Diffraction Data Collected in Oscillation Mode. In Methods in Enzymology; Carter Jr., C. W., Sweet, R. M., Eds.; Academic Press: New York, 1997; Vol. 276, pp 307-326.

(6) McCoy, A. J.; Grosse-Kunstleve, R. W.; Adams, P. D.; Winn, M. D.; Storoni, L. C.; Read, R. J. Phaser Crystallographic Software. J. Appl. Crystallogr. 2007, 40 (4), 658-674.

(7) Emsley, P.; Lohkamp, B.; Scott, W. G.; Cowtan, K. Features and Development of Coot. Acta Crystallogr. Sect. D Biol. Crystallogr. 2010, 66 (4), 486-501.

(8) Murshudov, G. N.; Skubak, P.; Lebedev, A. A.; Pannu, N. S.; Steiner, R. A.; Nicholls, R. A.; Winn, M. D.; Long, F.; Vagin, A. A. REFMAC 5 for the Refinement of Macromolecular Crystal Structures. Acta Crystallogr. Sect. D Biol. Crystallogr. 2011, D67, 355-367.

(9) Barducci, A.; Bussi, G.; Parrinello, M. Well-Tempered Metadynamics: A Smoothly Converging and Tunable Free-Energy Method. Phys. Rev. Lett. 2008, 100 (2), 1-4.

(10) Phillips, J. C.; Braun, R.; Wang, W.; Gumbart, J.; Tajkhorshid, E.; Villa, E.; Chipot, C.; Skeel, R. D.; Kalé, L.; Schulten, K. Scalable Molecular Dynamics with NAMD. J. Comput. Chem. 2005, 26 (16), 17811802.

(11) Bonomi, M.; Branduardi, D.; Bussi, G.; Camilloni, C.; Provasi, D.; Raiteri, P.; Donadio, D.; Marinelli, F.; Pietrucci, F.; Broglia, R. A.; Parrinello, M. PLUMED: A Portable Plugin for Free-Energy Calculations with Molecular Dynamics. Comput. Phys. Commun. 2009, 180 (10), 1961-1972.

(12) Qin, Z.; Buehler, M. J. Molecular Mechanics of Mussel Adhesion Proteins. J. Mech. Phys. Solids 2014, 62, 19-30.

(13) Qin, Z.; Fabre, A.; Buehler, M. J. Structure and Mechanism of Maximum Stability of Isolated AlphaHelical Protein Domains at a Critical Length Scale. Eur. Phys. J. E 2013, 36 (5).

(14) Vanommeslaeghe, K.; Hatcher, E.; Acharya, C.; Kundu, S.; Zhong, S.; Shim, J.; Darian, E.; Guvench, O.; Lopes, P.; Vorobyov, I.; Mackerell, A. D. CHARMM General Force Field: A Force Field for Drug-Like Molecules Compatible with the CHARMM All-Atom Additive Biological Force Fields. J. Comput. Chem. 2010, 31 (4), 671-690.

(15) MacKerell, A. D.; Bashford, D.; Bellott, M.; Dunbrack, R. L.; Evanseck, J. D.; Field, M. J.; Fischer, S.; Gao, J.; Guo, H.; Ha, S.; Joseph-McCarthy, D.; Kuchnir, L.; Kuczera, K.; Lau, F. T. K.; Mattos, C.; Michnick, S.; Ngo, T.; Nguyen, D. T.; Prodhom, B.; Reiher, W. E.; Roux, B.; Schlenkrich, M.; Smith, J. C.; Stote, R.; Straub, J.; Watanabe, M.; Wiórkiewicz-Kuczera, J.; Yin, D.; Karplus, M. All-Atom Empirical Potential for Molecular Modeling and Dynamics Studies of Proteins. J. Phys. Chem. B 1998, 102 (18), 3586-3616.

(16) Binkley, J. S.; Pople, J. A.; Hehre, W. J. Self-Consistent Molecular Orbital Methods. 21. Small SplitValence Basis Sets for First-Row Elements. J. Am. Chem. Soc. 1980, 102 (3), 939-947.

(17) Goodman, M.; Melacini, G.; Feng, Y. Collagen-like Triple Helices Incorporating Peptoid Residues. J. Am. Chem. Soc. 1996, 118 (44), 10928-10929.

(18) Melacini, G.; Feng, Y.; Goodman, M. Collagen-Based Structures Containing the Peptoid Residue NIsobutylglycine (Nleu): Conformational Analysis of Gly-Nleu-Pro Sequences by 1H-NMR and Molecular Modeling. Biochemistry 1997, 36 (29), 8725-8732. 